\title{
Tumor Targeting Strategies of Smart Fluorescent Nanoparticles and Their Applications in Cancer Diagnosis and Treatment
}

\author{
Jiuyang He, Chenchen Li, Lin Ding, Yanan Huang, Xuelian Yin, Junfeng Zhang, Jian Zhang, \\ Chenjie Yao, Minmin Liang, Rogério P. Pirraco, Jie Chen, Quan Lu, Ryan Baldridge, \\ Yong Zhang, Minghong Wu,* Rui L. Reis,* and Yanli Wang*
}

Advantages such as strong signal strength, resistance to photobleaching, tunable fluorescence emissions, high sensitivity, and biocompatibility are the driving forces for the application of fluorescent nanoparticles (FNPs) in cancer diagnosis and therapy. In addition, the large surface area and easy modification of FNPs provide a platform for the design of multifunctional nanoparticles (MFNPs) for tumor targeting, diagnosis, and treatment. In order to obtain better targeting and therapeutic effects, it is necessary to understand the properties and targeting mechanisms of FNPs, which are the foundation and play a key role in the targeting design of nanoparticles (NPs). Widely accepted and applied targeting mechanisms such as enhanced permeability and retention (EPR) effect, active targeting, and tumor microenvironment (TME) targeting are summarized here. Additionally, a freshly discovered targeting mechanism is introduced, termed cell membrane permeability targeting (CMPT), which improves the tumor-targeting rate from less than $5 \%$ of the EPR effect to more than $50 \%$. A new design strategy is also summarized, which is promising for future clinical targeting NPs/ nanomedicines design. The targeting mechanism and design strategy will inspire new insights and thoughts on targeting design and will speed up precision medicine and contribute to cancer therapy and early diagnosis.

\section{Introduction}

In 1948, it was discovered that cytotoxic folate antimetabolites could treat childhood leukemia ${ }^{[1]}$ and the basic approach for cancer therapy has remained the same way: surgery followed by chemotherapy with various cytotoxic compounds or radiation. ${ }^{[2]}$ Conventional cytotoxic chemotherapy usually kills dividing cells rapidly in the body by interfering with cell division. However, commonly used chemotherapy drugs have poor selectivity, which not only kill tumor cells but also damage normal cells and tissues, causing serious toxicity and side effects such as myelosuppression, nausea, vomiting, hair loss, and reduced fertility. ${ }^{[3]}$ The intrinsic limits of conventional cancer therapies like insufficiency in water solubility of drugs, drug resistance after repeated administration, and off-targeting to cancer cells make it difficult to cure cancer. ${ }^{[4]}$
Dr. J. He, Dr. C. Li, Dr. L. Ding, Dr. Y. Huang, Dr. X. Yin, Dr. J. Zhang,

Prof. J. Chen, Prof. Y. Zhang, Prof. Y. Wang

Tumor Precision Targeting Research Center

School of Environmental and Chemical Engineering

Shanghai University

Shanghai 200444, P. R. China

E-mail:wangyanli@staff.shu.edu.cn

Dr. J. He, Prof. M. Liang

Institute of Biophysics

Chinese Academy of Sciences

Beijing 100101, P. R. China

Dr. C. Li, Dr. L. Ding, Dr. Y. Huang, Dr. X. Yin, Dr. J. Zhang, Dr. C. Yao,

Prof. M. Wu, Prof. Y. Wang

Institute of Nanochemistry and Nanobiology

School of Environmental and Chemical Engineering

Shanghai University

Shanghai 200444, P. R. China

E-mail:mhwu@shu.edu.cn

The ORCID identification number(s) for the author(s) of this article can be found under https://doi.org/10.1002/adma.201902409.

DOI: 10.1002/adma.201902409

\author{
Dr. L. Ding, Dr. R. Baldridge \\ Department of Biological Chemistry \\ The University of Michigan \\ Ann Arbor, MI 48109, USA \\ Prof. J. Zhang \\ Universal Medical Imaging Diagnostic Research Center \\ Shanghai 200233, P. R. China \\ Dr. C. Yao, Dr. Q. Lu, Prof. Y. Wang \\ Harvard T. H. Chan School of Public Health \\ Harvard University \\ Boston, MA 02115, USA \\ Dr. R. P. Pirraco, Prof. R. L. Reis \\ 3B's Research Group \\ I3Bs - Research Institute on Biomaterials \\ Biodegradables and Biomimetics \\ University of Minho \\ Headquarters of the European Institute of Excellence on Tissue \\ Engineering and Regenerative Medicine \\ AvePark \\ Parque de Ciência e Tecnologia \\ Zona Industrial da Gandra, 4805-017 Barco, Guimarães, Portugal \\ E-mail: rgreis@i3bs.uminho.pt
}


The advent of "targeted" cancer therapies changed the situation. The targeted nanomedicines prompt the growing interests in the applying of nanotechnology in the cancer diagnosis and therapy. ${ }^{[5]}$ The major goal of targeted therapies is to fight cancer cells more accurately with fewer potential side effects. ${ }^{\left[{ }^{[6]}\right.}$ With the continuous development and progress of imaging technology in spatial and temporal resolution, scientists can detect the activity of tumors and deep tissues of body through live imaging. It is obvious that the targeting imaging of tumors has a great significance for cancer diagnosis and treatment. Nowadays, various biomedical imaging technologies are blooming, and they have become accurate and powerful tools in clinical diagnosis and therapy assessment for cancer. They provide a noninvasive, highly sensitive, and specific observation way for identifying and monitoring the pathological and physiological events associated with human cancer. ${ }^{[7,8]}$ For instance, fluorescence imaging (FI), computed tomography (CT), photoacoustic imaging (PAI), ultrasound imaging (USI), positron emission tomography (PET), magnetic resonance imaging (MRI), photothermal imaging (PTI), and Raman imaging (RI) have been well developed and play a great role in preclinical and clinical practice. ${ }^{[7-9]}$ Compared with other technologies, FI technology has many advantages such as the high sensitivity, noninvasive, and real-time safe detection, and readily available instrumentation. ${ }^{[10]}$ It is quite obvious that the targeting imaging of tumors has a great significance for cancer diagnosis and treatment. Compared with radioisotope labeling, MRI, electrochemical detection, and other technologies, FI technology has many advantages such as the highly sensitivity, noninvasive, and real-time safe detection and readily available instruments. ${ }^{[10]}$ Using fluorescent dyes conjugated with specific targeting molecules that are able to bind with the receptors overexpressed in malignancy can specifically target to malignant tumors and distinguish tumor from normal tissues, which has obvious advantages for the early diagnosis and accurate surgical resection of malignant tumors. ${ }^{[11]}$ Fluorescent dyes including fluorescein, rhodamine, cyanine, and so on are widely recognized as one of the simple and effective methods for labeling tumor cells. ${ }^{[10]}$ However, fluorescent dyes have the disadvantages of high toxicity, poor photostability, low quantum yield, and short fluorescent lifetime etc. ${ }^{[12]}$ Along with the great progress in the field of nanotechnology, many classes of nanomaterials (organic, inorganic, and metallic) are currently employed as fluorescent emitters, called FNPs. ${ }^{[13]}$ Compared to conventional fluorescent dyes, FNPs have stronger fluorescent brightness, better photostability, water dispersibility, and biocompatibility, which enable FNPs to meet the requirements

Dr. R. P. Pirraco, Prof. R. L. Reis

ICVS/3B's PT Government Associate Lab

4805 Braga/Guimarães, Portugal

Prof. Y. Zhang

Department of Biomedical Engineering

National University of Singapore

Singapore 119077, Singapore

Prof. R. L. Reis

The Discoveries Centre for Regenerative and Precision Medicine

Headquarters at University of Minho

Avepark, 4805-017 Barco, Guimarães, Portugal

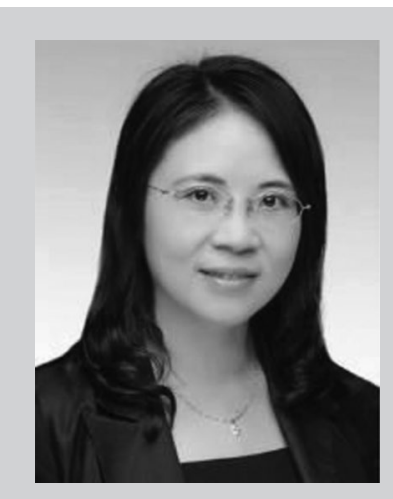

Minghong Wu obtained her Ph.D. degree from Shanghai Institute of Applied Physics of Chinese Academy of Sciences in 1999. Now, she is vice president of Shanghai University. She is a National Outstanding Youth, Yangtze River Scholar of China and the Foreign Academicians of the Russian Academy of Engineering and Russian Academy of Science. Her research interests mainly focus on bioeffects and safety evaluation of nanomaterials and environmental pollution analysis and control.

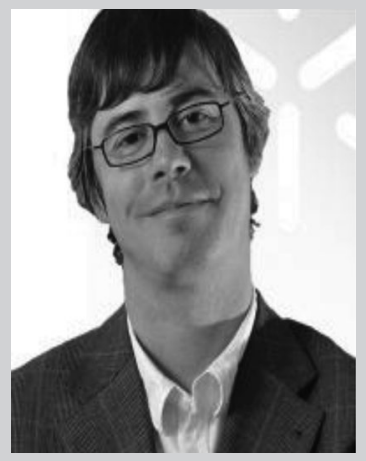

Rui L. Reis obtained his Ph.D. and D.Sc. in polymer engineering-biomaterials \& tissue engineering from the University of Minho, Portugal. He is vice president for Research and Innovation of UMinho and the director of the 3B's Research Group and ICVS/3B's Associate Laboratory. He is a full professor of Tissue Engineering, Regenerative Medicine and Stem Cells at UMinho and honorary professor in four different Asian Universities. His main area of research is the development of biomaterials from natural origin polymers, and using those in combination with different stem cells for several strategies for tissue engineering and regenerative medicine, applied to distinct human tissues.

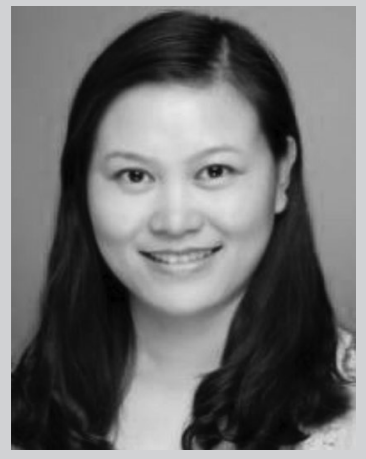

Yanli Wang obtained her Ph.D. degree in Environmental Engineering from Shanghai University in 2010. Now, she is a director of the Tumor Precision Targeting Research Center and a professor of the School of Environmental and Chemical Engineering, Shanghai University. Her main research interests include: application of intelligent targeted fluorescent nanomaterials in tumor diagnosis; intelligent targeted nanodrug design and its application in tumor therapy; the development of a tumor marker detection kit; and biosecurity of nanomaterials.

for cancer therapy and diagnosis application fields. FNPs offer a multifunctional platform for tumor targeting diagnosis, therapy and show special superiority, shining on the 
battle against cancer, which has aroused great concern in recent years. ${ }^{[14,15]}$ Moreover, the complexity and heterogeneity of tumors require to choose the applicable FNPs and effective targeting strategies.[16] Among this big family of FNPs, there are mainly five types of nanomaterials: fluorescent dyedoped nanoparticles (FL dye-doped NPs), ${ }^{[13,17]}$ semiconductors quantum dots (QDs), ${ }^{[18,19]}$ metal nanoclusters $(\mathrm{MNCs}),{ }^{[20]}$ rare earth NPs, ${ }^{[21,22]}$ and fluorescent carbon-based nanomaterials (FCNMs). ${ }^{[23,24]}$

As mentioned above, there are some disadvantages of fluorescent dyes that can be overcome by using nanocarriers. Nanocarriers can carry a large amount of fluorescent dyes inside by embedding, covalent linkage, or absorption etc., protecting the fluorescent dyes from being destroyed to improve the photostability and emit stronger fluorescence. ${ }^{[25]}$ Silica NPs labeled with fluorescent dyes are one of the most widely used nanocarriers for cancer bioimaging and theranostic applications. ${ }^{[13,26]}$ However, nanomaterials without autofluorescence can only act as a carrier with disadvantages of large cytotoxicity from surfactant and leakage of fluorescent dyes, which limits their application. Therefore, intrinsically luminous FNPs, such as QDs, MNCs, upconversion nanoparticles (UCNPs), and FCNMs are extensively studied. QDs are kind of ultrasmall semiconductor NPs, only several nanometers in size. Most of them composed of elements from groups II to VI, III to IV, or IV to VI from the periodic table. Such a small size gives them excellent optical and biological properties in molecular imaging and biomedical diagnostics. ${ }^{[18]}$ Notably, QDs have a broad absorption spectrum and a narrow emission spectrum with strong antiphotobleaching, long fluorescence lifetime, and extensive tunable size. ${ }^{[27,28]}$ Extensive research during the past more than 30 years have been developed to get the high-quality and water-soluble QDs probes for biology and nanomedicine applications since it was first reported in 1983. ${ }^{[28,29]}$ However, the in vivo toxicity triggered by the particle and the subsequent release of toxic metals and ions greatly limits theirs biological applications. ${ }^{[30]}$ Recent advances in nanotechnology have given rise to a new class of FNPs called MNCs, e.g., AuNCs, AgNCs, and CuNCs, whose diameters are below $2 \mathrm{~nm}$, composed of several hundreds of metal atoms in a transition state between a single metal atom and a larger metal nanoparticles (MNPs). ${ }^{[31]}$ Compared with larger MNPs, it has a lot of unique physicochemical properties, such as adjustable fluorescent emission, large stokes shift, high fluorescent stability, and high quantum yield, etc. ${ }^{[32]}$ In contrast to conventional fluorophores and QDs, the toxicity of MNCs is reduced greatly and the biocompatibility of MNCs is significantly improved. ${ }^{[32]}$ Therefore, they are widely used for bioimaging and cancer diagnosis and treatment as a new type of nanofluorescent probe. ${ }^{[33]}$ Another one of the most active fields of research in the past decades is the development of rare-earth-doped nanoparticles with unique optical properties. ${ }^{[2,34]}$ Among the most widely used are UCNPs usually synthesized with host lattices such as $\mathrm{LaF}_{3}, \mathrm{YF}_{3}, \mathrm{Y}_{2} \mathrm{O}_{3}, \mathrm{LaPO}_{4}$, $\mathrm{NaYF}_{4}$ doped with trivalent rare earth ions such as $\mathrm{Yb}^{3+}, \mathrm{Er}^{3+}$, $\mathrm{Tm}^{3+}$, etc. ${ }^{[21]}$ In addition to the above materials, FCNMs is also a promising type of nanomaterials that are applied in biological fields, which includes carbon dots (CDs), graphene quantum dots (GQDs), polymer dots (PDs), and luminescent nanodiamonds (NDs). ${ }^{[35]}$ The low toxicity and good biocompatibility of
FCNMs make it an excellent substitute for semiconductor QDs. Along with enormous progress in the field of cancer nanomedicine, all these FNPs have been applied in cancer targeting diagnosis and therapy. Some results have demonstrated that MFNPs conjugating multiple components such as fluorescent molecules, tumor-targeting legends, anticancer drugs, or siRNA can achieve multiple functions for the application in targeting cancer diagnosis and treatment. ${ }^{[36]}$ Herein, we will focus on the main targeting strategies, including the EPR effect, active targeting, and TME to claim the application of FNPs in tumor targeting application. Beyond that, we will also introduce the new targeting strategy called CMPT proposed by Wang's group, which improves the tumor-targeting rate from less than $5 \%$ of the EPR effect to more than 50\%.[37] The CMPT mechanism will stimulate new insights for the targeting design, accelerate the development of tumor precision medicine, and contribute to cancer treatment and early diagnosis.

\section{Tumor Targeting Strategies}

The targeting property of traditional antineoplastic chemotherapy drugs is too poor hampering the distinction between normal tissue and tumor tissue. The rapid elimination from the circulatory system, systemic toxicity, and side effects are the main barriers for the application in cancer. ${ }^{[3]}$ The targeting nanomedicines/nanoparticles design and their targeting mechanisms is the way to improve the targeting efficiency and lower the side effects. Figure 1 briefly summarizes the current research status of tumor targeting strategies .

\subsection{Passive Targeting}

The passive targeting mainly refers to the EPR effect, which was first proposed by Matsumura and Maeda in 1986. ${ }^{[38,39]}$ Maeda found that a polymer accumulated in tumor tissues when conjugated with the anticancer protein. They also showed that many proteins progressively accumulated in the tumor tissues in vivo, and a ratio of the protein concentration in the tumor to that in the blood of 5 was obtained within 19 to $72 \mathrm{~h} .{ }^{[38]}$ The fundamental physiological feature of the EPR effect is the malformed vasculature coupled with poor lymphatic drainage of solid tumors tissues allowing the large particles to leak from blood vessels and passively accumulate in the tumor sites. ${ }^{[40,41]}$ Traditional small molecule drugs have low selectivity and most of such drugs are distributed in normal tissues, resulting in severe systemic toxicity. It is obvious that systemic adverse effects were reduced and therapeutic effects were improved by tumor targeting anticancer drugs nanocarrier designing (Figure 2) ${ }^{[42,43]}$ Meanwhile, the concentration of macromolecular drugs in tumor tissues is far more than five to tenfold, which is very difficult to reach for small molecular drugs. ${ }^{[4]}$

The EPR effect became the "gold standard" for nanoparticles anticancer drug design, including NPs. ${ }^{[45]}$ The EPR effect mainly depends on the size, surface properties of the nanocarriers, and the physiological properties of the tumors. So, to achieve optimal targeting and therapeutic efficacy, NPs must 


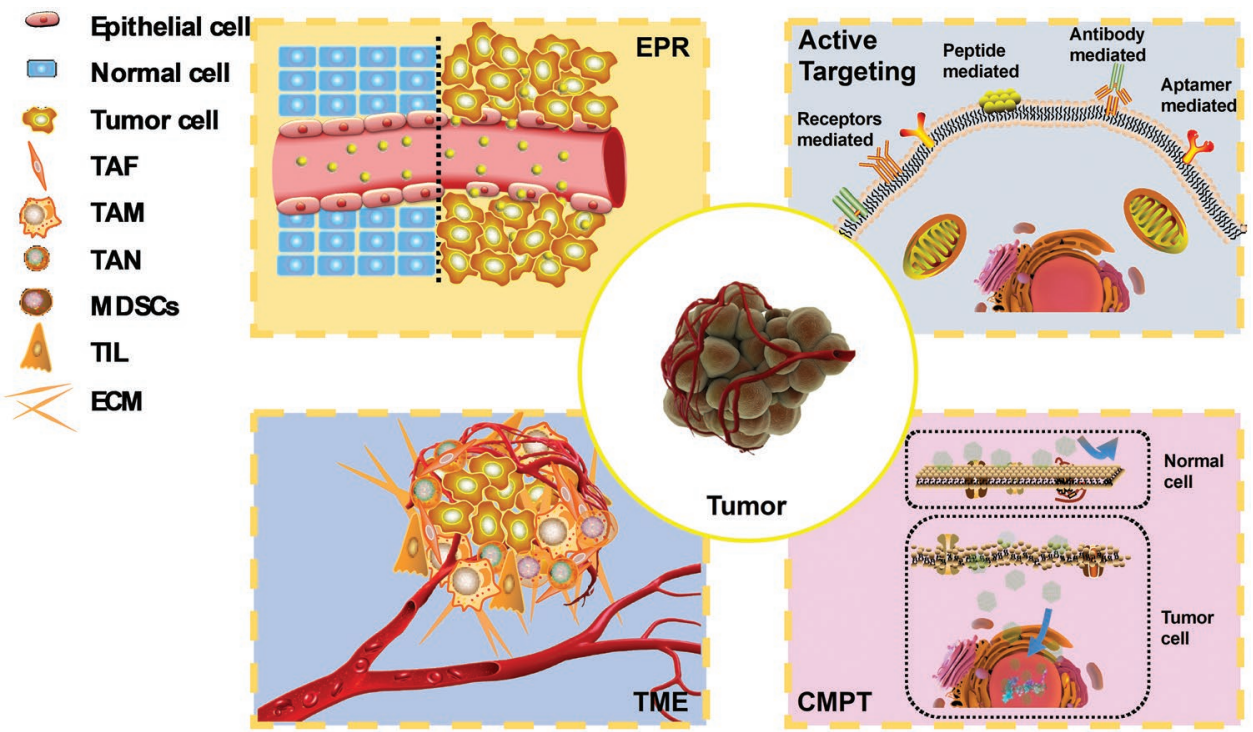

Figure 1. Schematic illustration of tumor targeting strategies. EPR: enhanced permeability and retention effect, TME: tumor microenvironment, CMPT: cell membrane permeability targeting mechanism. Image for CMPT: Adapted with permission. ${ }^{[3]}$ Copyright 2019, Wiley-VCH. TAF: tumor associated fibroblasts, TAM: tumor associated macrophage, TAN: tumor associated neutrophils, MDSCs: myeloid-derived suppressor cells, TIL: tumor-infiltrating lymphocytes, ECM: extracellular matrix.

be designed in the size range of $20-200 \mathrm{~nm}$, which can easily extravasate through the malformed tumor vessels, and the accumulation in tumors is further enhanced because of poor lymphatic drainage. ${ }^{[46]}$ Nanocarriers have several advantages over conventional low-molecular-weight drugs including a large loading capacity, protecting drugs from degradation, specific targeting, and controlled release. ${ }^{[47,48]}$ Furthermore, their physical and chemical properties can be optimized by changing the shape, size, and surface properties. ${ }^{[49]}$ Thus, the fields of nanomedicine are developed rapidly. Potential advantages of NPs include prolonged circulation time of drugs, decreased kidney or liver clearance rate, and distribution lead to minimal nonspecific accumulation and enhance therapeutic effect. ${ }^{[50,51]}$ For example, large micelles (less than $100 \mathrm{~nm}$ ) can easily escape from renal excretion, but are still small enough to enhance the leakage of tumor blood vessels. ${ }^{[52]}$

Molecular imaging is an excellent method for visual monitoring of cellular processes. By monitoring probes in vivo, molecular dynamics in cells are tracked. Therefore, visual diagnosis is great significant in medicine and clinic. ${ }^{[28,53]}$ In recent years, an increasing number of FNPs are used to improve the cancer diagnostic and therapeutic imaging, primarily for preoperative and

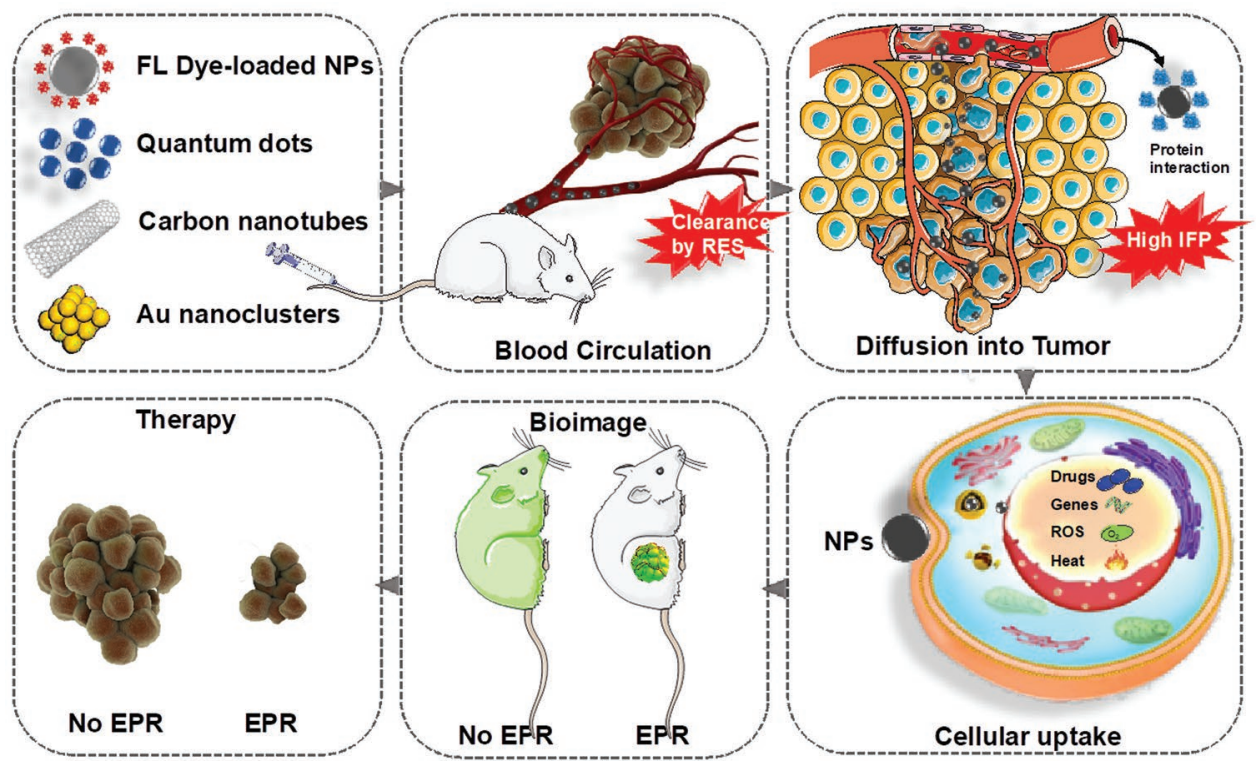

Figure 2. The process of FTNPs targeting to tumor through EPR effect and therapy effect. RES: reticuloendothelial system, IFP: tumor interstitial pressure, ROS: reactive oxygen species. 
intraoperative FI observation. ${ }^{[54]}$ There have been many reports about the FNPs designed based on EPR effect for visual targeting imaging.

\subsubsection{Fluorescent Dye-Doped NPs}

NPs combined with fluorescent dyes for imaging are a common strategy. It is an excellent way to produce enhanced fluorescent signals by selecting suitable NPs and modifying the surface with fluorescent dyes. ${ }^{[5]}$ A variety of NPs have been used including silica NPs, ${ }^{[56]}$ chitosan NPs, ${ }^{[57]}$ iron oxide NPs, ${ }^{[58]}$ AuNCs, ${ }^{[59]}$ and calcium phosphate NPs, ${ }^{[60]}$ and so on. Primarily, organicbased fluorescent dyes are used, for example, indocyanine green (ICG) ${ }^{[60,61]} \mathrm{Cy5}$, or Cy5.5, ${ }^{[58,62]}$ fluorescein isothiocyanate (FITC), ${ }^{[63]}$ etc. Zhang et al. synthesized a new type of metabolizable and efficient radiosensitizers for cancer radiotherapy, which combined ultrasmall AuNCs $(<2 \mathrm{~nm})$ with biocompatible coating ligands (glutathione, GSH). They labeled the new $\mathrm{Au}_{25} \mathrm{NCs}$ with Cy5 for FI. As shown in the result of in vivo experiment, the $\mathrm{Au}_{25} \mathrm{NCs}$ displayed higher tumor accumulation via the improved EPR effect and had a better cancer therapeutic effect. ${ }^{[59]}$ Altinoglu et al. studied the EPR effect in nude mice implanted with subcutaneous human breast adenocarcinoma tumors by ICG-doped calcium phosphate NPs (CPNPs). Their results showed that PEGylated CPNPs encapsulation prolonged circulation time in vivo due to the EPR effect. The CPNPs was still visible even more than $96 \mathrm{~h}$ postinjection. Moreover, the ICG-CPNP displayed deeper penetration capacity than free fluorophore. ${ }^{[60]}$

\subsubsection{Quantum Dots}

QDs are also known as semiconductor nanocrystals with an approximate spherical shape. Its 3D size ranges from 2 to $10 \mathrm{~nm}$ with obvious quantum effects resulting in unique optical and electrical properties, especially strong photoluminescence, high sensitivity, and good stability. Fluorescent QDs have tunable fluorescent emission spectrum from visible to infrared wavelengths, large absorption coefficient across wide spectrum range, and very high optical stability. ${ }^{[55,64]}$ However, cytotoxicity related to heavy metals remains a hot topic and limit for future bioimaging applications of QDs. ${ }^{[55]}$ The advent of GQDs seems likely to solve the problem. GQDs have been found to exhibit better biocompatibility, lower toxicity, and better photostability against photobleaching and blinking. ${ }^{[65]}$

QDs seem too small for the EPR effect, but researchers have come up with some strategies. NPs with diameter of about $100 \mathrm{~nm}$ showed good EPR effect of tumor accumulation, but their large size hinders penetration into the dense collagen matrix. Wong et al. ${ }^{[6]}$ presented a multistage system, in which the size decreased from 100 to $10 \mathrm{~nm}$ after leakage from tumor vessels to tumor microenvironment (TME). They used QDs as a model to test whether it was feasible. They utilized collagen gel to simulate the interstitial matrix of a solid tumor. The two kinds of designed experimental QDs (silica QDs and QDs Gel NPs) before or after cleaving were placed in contact with the gel and incubated for $12 \mathrm{~h}$. The results indicated that both silica QDs and QDs Gel NPs have negligible permeability before cleaving and were excluded from collagen matrix. However, after cleavage of QDs Gel NPs, the freed QDs were able to penetrate over a millimeter into the gel. The in vivo image indicated that the QDs Gel NPs achieved more accumulation after cleaved. ${ }^{[67]} \mathrm{Du}$ et al. synthesized a kind of GQDs with an average diameter of 2-5 $\mathrm{nm}$, which increased to about $10 \mathrm{~nm}$ after Chlorin e6 (Ce6) conjugation. The GQDs-SS-Ce6 had excellent therapeutic effect on nude mice bearing HeLa tumor. Effective tumor suppression of GQDs-SS-Ce6 in tumor treatment is mainly due to the improved the EPR effect of smaller GQDs nanosystem as manifested by the above in vivo and ex vivo imaging experiments. ${ }^{[68]} \mathrm{QDs}$ have been verified to enhance the EPR effect due to the better ability of small size penetration in tumor sites, ${ }^{[66,68-70]}$ and some small size GQDs can produce singlet oxygen, killing cancer cells. ${ }^{[69,71]}$

\subsubsection{Carbon Nanotubes}

Carbon nanotubes (CNTs), including single-walled carbon nanotubes (SWNTs) and multiwalled carbon nanotubes (MWNTs), have attracted much attention since their discovery in 1990. ${ }^{[72]}$ The unique optical properties of CNTs, especially SWNTs, give them great potential in the field of biological imaging. SWNTs exhibit intrinsic photoluminescence (PL) in the near-infrared (NIR) spectrum, within the "biological window" (700-1300 nm) where absorption, scattering, and autofluorescence by tissues, blood, and water are minimized. ${ }^{[73]}$

Countless articles have reported the application of SWNTs. For example, functional SWNTs can avoid rapid clearance by the immune system, ${ }^{[74]}$ and have been used for drug carrier ${ }^{[7]}$ and NIR imaging. ${ }^{[76]}$ Liu et al. reported a kind of PEG-functionalized SWNTs; they detected blood circulation up to 1 day with the SWNTs: biliary and renal are the main excretion pathways. Their results suggest that increased circulation time contributes to increased passive tumor accumulation of EPR effects. ${ }^{[7]}$

Impurities of MNPs contained in CNTs samples can be utilized for MRI to provide strong T2-weighted imaging contrast. ${ }^{[78,79]}$ In addition, radionuclides can be coupled to and even inserted into CNTs to present more imaging modalities, including PET ${ }^{[80]}$ and single-photon emission CT. ${ }^{[81]}$ Choi et al. demonstrated for the first time the use of the SWNTs/iron oxide NPs complexes as multimodal biomedical imaging agents. By encapsulation with DNA, the SWNTs/iron oxide NPs complexes are individually dispersed in aqueous solution and are more easily introduced into a biological environment. The application of the NIR mapping and MRI realized the multimodal biomedical imaging. ${ }^{[79]}$

\subsubsection{Au Nanoclusters}

The low toxicity, bright NIR fluorescence, and ultrasmall size give AuNCs a promising prospects in biomedical application field. ${ }^{82,83]}$ Protein- and peptide-stabilized AuNCs are especially suitable for bioimaging and therapy, owing to their unique functionality, easy conjugation, biocompatibility, large stokes shift, long lifetime, as well as photo and chemical stability. ${ }^{[84]}$ Wu et al. showed the possibility of using ultrasmall NIR AuNCs for tumor FI in vivo. They first investigated AuNCs in 
living mice and found that the uptake of BSA-AuNCs by the reticuloendothelial system (e.g., liver and spleen) is relatively low in comparison with other nanomaterials, partly due to their ultrasmall hydrodynamic size. Furthermore, by selecting MDA-MB-45 and HeLa tumor xenograft models, the EPR effect of ultrasmall NIR AuNCs has been demonstrated in tumorbearing mice. ${ }^{[82]}$ GSH-AuNCs have been implemented in bioimaging to assess biodistribution, renal clearance, pharmacokinetics, and tumor accumulation. ${ }^{[85]}$

\subsubsection{The Defects of EPR Effect}

Some of the NPs approved by the US Food and Drug Administration (FDA) such as liposomal doxorubicin (Doxil/Caelyx) ${ }^{[86]}$ or daunorubicin citrate liposomes (DaunoXome) ${ }^{[87]}$ have reduced the side effects, but only mild improvements have been seen in the patient survival rate. ${ }^{[48,88]}$ In fact, the tumor targeting efficiency of NPs/nanomedicines designed by the EPR mechanism is very low, less than $5 \% .{ }^{[43,52,89]}$ Chan et al. reviewed more than 100 nanomedicine papers from the past 10 years, and found that an average of just $0.7 \%$ of any NPs dose, whether actively targeted or not, gets into tumors. ${ }^{[0]}$ There are some reasons for this, resulting in low targeting rates. For example, abnormal tumor vasculature, high interstitial fluid pressure, growth-induced solid stress, solid stress from abnormal stromal matrix, and so on. ${ }^{[22,91]}$ Another problem is the pathophysiological heterogeneity of tumors. Different tumors vary greatly, especially in the central area of cancer, and do not exhibit the EPR effect. ${ }^{[92]}$ Some articles pointed out that most of the NPs are accumulated in the liver, spleen, and other organs for a long time. The incomplete metabolism will induce long-term organ damage. ${ }^{[43,93]}$ Due to the passive targeting effect based on the EPR effect being disappointing, the researchers have thought and sought other ways to improve the specific targeting rate of tumors, such as active targeting, the TME, and CMPT etc.

\subsection{Active Targeting}

For anticancer active targeting, two types of cellular targeting are distinguished: active targeting to cancer cells due to the overexpression of transferrin, folate, epidermal growth factor (EGF), or glycoproteins and so on and active targeting to the tumor endothelium due to the overexpression of the vascular endothelial growth factors (VEGF), $\alpha_{\mathrm{v}} \beta_{3}$ integrins, the vascular cell adhesion molecule-1 (VCAM-1) or matrix metalloproteinases (MMP) etc. For targeting approach, it can be divided into the following categories: receptor-mediated

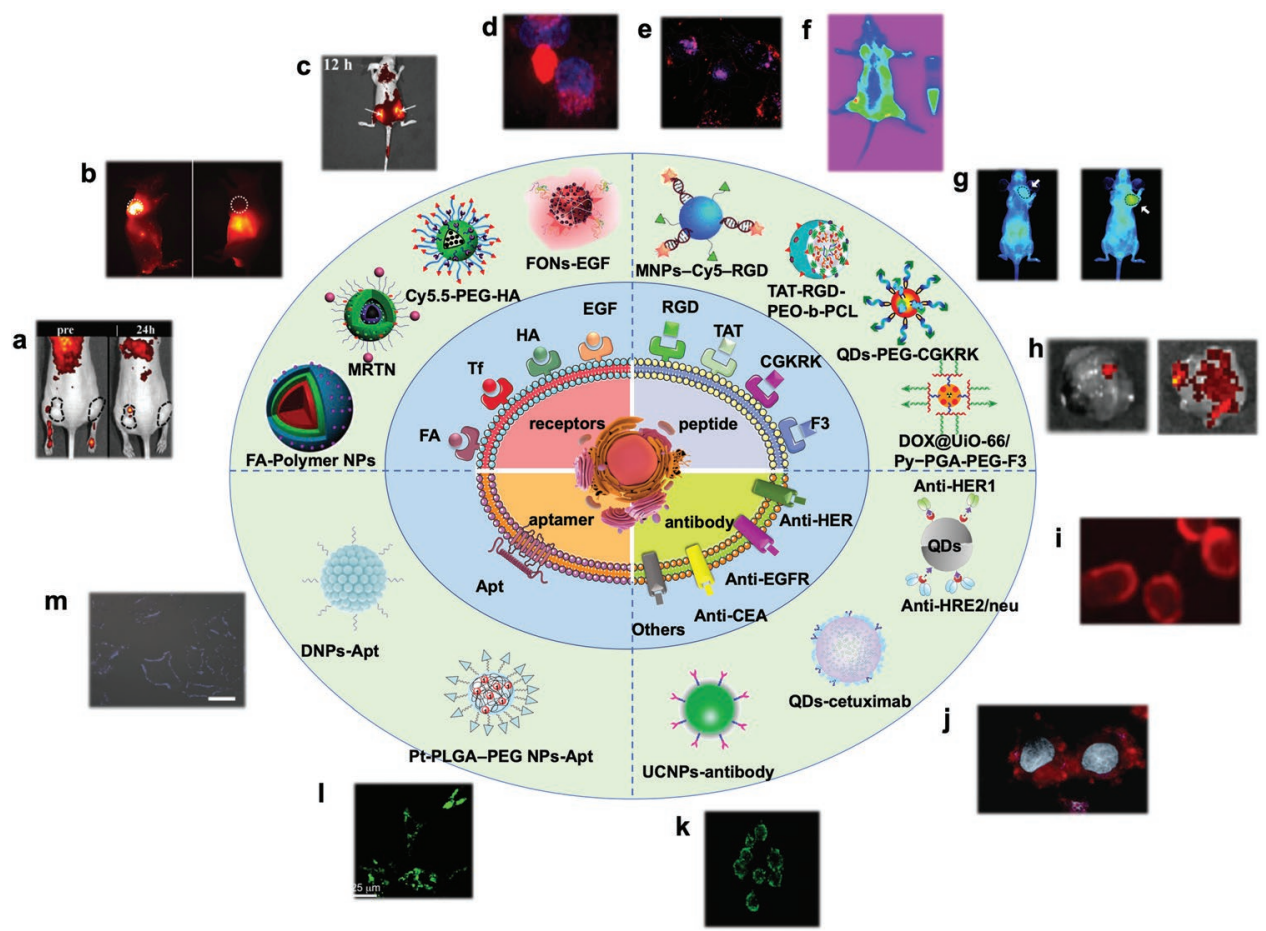

Figure 3. Schematic illustration of active targeting. Receptor-mediated targeting: a) FA-Polymer NPs. Reproduced with permission. ${ }^{[96]}$ Copyright 2013 , Wiley-VCH. b) MRTN. Reproduced with permission. ${ }^{[18]}$ Copyright 2014, Wiley-VCH. c) Cy5.5-PEG-g-A-HA NPs. Reproduced with permission. ${ }^{[127]}$ Copyright 2018, American Chemical Society. d) FONs-EGF. Reproduced with permission. ${ }^{[132]}$ Copyright 2017, RSC Pub. Peptide-mediated targeting: e) MNPs-Cy5-RGD. Reproduced with permission. ${ }^{[134]}$ Copyright 2009, Wiley-VCH. f) TAT-RGD-PEO-b-PCL. Reproduced with permission. ${ }^{[149]}$ Copyright 201 1, American Chemical Society. g) QDs-PEG-CGKRK. Reproduced with permission. ${ }^{[151]}$ Copyright 2015, Wiley-VCH. h) DOX@UiO-66/Py-PGA-PEG-F3. Reproduced with permission. ${ }^{[152]}$ Copyright 2017, American Chemical Society. Antibody-mediated targeting: i) QDs-antibody. Reproduced under the terms of the CC-BY Creative Commons Attribution License (https://creativecommons.org/licenses/by/4.0/). ${ }^{[157]}$ Copyright 2012, The Authors, Published by PLOS. j) QDs-cetuximab. Reproduced with permission. ${ }^{[162]}$ Copyright 2012, Future Medicine Ltd. k) UCNPs-antibody. Reproduced with permission. ${ }^{[167]}$ Copyright 2009, American

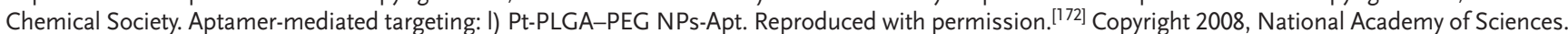
m) DNPs-Apt. Reproduced with permission. ${ }^{[173]}$ Copyright 2016, Springer Nature. 
targeting; peptide-mediated targeting; antibody-mediated targeting; aptamer-mediated targeting ${ }^{[94]}$ (Figure 3).

\subsubsection{Receptor-Mediated Targeting}

Receptor-mediated targeting is a common strategy to design fluorescent nanocarriers for active targeting to tumors by binding the ligands matched to the overexpressed receptors on tumors. At present, the most studied receptors that act as active target vectors mainly include folate receptors (FR), transferrin receptors (TfR), hyaluronic acid receptors (HAR), epidermal growth factor receptors (EGFR), etc. ${ }^{[94,95]}$

FR overexpressed in many cancer types provides an effective strategy for targeting to tumors by folic acid (FA) functionalized FNPs. Ahmed's group reported multifunctional polymer NPs with fluorescent multiblock for bioimaging and FA for tumor targeting (Figure 3a). ${ }^{[96]}$ While Rosenholm et al., ${ }^{[97]}$ Nakamura et al., ${ }^{[98]}$ and Santiago et al. ${ }^{[99]}$ designed multifunctional silica NPs with fluorescent and targeting moieties for specifically targeting cancer cells with FA as a targeted ligand for active targeting. Liong et al. had also designed the multifunctional inorganic NPs conjugated with FA for increasing the uptake of hydrophobic anticancer drugs by cancer cells. In addition, it has dual-imaging capability of MRI imaging by superparamagnetic iron oxide nanocrystals and optical imaging by conjugating with FITC. Their result show that the highly versatile MFNPs can be used for drug delivery, MRI, and magnetic manipulation, FI and cell targeting simultaneously, with the potential for simultaneous imaging and therapeutic applications. ${ }^{[100]}$ Liu et al. used black phosphorus nanosheet (BPNS) as a nanocarrier functionalized with FA and a DNA aptamer (Apt) for specific recognition. ${ }^{[101]}$ Modified fluorescent QDs as a targeting and delivery system are also potentially effective tools for tumor optical imaging, diagnosis, and treatment, which has been studied for many years. ${ }^{[102]}$ Besides, Prasad and co-workers ${ }^{[103]}$ and Chatterjee et al. ${ }^{[104]}$ have shown a new approach for in vitro and in vivo bioimaging utilizing UCNPs about 10 years ago. To enhance the tumor selectivity, Hu et al., ${ }^{[105]}$ Xiong et al., ${ }^{[106]}$ and Cao et al. ${ }^{[107]}$ have developed UCNPs conjugated with FA for in vitro and in vivo targeted imaging. In order to improve the local effective treatment concentration of drugs and minimize toxicity and side effects of patients, researchers have taken a variety of approaches to modify the UCNPs for multifunctional application, such as targeting bioimaging with FA, drug delivery for chemotherapy, and photodynamic therapy (PDT). ${ }^{[108]}$ As mentioned above, tumor-specific targeted therapy based on FA is one of the most widely applied and important methods. However, the expression of FR in normal tissues will lead to unexpected results with poor targeting effect and unsatisfactory therapeutic effects. Very recently, Yu et al. developed a preprotective strategy using a switchable UCNPs nanocomposite conjugated with two types of DNA of different length, shorter DNA modified by FA and longer DNA modified by Ce6. In normal tissues, FA is protected by longer DNA, which can be triggered in tumor site to exposed FA for precise targeting and PDT just as shown in Figure 4. ${ }^{[109]}$ As FCNMs are a kind of novel fluorescent nanomaterial exhibiting promising applications in the biological field, they have attracted plenty of interests to combine with FA for active targeting. Such as carbon dots $(\mathrm{CDs}),{ }^{[110]}$ nanodiamonds (NDs), ${ }^{[111]}$ and GQDs. ${ }^{[112]}$

TfR is a dimeric transmembrane glycoproteins receptor for transferrin, which import iron by receptor-mediated endocytosis of transferrin iron complex. Studies have shown that TfR highly expressed on the surface of many types of tumor cells. ${ }^{[113]}$ Thus, Tf-conjugated FNPs could selectively target to TfR-overexpressed tumor cells by match between Tf and TfR. ${ }^{114]}$ So far, a lot of FNPs conjugated with Tf have been studied deeply to improve the targeting efficacy. For instance, organically modified silica NPs incorporating rhodamine-B, ${ }^{[115]}$ FITC-modified mesoporous silica NPs (FMSNs), ${ }^{[116]}$ magnetic nanocarrier based on chitosan and rhodamine-B decorated superparamagnetic iron oxide NPs (SPIO NPs), ${ }^{[117]}$ multifunctional rattle-type nanoparticles (MRTNs) (Figure 3b), ${ }^{[118]}$ fluorescent calcium phosphosilicate nanocomposite particles (CPNPs) dropped of ICG ${ }^{[119]}$ and liquid crystal NPs (LCNPs) incorporated with fluorescent dye. ${ }^{[120]}$ In addition to these, Muthu et al. developed advanced theranostic micelles conjugated with Tf and ultrabright AuNCs and carried docetaxel (DTX) for simultaneous cancer imaging and therapy. ${ }^{[121]} \mathrm{Xu}$ et al. designed a dual-targeting carrier of paclitaxel based on hyperbranched copolymer NPs conjugated with Tf and RGD (arginine-glycine-aspartic acid) peptide, which is also a targeting ligand that will be reviewed in the next section of 2.2.2. ${ }^{[122]}$

Hyaluronic acid (HA) is a main component of the extracellular matrix (ECM) and intercellular substance. HA plays an important role in maintaining the structure of the extracellular matrix and regulates intracellular activities with a $\mathrm{MW}$ (molecular weight) less than $80000 .{ }^{[123]}$ It has tumor targeting and antitumor effect through binding to the overexpressed HAR on tumor cell surface, resulting in enhancement of tumor cells internalization. It could regulate tumor angiogenesis, tumor metastasis and invasion, and increase the drug concentration of lesion area to achieve the purpose of targeted therapy. ${ }^{[124]}$ There are four kinds of specific HAR: CD44, RHAMM, IVd4, and LEC overexpressed on the cell membrane surface. CD44 receptor, a transmembrane glycoprotein, is the most important HAR on the cell surface and the main site of binding to HA. Liu et al. prepared bilayered NPs decorated by a lipophilic NIR fluorescent dye, stearic acid-grafted polyethyleneimine and HA (DiR-PgSHA NPs) for in vivo tumor-targeted optical imaging. ${ }^{[125]} \mathrm{Li}$ et al. developed intrinsically redox-sensitive nanogels based on fluorescent photoclick cross-linking with L-cystine dimethacrylamide (MA-Cys-MA) and CD44-targeting hyaluronic acid (HA-NGs), showing highly efficient loading and breast tumor-targeted delivery of cytochrome $\mathrm{c}$ (CC). ${ }^{[126]}$ Meanwhile, Cheng et al. designed Cy5.5-PEG-HA NPs combined with cisplatin for selectively targeting tumors therapy and fluorescence imaging in vivo (Figure 3c). ${ }^{[127]}$ Cy5.5-PEG-HA NPs have clear fluorescence imaging in the body and show an effective accumulation at the tumor site.

EGF can stimulate cell growth strongly by binding to its receptor (EGFR), resulting in cellular proliferation, differentiation, and survival. ${ }^{[28]}$ The higher expression of EGFR in tissues is associated with several cancers. ${ }^{[129]}$ Tseng et al. used gelatin NPs (GPs) modified with FITC-biotinylated EGF as drug delivery strategy for lung cancer targeting, imaging, and treatment via inhalation. ${ }^{[130]}$ Yuan et al. designed dendrimertriglycine-EGF NPs for tumor imaging and targeted drug delivery. ${ }^{[131]}$ Faucon et al. demonstrated that fluorescent organic 

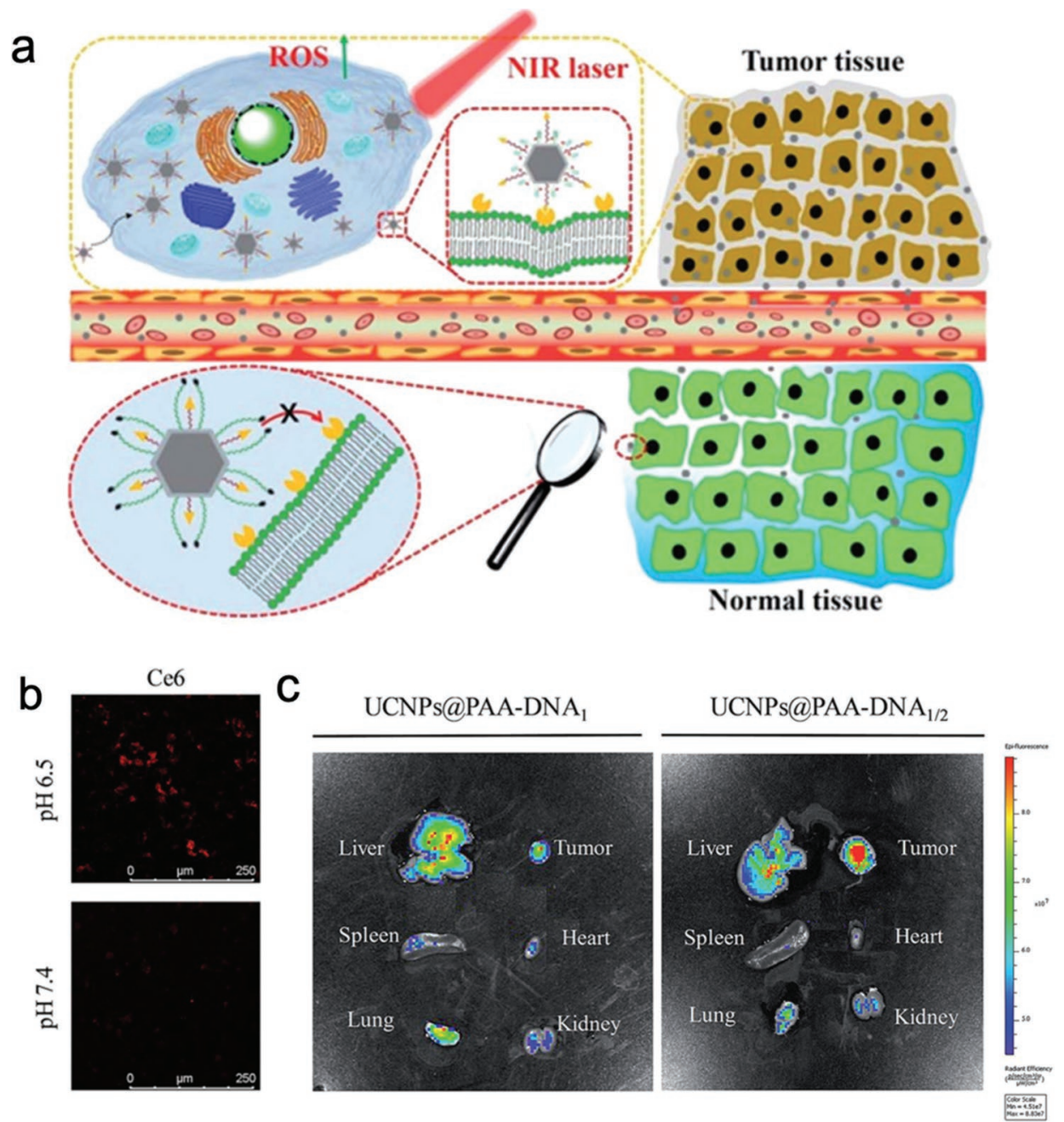

Figure 4. a) Precise tumor targeting and specific PDT for cancer of UCNPs@PAA-DNA. b) Confocal images of MCF-7 cells incubated with UCNPs@ PAA-DNA $1 / 2$ at $\mathrm{pH} 6.5$ and 7.4. c) In vivo imaging of five major organs harvested from a mouse at $8 \mathrm{~h}$ postinjection with UCNPs@PAA-DNA $($ Ce6) (left) or UCNPs@PAA-DNA $1 / 2$ (right). a-c) Reproduced with permission. ${ }^{[109]}$ Copyright 2018, The Royal Society of Chemistry.

NPs (FONPs) covalent attached with EGF at sub-nanomolar concentrations could serve as ultrabright targeting probes for breast cancer cells based on EGFR-overexpression (Figure 3d). ${ }^{[132]}$

\subsubsection{Peptide-Mediated Targeting}

As tumors proliferating, massive new vessels formation must occur to supply nutrition for the tumors. As an adhesion molecule of cells, integrin $\alpha_{\mathrm{v}} \beta_{3}$ is highly expressed in various tumor cells and plays an important role in tumor angiogenesis and metastasis. Therefore, integrin $\alpha_{\mathrm{v}} \beta_{3}$ can be a target for antitumor targeting nanodrugs, showing the effect of inhibiting tumor growth, tumor targeting, and drug delivery. Studies have confirmed that ligands containing arginine-glycine-aspartic acid (RGD) have a high specificity and affinity for integrin $\alpha_{v} \beta_{3}$.

Some scientists prefer FL dye-doped NPs as nanocarriers for bioimaging. Drug delivery nanocarriers conjugated with RGD as targeting moiety and fluorescent dyes as imaging moiety have been demonstrated. ${ }^{[133-136]}$ Lee et al. developed "all-in-one" cancer cell-specific probes based on magnetic NPs conjugated with siRNAs, targeting moieties RGD, and fluorescent dyes Cy5 (MNPs-Cy5-RGD) for simultaneous delivery and multimodal imaging (Figure 3e). ${ }^{[134]}$ Akhavan and Ghaderi designed rGONM-PEG-Cy7-RGD containing graphene oxide nanoplatelets modified with RGD and Cy7 for in vivo tumor targeting and FI of human glioblastoma U87MG tumors. ${ }^{[135]}$ Alvero et al. developed a PLGA-PEG-RGD nanoplatform modified with three different fluorescent dyes of deep infrared (DIR), Coumarin-6 (C6) and ICG for visualization of ovarian cancer micrometastasis, reducing inadvertent injury in surgery. ${ }^{[136]}$

Fluorescent QDs have become the focus of many scientists due to their unique optical properties. Li et al. used NIR QDs as fluorescent probes modified with cyclic RGD to form tumorspecific bioconjugates for tumor-targeted imaging. According to their results, the tumor visualization, identification, and resection could be promoted via FI guidance. ${ }^{[137]}$ Zhang et al. proved that $\mathrm{Ag}_{2} \mathrm{~S}$ QDs conjugated with specific ligand-RGD is a promising NIR-II probe with bright photoluminescence and high biocompatibility for targeted labeling and imaging of cancer cells. ${ }^{[138]} \mathrm{Lu}$ et al. synthesized excellent aqueous dispersible near-infrared-emitting QDs (aqQDs) modified 
with RGD peptides for in vivo active tumor targeting. The RGD-decorated aqQDs exhibit highly biospecific properties, being highly sensitive and specific for tumor sites. ${ }^{[139]}$

As luminescent AuNCs show bright fluorescence as well as unique plasmon properties, $\mathrm{Su}$ et al. designed and synthesized fluorescent BSA-encapsulated AuNCs conjugated in a nanogel system, followed by tumor targeting peptide iRGD, which allowed for tumor targeting drug delivery. ${ }^{[140]}$ Chen et al. established a novel nanoplatform of AuNC-cRGD-Apt (aptamer) with dual targeting function by conjugation with cyclic RGD (cRGD) and Apt AS1411 for tumor targeting, diagnosis, and therapy. ${ }^{[141]}$ Liang et al. reported a green and one-step strategy to synthesize c(RGDyC)-modified AuNCs (c(RGDyC)-AuNCs) as highly efficient tumor-targeted radiotherapy sensitizers with bright red/ NIR fluorescence and active tumor targeting property. ${ }^{[142]}$

Beyond that, UCNPs is also combined with RGD for cancer targeting and imaging. ${ }^{[143]} \mathrm{Cao}$ et al. reported ultrasmall sub-5 $\mathrm{nm} \mathrm{KGdF}$ rare earth NPs as nanofluorescent probes for in vitro and in vivo tumor targeting imaging by conjugating with the RGD peptide, which exhibited up/down-conversion luminescence by doped $\mathrm{Yb}^{3+} / \mathrm{Tm}^{3+}$ and $\mathrm{Eu}^{3+}{ }^{3144]}$ SWNTs have been demonstrated as promising candidates for bioimaging and biosensing with unique fluorescence in the NIR region. ${ }^{[145]}$ Polo et al. anchored RGD onto SWNTs by confining peptide motifs via noncovalent adsorption of single-stranded DNA (ssDNA), which is a novel and straightforward approach to tune binding affinities of RGD peptide. ${ }^{[146]}$ There are also many other FNPs used for RGD connected targeting, such as luminescent NPs, ${ }^{[147]}$ micelle NPs, ${ }^{[133]}$ and fluorescent liposomes. ${ }^{[148]}$

In addition to RGD peptides, some other tumor targeting peptides have also been studied (Figure $3 \mathrm{f}-\mathrm{h}$ ), such as cellpenetrating peptide TAT, ${ }^{[149,150]}$ tumor-specific vascular homing peptide CGKRK (Cys-Gly-Lys-Arg-Lys), ${ }^{[151]}$ and nucleolin specifically targeting F3 peptide. ${ }^{[152]}$ TAT peptide is a type of cellpenetrating peptide, usually decorating to the surface of NPs to improve nuclear translocation. Guan et al. developed fluorescent protein NPs based on TAT peptide and enhanced green fluorescent protein (EGFP) by gene engineering method. This fluorescent protein NPs showed selective tumor accumulation suggesting a potential application in tumor imaging and anticancer drug delivery. ${ }^{[150]}$ Liu et al. designed a versatile bioimaging probe using highly luminescent cadmium-free $\mathrm{CuInSe} \mathrm{S}_{2}$ ZnS core/shell QDs conjugated with CGKRK tumor targeting peptides for tumor-targeted multimodal optical imaging. ${ }^{[151]}$

\subsubsection{Antibody-Mediated Targeting}

An antibody (Ab), also known as immunoglobulin (Ig), secreted by B cells which could bind to the corresponding antigen (Ag) specifically and precisely. ${ }^{[153]}$ There are many advantages of $\mathrm{Ab}$, such as high specificity, high sensitivity, and easy preparation, etc. Therefore, $\mathrm{Ab}$ has become the mainstream study of cancer targeting application relied on the specific binding of $\mathrm{Ag}$ and $\mathrm{Ab}$ targeting to specific tumor tissues, which could improve the therapeutic effect and reduce the side effects. Monoclonal antibody $(\mathrm{mAb})$ is a category of Abs produced by identical immune cells. In is interesting that $\mathrm{mAb}$ has monovalent affinity, which means that it can bind to the same epitope of an Ag. Bispecific
$\mathrm{mAb}$ can also be designed to increase the therapeutic targets of one single $\mathrm{mAb}$ to two epitopes. Therefore, $\mathrm{mAb}$ has been considered as a bullet of the targeted nanocarrier of chemotherapy drugs and as powerful tools for manipulating anticancer immune responses. ${ }^{[154]}$ With increasingly promising clinical results, the discovery and development of therapeutic Abs and their derivatives have become a hot topic in recent years.

Human epidermal growth factor receptor 2 (HER2) is the homologous gene of neu oncogene (HER2/neu) in rats. ${ }^{[155]}$ This receptor signals play an important role in cancer cell proliferation, differentiation, adhesion, motility, and apoptosis. Hun et al. designed a novel kind of polymer fluorescent NPs (PFNPs) modified with anti-HER2 $\mathrm{mAb}$ for detecting ovarian cancer cells with fluorescence microscopy imaging technology. The mAb-coupled PFNPs can effectively identify the ovarian cancer cells with good sensitivity and excellent photostability, providing a new approach for diagnosis and therapy of ovarian cancer. ${ }^{[156]}$ Zdobnova et al. ${ }^{[157]}$ (Figure 3i) and Balalaeva et al. ${ }^{[158]}$ designed fluorescent nanocomplexes based on QDs and tumor-specific targeting Ab, such as anti-HER1 Ab and anti-HER2/neu scFv Ab, that simply combining the targeting and visualization functions in one system. Herceptin, the brand name of Trastuzumab, is a humanized $\mathrm{mAb}$ worked by specific binding to HER2 receptor and slowing down cell duplication to target breast cancer cells and treat breast cancer. Wang et al. designed a new nanomaterial platform of fluorescent BSA-protected AuNCs conjugated with Herceptin (AuNCs-Her) for specific targeting to breast cancer cells and tumor tissue as a novel fluorescent agent for simultaneous imaging and cancer therapy. They found that AuNCs-Her could escape from the endosome and carried the Herceptin to the nucleus of breast cancer cells to enhance the therapeutic efficacy. ${ }^{[159]}$

Cetuximab, an anti-EGFR mAb as the EGFR inhibitor, is one of the first FDA-approved mAbs for cancer treatment. ${ }^{[160]}$ Cho et al. demonstrated the potential application of cetuximabconjugated magnetofluorescent silica NPs for the detection of EGFR-positive colon cancer using in vivo imaging approaches. ${ }^{[161]}$ Deepagan et al. prepared MFNPs based on QDs and drug inside the PLGA matrix and conjugated cetuximab for targeting EGFR overexpressed cancer cells (Figure 3j). ${ }^{[162]}$ Yang et al. used a single-chain anti-EGFR Ab (ScFvEGFR) as targeting molecule conjugated to the surface of QDs, specifically binding to EGFR overexpressed on cancer cells with a fluorescent signal for optical imaging. ${ }^{[163]}$ Carcinoembryonic antigen (CEA) is a set of glycoproteins highly related to cell adhesion, which are normally produced during fetal development but stopped before birth. ${ }^{[164]}$ Consequently, the CEA level is usually very low in healthy adults' blood but increased in some types of cancer, which means that it can be used as a tumor target in cancer targeting therapy. Tiernan et al. ${ }^{[165]}$ reported fluorescent dye-doped silica NPs and rare earth doped UCNPs conjugated with targeted anti-CEA Ab for cancer targeting imaging and therapy. $\mathrm{Li}$ et al. ${ }^{[166]}$ reported a soft nanomaterial-based targeting polymersomes with NIR dyes and Abs (anti-CEA Ab and anti-EGFR Ab). Recently, Wang et al. synthesized Ab-UCNPs conjugates based on core-shell NPs UCNPs@SiO 2 linked to rabbit anti-CEA8 $\mathrm{Ab}$, which could specific attach to the surface of HeLa cells (Figure 3k). ${ }^{[167]}$ Additionally, some other Abs are also used to combine with FNPs for targeting cancer and therapy. Wu et al. used poly lactic-co-glycolic acid NPs (PLGA NPs) conjugated 
with MUC1 $\mathrm{Ab}$ as a nanocarrier for specific targeting delivery of paclitaxel into human pancreatic ductal adenocarcinoma cells in vitro and in vivo and loaded with FI agents for visual imaging. ${ }^{[168]}$ Zheng et al. designed an ICG-containing nanostructure (ICG-PL-PEG) conjugated with integrin $\alpha_{\mathrm{v}} \beta_{3} \mathrm{mAb}$ leading to selective internalization and retention in target tumor cells. ICG-PL-PEG has both fluorescent marker and imagingguided photothermal therapy capabilities, showing great potential for clinical applications. ${ }^{[169]}$

\subsubsection{Aptamer-Mediated Targeting}

Nucleic acid Apt is a single-chain oligonucleotide with 20-60 bases screened by systematic evolution of ligands by exponential enrichment (SELEX) with functions of high affinity and specific binding, which were first screened out by Ellington ${ }^{[170]}$ in 1990. By virtue of its inherent nature of high specificity and high affinity, Apt has been widely studied by researchers for diagnosis and treatment of many diseases, especially for tumor-targeted therapy. Compared to $\mathrm{Ab}$, nucleic acid aptamers have many unique advantages, such as small molecular weight, artificial synthesis, high stability, and low immunogenicity, suggesting that nucleic acid Apt is an ideal tool for cancer-targeted therapy. In recent years, researchers have constructed a variety of AptFNPs complexes for specific targeting imaging and recognition of cancer cells. For, e.g., chitosan NPs-Apt, ${ }^{[171]}$ Pt-PLGA-PEG NPs-Apt, ${ }^{[172]}$ tryptophan-phenylalanine dipeptide NPs (DNPs) (Figure 3m), ${ }^{[173]} \mathrm{MnO}_{2}$ nanosheet-Apt, ${ }^{[174]}$ rGO nanosheetsApt, ${ }^{[175]}$ AgNCs-Apt, ${ }^{[176,177]}$ etc. Dhar et al. have reported a unique strategy using PLGA-b-PEG NPs functionalized with PSMA targeting Apt on the surface as a vehicle for targeted delivery of platinum (IV) to prostate cancer cells (Figure 31). ${ }^{[172]}$ Using Apt technology, Tallury et al. synthesized fluorescent chitosan NPs, which were specifically targeted to human leukemia cells. ${ }^{[171]}$ According to many studies, DNA Apt can specifically bind Mucin 1 (MUC1) which can target NPs to a cancer cell of interest. ${ }^{[178]}$ Fan et al. designed DNPs based on dipeptide to shift the peptide's intrinsic fluorescence from the ultraviolet to the visible range as imaging probes. And then the DNPs were further functionalized with MUC1 Apt and doxorubicin for targeting cancer cells and monitoring drug release by real time fluorescent image. ${ }^{[173]}$

Active targeting is a very important consideration when designing an antitumor drug delivery nanocarrier. It determines the actual drug delivery effect and the bioavailability of the drug. Active targeting therapeutic strategies are expected to target tumor tissues more specifically than just EPR effect. The increased effectiveness of active targeting nanoparticles is due to the improved targeted cell recognition and targeted cell uptake rather than better tumor accumulation. ${ }^{[11,179]}$ However, an emerging field of nanotoxicology has concerns regarding whether NPs could pose a threat to both the environment and human health with side effects which need more study. ${ }^{[180]}$

\subsection{The Tumor Microenvironment}

TME, i.e., the internal environment where tumor cells are generated and reside, including not only the tumor cells themselves,

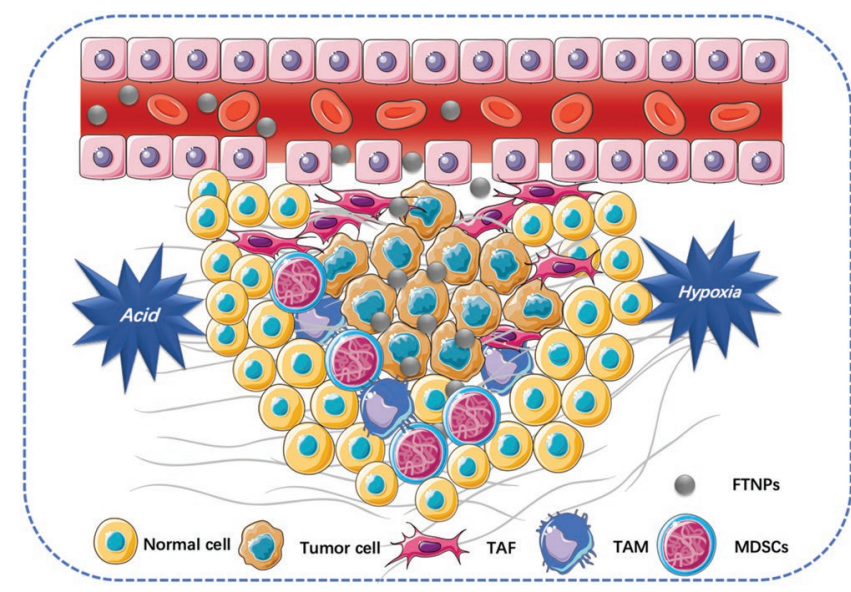

Figure 5. Schematic diagram of FTNPs targeting to the TME composed of tumor cells, stroma cells, and external physiological environment.

but also the surrounding multiple cells, such as fibroblasts, adipocytes, immune and inflammatory cells, glial cells and other cells, as well as the intercellular substance, microvessels and the biological molecules infiltrated in the ECM. ${ }^{[181]}$ It has become evident the need of seeking a new and alternative targeting strategy, TME, for cancer treatment as it plays an important role in development, progression, and metastasis of a tumor and in the development of drug resistance. ${ }^{[52]}$ There are many differences in physicochemical properties between TME and normal internal environments of the human body, such as low oxygen, low $\mathrm{pH}$, and high pressure. ${ }^{[182]}$ More than 100 years ago, Paget first postulated the important role played by microenvironment in metastasis formation and proposed the famous concept of "seed and soil" based on clinical observation of organ-specific metastasis of breast cancer. ${ }^{[183]}$ However, this hypothesis did not receive enough attention at that time, and the treatment idea was limited to the tumor cells themselves, which lead to an extremely difficult battle against cancer. Until recently, more and more scientists began to realize that tumor and TME are an integral whole (Figure 5). Therapeutic strategies of targeting to TME have their own advantages, such as tumor stromal cells having genetic stability with less mutation and resistance. The heterogeneity of the TME is smaller than that of tumor cells, and the therapeutic effect is more stable. Studies found that nanomedicines can accumulate in the tumor site through the EPR effect, but most of them are only retained in the perivascular areas with limited ability to penetrate into tumor cells due to the dense interstitial matrix. ${ }^{[184]}$ Dong et al. presented mesoporous silica nanoparticles (MSN) loaded with a chemotherapeutic agent, DOX, as well as a NO donor (S-nitrosothiol) to create DN@MSN, which could active MMP to degrade collagen in the tumor extracellular matrix. According to their results, DN@MSN enhanced the EPR effect of NPs and improved the tumor penetration of both the nanovehicle and cargo (DOX), leading to significantly improved antitumor efficacy. ${ }^{[185]}$ Therefore, it is necessary to study the TME from both biological and philosophical perspectives.

\subsubsection{Physiological Environment}

As mentioned above, the TME is quite different from normal human internal environments in terms of physical and 
chemical properties, and its characteristics of low oxygen, low $\mathrm{pH}$, and high pressure are quite remarkable, resulting in many growth factors, such as cytokines and various immune inflammatory reactions produced by proteolytic enzymes, which are very conducive to tumor proliferation, invasion, adhesion, angiogenesis and promote the generation of malignant tumors. ${ }^{[186]}$

Hypoxia: Thomlinson and Grey became aware of the hypoxia in many malignant tumors in 1955. ${ }^{[187]}$ Necrosis often occurs in anoxic regions, which is more prone to tumor proliferation and metastasis. Many studies around the world have found that hypoxia-inducible factor- $1 \alpha$ (HIF-1 $\alpha$ ) can be highly expressed in hypoxic tumor tissues, ${ }^{[188]}$ which plays an important role in tumor development and metastasis, making it became an important antitumor target. ${ }^{[189]}$ Kiyose et al. developed hypoxiaresponsive near-infrared fluorescent probes conjugating a black hole quencher (BHQ-3) as a hypoxia-responsive moiety for FI of hypoxic cancer cells and real-time monitoring of ischemia. ${ }^{[190]}$ Since a BHQ-3 with an azo-linkage quenched the NIR emissions, the probes were nonfluorescent under normoxic conditions, while under hypoxic conditions, the azo-linkage was reduced and the fluorescence was mostly recovered. Similarly, Piao et al. and Cai et al. developed fluorescent probes to detect different levels of hypoxia. ${ }^{[191]}$ Although many fluorescent probes have shown promising results in vitro, the in vivo application has been limited because of nonselectivity and instability of fluorescent probes under physiological conditions. Therefore, it is necessary to develop novel nanocarriers, such as FNPs, for hypoxic cancer targeting. Recently, various FNPs have been developed for targeted cancer imaging. ${ }^{[192]}$ Bartholomeusz et al. described a new approach for delivering small interfering RNA (siRNA) into cancer cells by noncovalently binding siRNA with SWCNTs targeted to hypoxia-HIF-1 $\alpha$ which strong specific inhibit the cellular HIF- $1 \alpha$ activity implied that SWCNT/siRNA complexes have the promising value as therapeutic agents. ${ }^{[193]}$ Perche et al. first reported the specific nanocarrier based on hypoxia-induced siRNA uptake and silencing as well as azobenzene imparts hypoxia for cancer targeting. They found that hypoxia-activated green fluorescent protein (GFP) is silence in vitro and downregulate in vivo in GFP-expressing tumors after intravenous administration which means that this designed nanocarrier represents a tumor-environment-responsive modality for tumor targeting. ${ }^{[194]}$

Low $p H$ : Hypoxia can induce intracellular glycolysis, leading to a drop in $\mathrm{pH}$. However, experiments have shown that even in the situation of low lactate or artificially increased tumor tissue oxygen pressure or blood supply, low pH still exists. Regardless of the cause, the extracellular microenvironment is acidic ( $\mathrm{pH}$ 6.5-6.9), and the cancer cells themselves remain neutral $(\mathrm{pH}$ 7.2-7.4). Chen et al. designed and synthesized pH-triggered probes based on the encapsulation of the $19 \mathrm{~F}$ contrast agent in AuNP-capped fluorescein-functionalized mesoporous silica NPs (FMSNs), called Au-FMSNs, for the intracellular MRI and FI. ${ }^{195]}$ Zhou et al. have reported some tunable, pHactivatable micellar (pHAM) NPs with $\mathrm{pH}$-sensitive dye, which could render a fast and ultrasensitive response to changes in pH value. ${ }^{[196]}$ Zhao et al. designed an oligopeptide self-assembly fluorescent nanostructure, which can be triggered from selfassembled stage to dissociated stage when encountering a subtle $\mathrm{pH}$-changed TME. ${ }^{197]}$

\subsubsection{Tumor Stroma Cells}

At present, it is increasingly recognized that tumor stroma contains different cell types, including tumor-associated fibroblasts (TAFs), tumor-associated macrophages (TAMs), and neovascularization cells, and so on, which play different and important roles in promoting the formation of tumor invasion and metastasis and serve as the soil for tumor growth. Each cell type plays different roles and has their own different functions.

Tumor-Associated Fibroblasts (TAFs): TAFs are the main member of tumor stroma cells with the function of secreting extracellular matrix components, growth factors, cytokines, and hormones, which can promote tumor initiation, progression, and metastasis. ${ }^{[198]}$ Miao et al. argues that NPs might be exploited to target the expression of secreted cytotoxic proteins from TAF as a new anticancer strategy. In order to prove their idea, lipid-coated protamine DNA complexes (LPD NPs) were loaded with TNF-related factor sTRAIL which triggered apoptosis in a wide range of tumor cells and incorporated with DiI fluorescent probe. According to their result, TAF could be used as sTRAIL producing cells that triggered apoptosis in tumor cell nests, which offered an effective strategy to treat desmoplastic cancers and further suppressed tumor growth. ${ }^{199]}$

Myeloid-Derived Suppressor Cells and Tumor-Associated Macrophages: MDSCs are a heterogeneous group of cells derived from bone marrow. It can significantly inhibit immune responses and regulate wound repair and inflammation, which is rapidly amplified in cancer. ${ }^{[200]}$ TAMs are a central component in the close association between chronic inflammation and cancer since they are recruited to tumor tissues as a response to cancer-associated inflammation and play an important role in the TME. ${ }^{[201]}$ TAMs are the major immunoregulatory cells to the immune response located in the stroma of solid tumor in the tumor progression (e.g., cancer cell proliferation, metastasis, and invasion) or in the antitumor processes. In malignant tumors, TAMs are closely related to the progression and metastatic invasion of tumors, which can provide inflammatory cytokines and growth factors for tumor cell survival. ${ }^{[202]}$ Hence, MDSCs and TAMs are expected to be a potential target for cancer treatments. Kourtis et al. examined the cell-level biodistribution kinetics after administering ultrasmall pluronic-stabilized poly (propylene sulfide) NPs labeled with Dy649-maleimide (NPs-Dy649) in the mouse. ${ }^{[203]}$ They found that these NPs have especially strong targeting to myeloid cells when administered intradermally (i.d.). In particular, MDSCs were efficiently and preferentially targeted in tumor-bearing mice, meaning that the NPs can be potentially useful for reversing the highly suppressive activity of these cells in the tumor stroma. Miller et al. designed the therapeutic NPs comprising a fluorescent platinum (IV) prodrug and a clinically tested polymer platform (PLGA-b-PEG) for the first time allow simultaneous imaging. They found that therapeutic NPs accumulated at high levels within TAMs served as cellular drug reservoirs. TAMs release the Pt payload into neighboring tumor cells over time. ${ }^{[204]}$ Cuccarese et al. used optical tissue clearing and a TAM-targeting injectable FNPs to examine 3D TAMs composition and nanoparticle-based drug delivery in murine pulmonary carcinoma, which offered a creative method for rapid tumor volume assessment and spatial information on TAMs infiltration at the cellular level in entire lungs. ${ }^{[205]}$ 


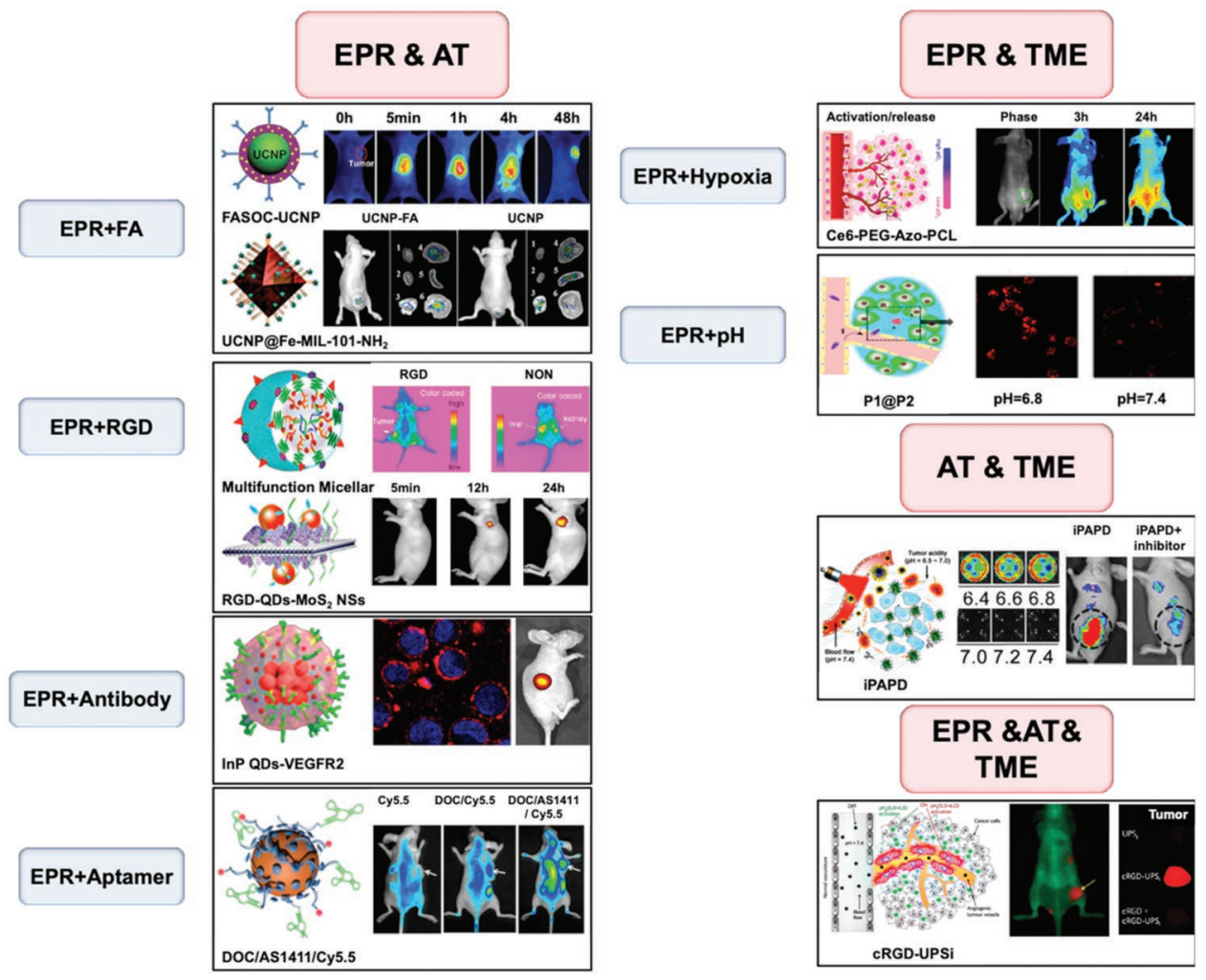

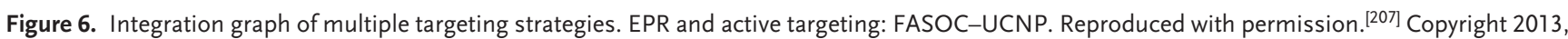
American Chemical Society. UCNP@Fe-MIL-101_NH2. Reproduced with permission. ${ }^{[208]}$ Copyright 2015, Wiley-VCH. Multifunctional Micellar. Reproduced with permission. ${ }^{1199]}$ Copyright 2011, American Chemical Society. RGD-QD-MoS, NSs. Reproduced with permission. ${ }^{[211]}$ Copyright 2017, RSC. InP QDs-VEGFR2 antibody. Reproduced with permission. ${ }^{[213]}$ Copyright 2017, American Chemical Society. DOC/AS1411/Cy5.5. Reproduced with permission. ${ }^{[215]}$ Copyright 2017, American Chemical Society. EPR \& TME: Ce6-PEG-Azo-PCL. Reproduced with permission. ${ }^{[216]}$ Copyright 2018, American Chemical Society. P1@P2. Reproduced with permission. ${ }^{[220]}$ Copyright 2017, American Chemical Society. Active targeting \& TME: iPAPD. Reproduced with permission. ${ }^{[228]}$ Copyright 2017, American Chemical Society. EPR effect \&Active targeting \&TME: cRGD-UPSi. Reproduced with permission. ${ }^{[227]}$ Copyright 2019, Springer Nature.

\subsubsection{Extracellular Matrix}

The ECM is a 3D network of extracellular macromolecules, such as collagen, enzymes, and glycoproteins, that provide structural and biochemical support to surrounding tumor cells and stromal cells. As many fibroblasts are transformed into CAFs during carcinogenesis, ECM production decreases, and malformed ECM is produced. In addition, CAFs produce matrix metalloproteinases (MMP) that cleave the proteins within the ECM, which may allow cancer cells to escape from their in situ location and metastasize to the whole body. Furthermore, dense and stiff ECM in solid tumor tissues can inhibit deep penetration of NPs drug carriers and decreases their therapeutic efficacy. So, Lee et al. suggest the ECM remodeling strategy for enhanced tumor targeting of Cy5.5-labeled glycol chitosan NPs. ${ }^{[206]}$

\subsection{Multiple Targeting Strategies}

FNPs combined with passive or active tumor targeting or other targeting strategies are promising for cancer diagnosis and therapy. However, suboptimal targeting effect of most targeting strategies, drug leakage during blood circulation, low tumor tissue accumulation/retention, and cellular internalization leads to unsatisfactory treatment outcome. To address these problems, the designed fluorescent targeting NPs (FTNPs) are expected to have multitargeting functions facing different environments. Multiple targeting, a novel targeting strategy that consists of two or more targeting stages including tumor tissue targeting based on EPR effect, tumor cell targeting based on targeting ligands and TME-based targeting and other strategies, shows great potential to enhance tumor therapeutic effect (Figure 6).

The multiple targeting nanoplatforms are generally based on the EPR effect combined with other strategies such as ligandbased active targeting, TME-based targeting, which are expected to show high stability in blood and enhance tumor retention, cellular internalization, and even nuclear uptake.

\subsubsection{EPR Effect and Active Targeting}

As shown in Figure 6, for the EPR effect combined with active targeting, there are several parts as reviewed. First, FA was used to improve the targeting efficiency of the EPR effect. Cui et al. developed a multifunctional nanostructure consisting 
of UCNPs and photosensitizer zinc (II) phthalocyanine (ZnPc) for PDT. The folate-modified amphiphilic chitosan (FASOC) was coated on the surface of UCNPs for active targeting and $\mathrm{ZnPc}$ anchoring close to the UCNPs. The overall size of the ZnPc-loaded FASOC-UCNPs was $\approx 50 \mathrm{~nm}$ in diameter, which led to accumulation in tumor tissues through the EPR effect and enhanced targeting to tumor by FA-based active ligand. ${ }^{[207]}$ Li et al. have designed octahedral core-shell nanostructures named UCNPs@Fe-MIL-101- $\mathrm{NH}_{2}$ modified with FA (UMP-FA) resulting in tumor targeted dual-mode imaging of upconversion luminescence (UCL) imaging and MRI. According to their result, there is a weak accumulation of UCNPs due to the EPR effect, while UMP-FA is successfully and efficiently delivered to tumors because of the receptor binding. ${ }^{[208]}$ Additionally, Fan et al. used H-ferritin (HFn) nanocarrier for crossing the blood brain barrier $(\mathrm{BBB})$ and specifically targeting and entering glioma cells to kill them through both passive targeting (EPR effect) and active targeting specific bound to HFn receptor overexpressed in glioma. ${ }^{[209]}$

Second, NPs were modified with RGD peptide to improve the targeting efficiency based on the EPR effect. Haedicke et al. used multifunctioned calcium phosphate NPs as carrier conjugating with i) Temoporfin as a photosensitizer, ii) the RGDfK peptide for tumor targeting, and iii) the fluorescent dye molecule DY682-NHS for near-infrared fluorescence (NIRF) optical imaging in vivo. ${ }^{[210]}$ Here, NP-DY682 showed just a short tumor accumulation and a fast elimination thereafter, suggesting an enrichment due to the EPR effect, while the RGD-conjugated NPs showed an enhanced specific accumulation at $24 \mathrm{~h}$ after injection. Xiong and Lavasanifar developed a polymeric micelles system that integrates multiple functions including near-infrared FI, dual targeting to cancer by the RGD peptides, and the TAT peptide for cancer targeted codelivery of siRNA and doxorubicin. ${ }^{[149]}$ Characterization studies provided evidence of the micelles with an appropriate size for tumor targeting by the EPR effect $(\approx 100 \mathrm{~nm})$, while the RGD allows for enhanced recognition and uptake of the nanocarrier by cancer cells. Zhang et al. have successfully prepared RGD-QD-MoS nanosheets (NSs) with excellent fluorescence, photothermal conversion, and cancer-targeting properties by functionalizing single-layer $\mathrm{MoS}_{2} \mathrm{NSs}$ with fluorescent QDs and RGD peptides. ${ }^{[211]}$ In addition, Mei et al. used two targeting ligands, angiopep-2 and activatable cell penetrating peptide (ACP) to modify NPs for tumor targeting delivery. As a result, NPs could significantly distribute into tumors through EPR while targeting ligands could improve the targeting ability of NPs. ${ }^{[212]}$

Third, antibodies and aptamers are also used to modify NPs to improve the targeting efficiency based on the EPR effect. Wu et al. modified near-infrared fluorescent QDs (InP QDs) with a vascular endothelial growth factor receptor 2 (VEGFR2) $\mathrm{mAb}$ for targeted drug delivery. The VEGFR2 Abs effectively bound to InP QDs to target tumor angiogenesis. In this design, the InP QDs-VEGFR2 can be delivered to tumor cells by both passive and active targeting modes.[213] Kwon et al. conjugated anti-MUC1 Abs, aberrantly overexpressed in breast cancer, and TCP1 peptides, a vasculature-targeting peptide for colorectal cancer, to multifunctional silica-based nanocapsules (SNCs) that encapsulated two distinct upconversion chromophore pairs with functions of selectively targeting cancer cells and
FI for early diagnosis of tumor malignancy. Both in vitro and in vivo experimental results showed greater accumulation of nanocapsules at tumor sites than the EPR effect, which still allowed accumulation at the tumor site in the absence of targeting moiety because of tumor vascular malformation. ${ }^{[214]}$ Wang et al. designed self-assembled multifunctional dioleoyl clofarabine (DOC) NPs as tumor-targeted drug delivery combined with Apt AS1411 and Cy5.5-labeled fluorescent DNA via molecular recognition between the clofarabine and the thymine on DNA for cancer targeting and FI. From their result, the fluorescence signal of DOC/Cy5.5 NPs at the tumor site increased, which could be attributed to the EPR effect. In contrast, DOC/ AS1411/Cy5.5 NPs could accumulate at the tumor site more effectively when loaded with AS1411, indicating that the Apt indeed enhanced the targeting capability to tumor. ${ }^{[215]}$

\subsubsection{EPR Effect and TME}

Using EPR combined with TME, mainly hypoxia ${ }^{[216]}$ and low $\mathrm{pH},{ }^{[217-221]}$ several strategies have been designed for cancer therapy. In the study of the Cheng's group, a supramolecular drug delivery system was constructed based on fluorescent star polycation P1 and charge-reversal anionic copolymer P2, obtaining P1@P2 which was stable in blood and accumulated in tumor through the EPR effect and responded to the tumor extracellular and intracellular microenvironment for programmed cellular uptake and drug release. ${ }^{[219]}$ Wang et al. developed a $\mathrm{pH} / \mathrm{H}_{2} \mathrm{O}_{2}$ responsive $\mathrm{Si}$ QD-based nanocomplexes, which could target the tumor site by the EPR effect and TME response. ${ }^{[220]}$ The combined strategy of EPR effect and TME improved the low targeting efficiency of EPR.

\subsubsection{Active Targeting and TME}

Recently, scientists used different ligand-modified FNPs to design microenvironment-responsive nanocarriers, such as FAconjugated $\mathrm{pH}$-sensitive hollow $\mathrm{ZnO},{ }^{[222]} \mathrm{pH}$-triggered Au-fluorescent mesoporous silica $\mathrm{NPs}^{[195]} \mathrm{HA}$-conjugated fluorescent carbon NPs, ${ }^{[223]}$ mesoporous silica NPs, ${ }^{[224]}$ and RGD-modified carbon dots, ${ }^{[225]}$ TAT-modified polymeric micelle, ${ }^{[226]}$ and so on. Wang et al. selected two established TME signals, namely angiogenic tumor vasculature and low extracellular $\mathrm{pH}$ as targets as design basis. They established a series of ultra $\mathrm{pH}$-sensitive (UPS) nanoprobes composed of ultra $\mathrm{pH}$-sensitive core for $\mathrm{pH}$ response, a series of fluorophores for multicolored imaging and a RGD targeting unit that combined active targeting and $\mathrm{pH}$ response. ${ }^{[227]}$ An acid-responsive diblock copolymer combined with an iRGD-modified polymeric prodrug of doxorubicin (DOX) termed as iPAPD, which could specifically accumulate at the tumor site through EPR effect, followed by $\mathrm{pH}$-triggered cellular uptake within the tumoral acidic microenvironment. ${ }^{[228]}$

\subsubsection{EPR Effect and Active Targeting and TME}

In order to further improve the efficiency, FA-functionalized amphiphilic alternating copolymer poly (styrene-alt-maleic 
anhydride) (FA-DABA-SMA) are designed for targeted drug delivery, which has three levels of control including the EPR effect, FA-based active targeting, and $\mathrm{pH}$ responsiveness in the cancer microenvironment simultaneously, showing a promising new active tumor targeting drug delivery system. ${ }^{[229]}$ The nanoparticle modified with EGFP-EGF1, which can bind well to A549 tumor cells and other stromal cells including neovascular cells, TAFs and TAMs, etc., and also accumulate at tumor site because of the EPR effect. ${ }^{[230]}$ Based on the acidic, angiogenic TME, the combined design strategy are tried. Ultra $\mathrm{pH}$-sensitive fluorescent nanoprobe containing ultra $\mathrm{pH}$-sensitive core, fluorophores and targeting unit are designed, which is robust and universal used in 10 different tumor models' detection. ${ }^{[227]}$

\subsection{Cell Membrane Permeability Targeting Mechanism}

At present, the main three mechanisms for designing nanomaterials improved the tumor targeting of the drugs, lower the side effects to normal tissues. However, the low targeting performance and the failure in the clinically application push the scientists in the targeting nanomedicine design field eager to find the new mechanism and strategies to develop the specific tumor targeting. Just recently, Wang and co-workers found a new graphene-based tumor cell nuclear targeting fluorescent nanoprobe (GTTN) shown in Figure 7. ${ }^{[37]}$ GTTN is a graphenebased amphiphilic fluorescent probe modified by sulfonic acid and hydroxyl groups. GTTN has an excellent fluorescence stability (Figure $7 \mathrm{~b}$ ) and ultrasmall size (3.35 $\pm 0.15 \mathrm{~nm}$ on average) with amphipathicity, which is very stable in the blood circulation. It does not combine with blood cells, hemoglobin, etc., and maintains its physical and chemical properties well in vivo. This probe has the characteristic of specific tumor nuclear targeting of tumor tissue in vivo but does not enter normal tissue cells (Figure 7c-e). GTTN recognizes tumor cells and normal cells through the differences of cell membrane's permeability (Figure 7a). Wang et al. named this new targeting mechanism as the cell membrane permeability targeting (CMPT) mechanism. Small size, amphiphilic structure, electronegativity of GTTN and their ability to keep their properties not altered by protein corona are important determinants for targeting to tumor nuclei. Deeper researches are needed to use CMPT mechanism to design different NPs/nanomedicines with great tumor targeting performance. GTTN can distinguish the interface between tumor tissue and normal tissue (Figure 7j) and recognize tumor tissue in a very early stage and track the invasion and metastasis of tumor cells at the single cell level. More importantly, the tumor targeting rate through GTTN can be as high as $50 \%$ (Figure $7 \mathrm{f}-\mathrm{i}$ ). Wang et al. used two methods to express the tumor targeting rate. One is using the fluorescent intensity of the tumor divided by the total fluorescent intensity of tumor. The other is the GTTN concentration in terms of the percentage of the injected dose (ID\%). The results of both methods showed that the highest targeting rate was about $50 \%$ at the tumor site, which is much higher than that of NPs/ nanomedicines designed with the EPR effect $(<5 \%)$. According to Chan and co-workers after surveying the literature from the past 10 years, only $0.7 \%$ (median) of the administered NPs dose is found to be delivered to a solid tumor. ${ }^{[231]}$ At present, after some efforts, (mainly the modification of nanomaterials themselves), some nanomaterials have improved the tumor targeting rate. Yu et al. designed a DNA/UCNPs nanocomposite to precisely target to tumor site through preprotect the FA by longer DNA, which could be triggered by the acidic TME. Through this strategy, the targeting effect of UCNPs@PAA-DNA $1 / 2$ on tumors was $12.1 \pm 0.7 \% \mathrm{ID} \mathrm{g}^{-1} \cdot{ }^{[109]}$ The targeting ratio of in vivo assembly NIR-II downconversion NPs (DCNPs) modified with complementary DNA (L1 or L2) and targeting peptides (folliclestimulating hormone, $\mathrm{FSH}_{\beta}$ ) for distinguishing tumor tissue from normal tissues were found to be of $\approx 17.5 \% \mathrm{ID} \mathrm{g}^{-1}$. $^{[232]}$ The calculation methods of targeting ratio are different make the targeting ratio is more complex and difficult to compare. ${ }^{[37]}$ As we mentioned earlier (part 2.1.5), even if the nanomaterials reach to the tumor tissue, it is difficult to actually enter into the tumor tissue. Therefore, the dose that actually enters into the tumor cell is much lower. GTTN targets to the tumor tissue cell nuclei directly with high targeting ratio. In addition, GTTN has good biocompatibility and low toxicity. It is metabolized very fast in vivo and can be metabolized completely after $48 \mathrm{~h}$ without accumulating in normal organs and producing long-term toxicity. Following this brand-new CMPT mechanism design principle, the NPs/nanomedicines can accurately target to the tumor cell nucleus in vivo with minimum uptake by normal tissues. With the development of material science and synthetic biology science, precisely engineering the NPs/nanomedicines according to the design principle is a complete reality. We are sharing a bright future for tumor therapy with CMPT.

\section{Biodistribution, Clearance Pathways, and Biosafety of FNPs}

Although targeted NPs have great potential in the diagnosis and therapy of cancer, their actual and potential toxicity are still a concern and are the major obstacle of clinical application. ${ }^{[233]}$ Successful translation of the FNPs from laboratories to clinics requires exhaustive and elaborate studies involving the biodistribution, clearance pathways, and biosafety for in vivo biomedical imaging applications. The United States FDA requires that agents injected into human body, especially diagnostic drugs, must be completely eliminated within a reasonable period of time. ${ }^{[234]}$ While the FTNPs designed as different modalities exhibit diversity in chemical structures, properties, and functionalities. They often share some similar distribution and clearing behaviors in vivo. However, FTNPs are often rapidly sequestered from the blood, then are caught and devoured by RES organs (liver, spleen, and so on). Excretion is an important biological process that prevents injury and toxicity by removing unwanted substances from the body. ${ }^{[51]}$

Kumar et al. synthesized organically modified silica (ORMOSIL) nanoparticles, conjugated with NIR fluorophores and ${ }^{124} \mathrm{I}$ for FI and PET imaging. Biodistribution studies showed that the ORMOSIL NPs accumulated more in liver, spleen, and stomach than in kidney, heart, and lungs. The clearance studies indicated hepatobiliary excretion of the nanoparticles. Histological analysis confirmed that the ORMOSIL NPs did not lead to any adverse effect or any other abnormalities in 

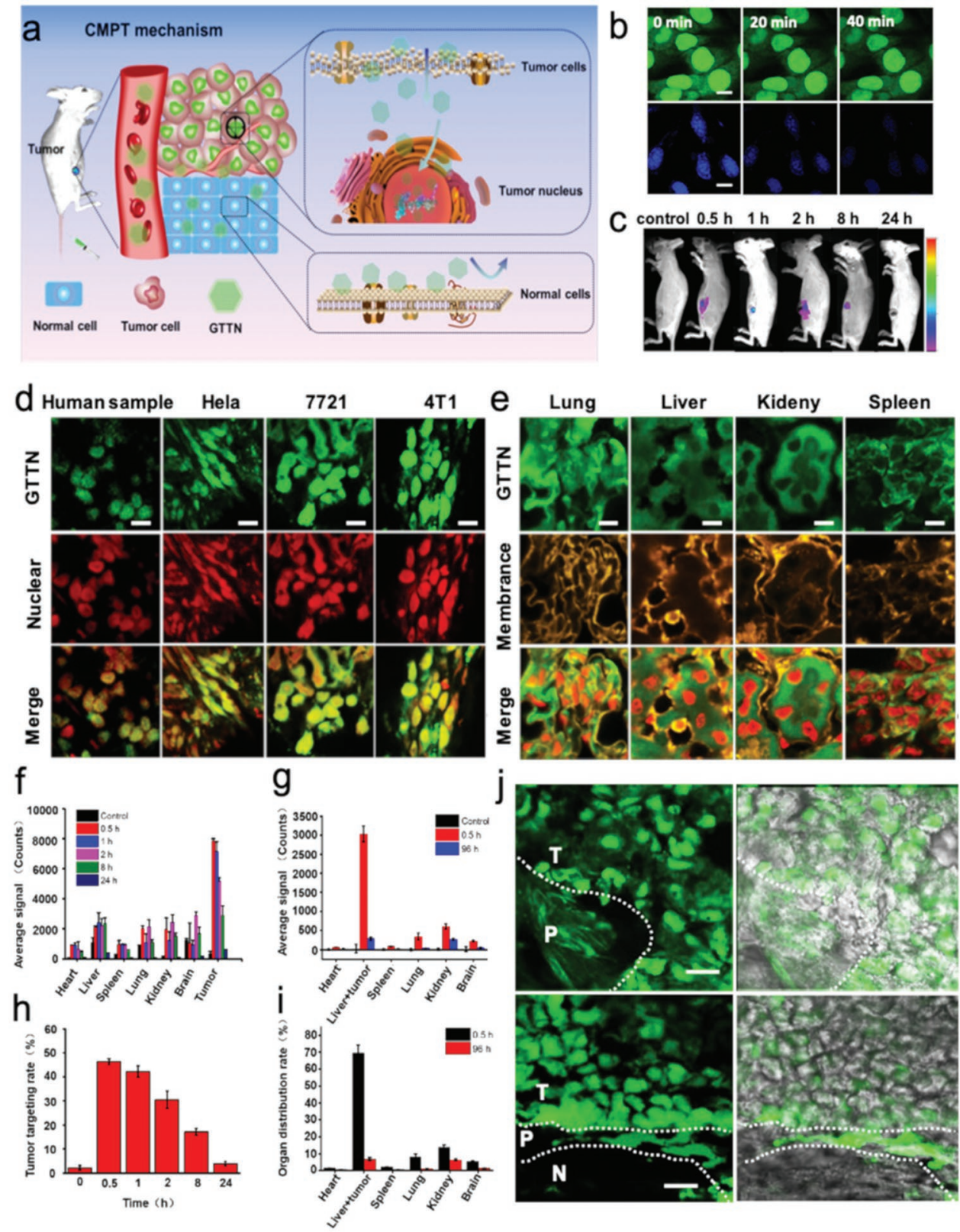

Figure 7. The mechanism of CMPT and the tumor cells nuclear targeting properties of GTTN. a) Schematic diagram of CMPT; b) High fluorescence stability of GTTN without quenching under $405 \mathrm{~nm}$ laser continuous irradiation for $40 \mathrm{~min}$. The above row (GTTN), the bottom row (DAPI); c) In vivo fluorescence images of tumor-bearing mice after the intravenous injection of $100 \mathrm{mg} \mathrm{kg}^{-1}$ GTTN for $0.5,1,2,8$, and $24 \mathrm{~h}$; d,e) Confocal images of frozen sections of tumor and normal tissues after the intravenous injection of GTTN for $0.5 \mathrm{~h}$. Scale bar, $20 \mu \mathrm{m}$. d) Subcutaneous tumor cells and human hepatoma tumor. e) Normal cells; f,g) Average signals of GTTN from isolated organs of ex vivo images after GTTN injection (100 mg kg ${ }^{-1}$ ) for $0,0.5,1,2,8$, and $24 \mathrm{~h}$. Mean $\pm \mathrm{SEM} ; n=5$ per group. f) Subcutaneous tumor model. g) Orthotopic tumor model; h,i) The tumor targeting rate after the intravenous injection of GTTN for different times. h) Subcutaneous tumor model. i) Orthotopic tumor model; j) Confocal images of tumor interfacial resolution. T: tumor tissue. P: pericarcinomatous tissue. N: normal tissue. Scale bar, $30 \mu \mathrm{m}$. a-j) Reproduced with permission. ${ }^{[3]]}$ Copyright 2019, Wiley-VCH.

the tissues. ${ }^{[235]}$ Zhou et al. reported that the glutathione-coated luminescent gold NPs (GS-AuNPs) were cleared through renal with more than $50 \%$ of the GS-AuNPs were found in urine within $24 \mathrm{~h}$ after injection. Only $(3.7 \pm 1.9) \%$ of the GS-AuNPs were accumulated in the liver with minimized nanotoxicity. ${ }^{[236]}$ $\mathrm{Lu}$ et al. found that fluorescent mesoporous silica nanoparticles (FMSNs) preferentially accumulate in tumors and the next strongest accumulation was found in liver and kidney. For biocompatibility experiments, there was very low toxicity observed in vivo. ${ }^{[237]}$ Tao and co-workers found that C-dots mainly accumulated in the RES organs, such as liver and spleen, after intravenous injection. This in vivo behavior is similar to many other nanomaterials for bioapplication. ${ }^{[238]}$ There are two main excretory pathways: the renal (urine) and hepatic (bile to feces) 
Table 1. The clearance pathways of FTNPs.

\begin{tabular}{|c|c|c|c|c|c|c|}
\hline Core structure & Surface & Size $[\mathrm{nm}]$ & Targeting strategy & Clearance pathway & In vivo toxicity & Refs. \\
\hline $\mathrm{Ag}_{2} \mathrm{~S}$ QDs & DHLA/six-armed PEG & 5.4 & EPR & Hepatic & Minimal toxicity & [250] \\
\hline $\mathrm{CdSe}_{0.25} \mathrm{Te}_{0.75} / \mathrm{CdS}$ & MUA & 7 & EPR & Hepatic & Nontoxicity & [251] \\
\hline Gold NPs & Glutathione & 2.5 & EPR & Renal & - & [239] \\
\hline Gold NPs & PEG & 2.3 & EPR & Renal & - & [240] \\
\hline Gold NCs & Glutathione & 2 & EPR \& active & Renal & Nontoxicity & [241] \\
\hline Gold nanocages & $\begin{array}{l}\text { Red blood cell } \\
\text { membranes }\end{array}$ & 89.05 & EPR & Renal & Nontoxicity & [242] \\
\hline $\mathrm{NaGdF}_{4}: \mathrm{Yb} \mathrm{NPs}$ & PEG2000 & 2.1 & EPR \& active & Renal & - & [243] \\
\hline Ultrasmall Pd nanosheets & Glutathione & 4.4 & EPR & Renal & Nontoxicity & [310] \\
\hline UCNPs $\left({ }^{153} \mathrm{Sm}\right)$ & PEG & 8 & EPR & Renal & - & [244] \\
\hline $\mathrm{Ba}_{2} \mathrm{CdF}_{7} \mathrm{NPs}$ & Targeted peptide & 6.5 & EPR\&active & Renal & Minimal toxicity & [245] \\
\hline Carbon dots & NIR dye ZW800 & 3 & EPR & Renal & - & [246] \\
\hline Gd-graphene carbon NPs & - & 5 & EPR & Renal & Nontoxicity & [247] \\
\hline Gd-carbon dots & - & 12 & EPR & Renal & - & [248] \\
\hline C60-based NPs & RGD & 106 & Active & Renal & Minimal toxicity & [249] \\
\hline GTTN & - & 3.5 & CMPT & Renal & Nontoxicity & [37] \\
\hline
\end{tabular}

pathways of FTNPs. According to our statistics, renal excretion is the main way of most of FTNPs cleared from the body, such as gold NPs, ${ }^{[239-242]} \mathrm{UCNPs}^{[243-245]}$ and FCNMs ${ }^{[227,246-249]}$ (Table 1). Only a little FNPs are eliminated through hepatic, such as $\mathrm{Ag}_{2} \mathrm{~S}$ QDs, ${ }^{[250]} \mathrm{CdSe}_{0.25} \mathrm{Te}_{0.75} / \mathrm{CdS},{ }^{[251]}$ and so on.

\section{Applications in Cancer Management}

FTNPs offer a useful platform for exploring the challenges in the field of nanomedicine, diagnosis, and cancer therapy. FNPs have been widely utilized in the development of highperformance biosensors to take advantage of their favorable biocompatibility, surface tailoring-ability, fast response, and good reproducibility. ${ }^{[252]}$ These advantages play a major role in tumor imaging and diagnosis, nanofluorescent biosensor, drug delivery, and surgical treatment.

\subsection{FI-Based Cancer Diagnosis}

In Table 2, the main medical-imaging modalities used in clinical practice today were summarized. The aforementioned tomographic imaging modalities that rely on deep-penetrating radiation can achieve infinite penetration depth but have major limitations including adverse effects to hazardous ionizing radiation (CT and PET), intrinsically limited spatial resolutions (MRI and PET), poor temporal resolution, lack of exogenous and endogenous probes, and non-real-time dynamic visualization due to the long collection time..$^{[7,250,253]}$ In contrast, in vivo FI does not suffer from these drawbacks like tomographic imaging modalities, providing the benefits of real-time imaging acquisition and diffraction-limited, spatial resolution in living organisms, and nonhazardous optical radiation of fluorescent probes, which has emerged as a promising tool for improving tumor diagnosis, monitoring therapy response and detecting residual tumor lesions. ${ }^{[254]}$ Despite the many advantages, in vivo FI has poor photon penetration depth in most mammalian tissues which are usually opaque to light in the visible spectrum (400-700 $\mathrm{nm}$ in wavelength) coupled with interference from the tissue autofluorescence. ${ }^{[255]}$ Therefore, it is essential to seek the deep-tissue and real-time FI probes such as NIR-I and NIR-II fluorophores or FNPs and develop new imaging instrumentation. In this section, we focus on the recent advances of FTNPs applied for biomedical imaging.

Fluorescence-based optical imaging technology provides an effective and promising way for safe, noninvasive, and real-time detection with the key advantages of real-time synchronization, high resolution, and specific targeting performance based on passive targeting or active targeting or both. ${ }^{[256]}$ Recently, FTNPs have been deeply studied because of their visual targeting imaging and recognition between tumor tissue and normal tissue for tumor early diagnosis and accurate surgical excision (Figure 8). Such as shown in Figure 8a, Robinson et al. functionalized the SWNTs with a novel polymer, prolonged the blood circulation, and improved the EPR effect. ${ }^{[257]}$ Liu et al. reported a kind of GS-coated AuNPs with diameters of $\approx 2.5 \mathrm{~nm}$. They compared in vivo passive tumor targeting by GS-AuNPs and IRDye 800CW. ${ }^{[239]}$ (Figure 8b) They found that GS-AuNPs behave like the IRDye $800 \mathrm{CW}$ in the initial stage of tumor targeting, but the tumor retention time of the GSAuNPs is much longer than the dye molecules, indicating that the GS-AuNPs retain the EPR effect while achieving efficient renal clearance. As shown in Figure 8a,c,d, researchers modified the NPs with PEG that improved the circulation time and enhanced the EPR effect because of the unique physiochemical property and excellent biocompatibility of PEG. ${ }^{[240,250,257]}$ Figure 8e-g shows the active targeting based on RGD and FA applied for precise tumor-targeted FI. ${ }^{109,232,258]}$ Especially, Wang et al. modified the DCNPs with DNA and RGD that could be 
Table 2. Biomedical imaging modalities.

\begin{tabular}{|c|c|c|c|c|c|}
\hline & Imaging media & Advantage & Disadvantage & Probes & Refs. \\
\hline $\mathrm{FI}$ & Fluorescence & $\begin{array}{c}\text { Low cost } \\
\text { High sensitivity } \\
\text { Multicolor imaging } \\
\text { Easy operation } \\
\text { Real-time monitoring } \\
\text { Nonhazardous radiation }\end{array}$ & $\begin{array}{l}\text { Poor tissue permeability } \\
\text { Autofluorescence of tissue }\end{array}$ & Fluorescent dyes and FNPs & {$[32,311]$} \\
\hline CT & X-ray & Not restricted by tissue penetration & $\begin{array}{l}\text { Hazardous ionizing radiation } \\
\text { No quantitative analysis }\end{array}$ & $\begin{array}{l}\text { lodinated compound } \\
\text { AuNPs }\end{array}$ & [312] \\
\hline PAI & Ultrasonic & $\begin{array}{l}\text { High tissue penetration } \\
\text { High resolution }\end{array}$ & Low microscopy imaging speed & $\begin{array}{l}\text { AuNPs } \\
\text { Carbon NPs } \\
\text { Polymer NPs }\end{array}$ & [313] \\
\hline USI & Ultrasonic & $\begin{array}{c}\text { Low cost } \\
\text { Nonionizing radiation } \\
\text { Fast imaging speed } \\
\text { High resolution } \\
\text { Strong contrast } \\
\text { Real-time imaging }\end{array}$ & $\begin{array}{l}\text { Not suitable for gas containing organs } \\
\text { Diagnostic accuracy has many influ- } \\
\text { encing factors }\end{array}$ & Gas-NPs & [314] \\
\hline PET & $\gamma$-ray & $\begin{array}{l}\text { High sensitivity } \\
\text { Not restricted by tissue penetration }\end{array}$ & $\begin{array}{l}\text { Hazardous ionizing radiation } \\
\text { Limited spatial resolutions }\end{array}$ & Radionuclide & {$[80,315]$} \\
\hline MRI & Magnetic field & $\begin{array}{l}\text { Not restricted by tissue penetration } \\
\text { Nonhazardous radiation }\end{array}$ & $\begin{array}{l}\text { High cost } \\
\text { Lower sensitivity } \\
\text { Long detection time } \\
\text { No quantitative analysis }\end{array}$ & Magnetic materials & {$[316]$} \\
\hline PTI & Infrared radiation & $\begin{array}{l}\text { Temperature sensitivity } \\
\text { Real-time monitoring }\end{array}$ & Limited spatial resolutions & Photothermal materials & [317] \\
\hline $\mathrm{RI}$ & Raman scattered light & $\begin{array}{c}\text { High resolution } \\
\text { Fast scanning speed } \\
\text { Avoiding autofluorescence of tissue } \\
\text { Qualitative, quantitative, and positioning analysis }\end{array}$ & $\begin{array}{c}\text { Poor tissue permeability } \\
\text { Long data acquisition and processing } \\
\text { time }\end{array}$ & $\begin{array}{c}\text { AuNPs } \\
\text { Carbon NPs }\end{array}$ & [318] \\
\hline
\end{tabular}

applied for metastatic ovarian cancer resection through imageguided surgery. ${ }^{[232]}$ Qi et al. introduced smart NPs combined PAI, FI, and PDT based on active tumor-targeting with YSA (YSAYPDSVPMMS) peptide as well as the passive tumortargeting EPR effect ${ }^{[259]}$ (Figure $8 \mathrm{~h}$ ).

Fluorescence-targeted imaging used FTNPs for the real-time and in situ detection of the tumors by monitoring the fluorescence phenomenon. ${ }^{[260]}$ FTNPs have shown good prospects in the field of tumor diagnosis, such as FL dye-doped NPs, ${ }^{[165,261,262]}$ QDs, ${ }^{[158,263]}$ MNCs, ${ }^{[176,264]}$ UCNPs, ${ }^{[265-267]}$ FCNMs, ${ }^{[24,218,268]}$ and semiconductor polymer NPs (SPNPs). ${ }^{[269,270]}$

ICG is the only NIR dye that is FDA approved for clinical use and pharmaceutical applications. So, FL dye-doped NPs are becoming more and more widely used in the diagnosis of cancer. FI of colorectal cancer cells can improve tumor localization, allow intraoperative staging, facilitate surgical resection, and thus improve the prognosis of patients. Both Tivony et al. ${ }^{[261]}$ and Tiernan et al. ${ }^{[165]}$ used fluorescent dye and anti$\mathrm{CEA} \mathrm{Ab}$ to modify NPs for medical targeting imaging of colorectal tumors in vitro and in vivo. Tiernan et al. demonstrated live, specific, in vivo imaging of colorectal cancer cells using Ab-targeted FNPs for the first time. In order to noninvasively observe the heterogen distribution of these abnormal indicators in vivo and further reveal their common behaviors, Ma et al. constructed a protease-triggered fluorescent probe composed by fluorescent dye Cy5.5 and biocompatible $\mathrm{Fe}_{3} \mathrm{O}_{4}$ NPs. This reasonable design allows NPs to map both the protease activity of MMP-9 and TME $\mathrm{pH}$ simultaneously, providing instant and quantifiable information on the local protease activity of MMP-9 and $\mathrm{pH}$ in tumors. ${ }^{[262]}$

Fluorescent QDs have become advanced contrast agents for efficient whole-body tumor imaging. Balalaeva et al. compared the biodistribution of QDs-PEG and QDs-4D5scFv (antiHER2/neu scFv Abs) and found that both two QDs probes can be successfully applied for in vivo tumor imaging, but the fluorescence signal of QDs-4D5scFv in the tumor is significantly stronger than that of QDs-PEG. ${ }^{[158]}$ Huang et al. designed and synthesized NGR peptides modified QDs which could cross the blood brain barrier and target to CD13-overexpressed glioma and tumor vasculature in vitro and in vivo, contributing to FI of this brain malignancy. ${ }^{[263]}$

MNCs with excellent physical and chemical properties are also an ideal scaffold for new chemical sensors and biological imaging probes. Sun et al. artificially designed AgNCs-Apt hybrids as a specific marker of the nucleus, the confocal image showed that the AgNCs-Apt hybrids were mainly distributed in the nucleus of living cells. ${ }^{[175]}$ Wang et al. found that cancerous cell incubated with micromolar chloroauric acid solutions could spontaneously biosynthesize AuNCs affording precise cell imaging which does not happen in normal cells, as demonstrated by human embryonic liver cells. In addition, injecting subcutaneously chloroauric acid solution around xenograft 


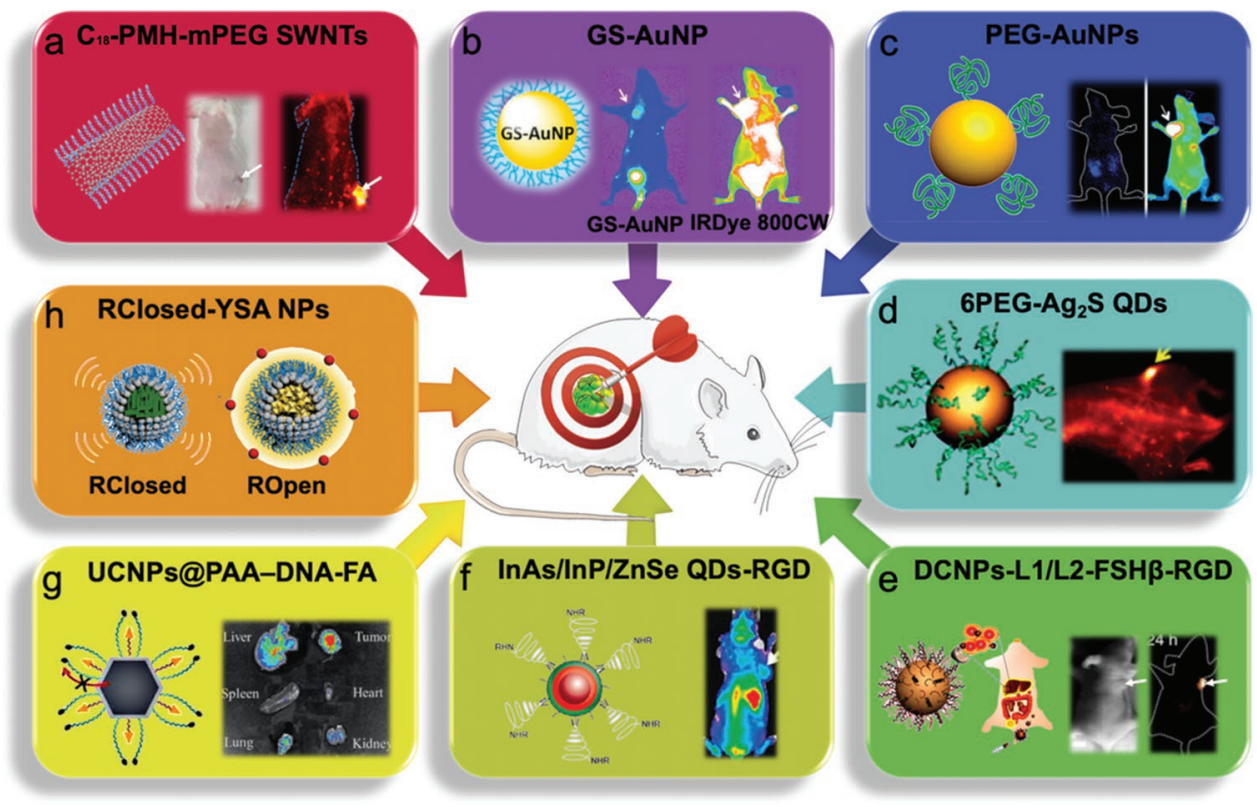

Figure 8. FI applications of FNPs. a) $\mathrm{C}_{18}-\mathrm{PMH}-\mathrm{mPFG}$ SWNTs. Reproduced with permission. ${ }^{[257]}$ Copyright 2012, American Chemical Society b) GS-AuNP. Reproduced with permission. ${ }^{[239]}$ Copyright 2013, American Chemical Society. c) PEG-AuNPs. Reproduced with permission. ${ }^{[240]}$ Copyright 2018, Wiley-VCH. d) 6PEG-Ag 2 S QDs. Reproduced with permission. [250] Copyright 2012, Wiley-VCH. e) DCNPs-L1/L2-FSH $\beta$. Reproduced under the terms of the CC-BY Creative Commons Attribution 4.0 International License (http://creativecommons.org/licenses/by/4.0/). ${ }^{[232]}$ Copyright 2018, The Authors, Published by Springer Nature. f) InAs/InP/ZnSe QDs. Reproduced with permission. ${ }^{[258]}$ Copyright 2010, American Chemical Society. g) UCNPs@PAA-DNA. Reproduced with permission. ${ }^{[109]}$ Copyright 2018, The Royal Society of Chemistry. h) RClosed-YSA NPs. Reproduced under the terms of the CC-BY Creative Commons Attribution 4.0 International License (http://creativecommons.org/licenses/by/4.0/). ${ }^{[259]}$ Copyright 2018, The Authors, Published by Springer Nature.

tumors allowed to effectively synthesize fluorescent AuNCs with bright fluorescence without the same effect in normal tissues. ${ }^{[264]}$

As UCNPs have emerged as a new class of fluorescent probes for biomedical imaging, different strategies have been studied for nanodiagnostics, such as FA-functionalized Gd2O3: $\mathrm{Eu}^{3+} \mathrm{NPs},{ }^{[265]}$ CEA Abs conjugated UCNPs, ${ }^{[266]}$ aptamertemplated $\mathrm{NaGdF}_{4}: \mathrm{Ce}^{3+}$, or $\mathrm{Eu}^{3+} \mathrm{NPs}^{[267]}$ Photoluminescent CDs have attracted ever-increasing interest because of alluring properties such as excellent biocompatibility, water solubility, superior cell membrane permeability, high photostability, and tunable surface functional groups. Zheng et al. synthesized a new type of CDs, which could penetrate the blood-brain barrier and precisely target glioma tissue with the glioma/normal brain ratio of $1.42 .{ }^{[24]}$ Fan et al. reported $\mathrm{pH}$-responsive fluorescent graphene quantum dots (pRF-GQDs) with low toxicity and a fluorescence transition in response to the acid TME. ${ }^{[218]}$

SPNPs are a new class of organic optical nanomaterials with advantages of excellent optical properties, high photostability, facile surface functionalization, and good biocompatibility for biomedical optical imaging applications. ${ }^{[271]}$ Distinct from inorganic NPs like QDs and MNCs, SPNPs are mainly composed of optically active semiconducting polymers (SPs) and amphiphilic polymer matrixes (optional). Zhu et al. designed SPNPs with core SPs, middle silica layer, and outer PEG corona for enhancing the in vivo NIR fluorescence molecular imaging. Multilayered nanostructures not only allow the lymph nodes tracking but also allow for sensitive tumor imaging. ${ }^{[269,272]}$ Chao et al. designed SPNPs via self-assembling from an amphiphilic semiconducting oligomer (ASO) for photoacoustic and fluorescence dual-modal imaging. The fluorescent intensity of tumor area increased gradually with time after tail vein injection of ASO, which suggests that ASO passively targeted to the tumor site by EPR effect. ${ }^{270]}$

The concept of biosensors was proposed in the $1960 \mathrm{~s}$, and comprehensively and deeply researched in the $1980 \mathrm{~s} .{ }^{[273]}$ The nanofluorescent biosensor is a new analytical system that uses fluorescent nanomaterials as carriers with the fluorescent signal as the detection object. As we mentioned above, a wide variety of FNPs show the superior optical properties, such as bright fluorescence, high photostability, and excellent biocompatibility to be applied for the construction of fluorescent biosensor platforms. ${ }^{[15,274]}$ For example, Shi et al. designed a nanomedicine, called "sense-act-treat" system, which combined a ratiometric $\mathrm{pH}$ sensor with therapeutic gold nanocage. This design could "sense" the tumor through two-state switching of fluorescence and further provide chemotherapy and hyperthermia for tumor treatment, showing the future potential application in cancer diagnosis and therapy. ${ }^{[275]}$ Saranya et al. designed smart programmable nanoarchitectures based on AuNPs linking with Raman-active fluorophores through a peptide linker, Phe-LysCys (FKC). The FKC was engineered with a cathepsin B (cathB) enzyme cleavage site for homing to cancer cells resulting in an on-off switching between the fluorescence and Raman modalities, which can be utilized for simultaneous detection of lung cancer. ${ }^{[276]}$ Ding and Tian developed a ratiometric fluorescence biosensor based on AuNCs-FA for targeted imaging and monitoring $\mathrm{pH}$ changes of cancer cells. ${ }^{[277]}$ Thioredoxin reductase 
(TrxR) is a redox regulating enzyme of which high levels are associated with the progress of tumors. Therefore, Sidhu et al. used CDs as analytical tools for sensing of TrxR and screening and detecting cancer cells. ${ }^{[278]}$ Therefore, the design of FNPs for biosensors could integrate clinically relevant diagnostic modalities for the multiplexed detection of cancer showing a bright future and prospects.

\subsection{Cancer Drug Delivery and Therapy}

Nanomaterials have obvious advantages in the targeted delivery of chemotherapy drugs and genes. Through the active or passive targeting of nanomaterials, drugs or genes carried by nanomaterials can be enriched in tumor tissues, thus increasing the concentration of the drug, prolonging the action time, protecting genes from being destroyed and reducing the toxic as well as side effects of normal tissue cells. Controlled drug delivery systems have several advantages over traditional pharmaceutical formulations. These can urge drug transportation to the intended destination in the body minimizing its impact and harmful effects on healthy tissue. Such form of delivery is most important in case of drugs with a very narrow therapeutic index or if the drug itself is a toxic compound. At present, FL dyedoped NPs, QDs, MNCs, UCNPs, FCNMs are the antitumor nanomaterials applied for optical cancer therapy. We have statistically analyzed the antitumor efficiency (AE) of different FTNPS based on diverse targeting strategy. These data are mentioned in the reference article or calculated by us as shown in Table 3.

Multifunctional DOC/AS1411/Cy5.5 NPs are designed for cancer targeting therapy. According to their result, these MFNPS containing drugs have an excellent ability for cancer targeting and drugs delivery in a controlled fashion with powerful and effective antitumor efficacy of $79.55 \%$ in vivo. ${ }^{215]} \mathrm{Wu}$ et al. reported a NIR prodrug DCM-S-CPT loaded in PEG-PLA NPS that show antitumor activity of $96.4 \%$, higher than free CPT, and is also retained longer in the plasma. ${ }^{[279]}$ Another group also applied a new kind of biocompatible and tumor-targeting magneto-gold@fluorescent polymer nanoparticle (MGFs-LyP-1) as drug delivery system. There is clear and convincing evidence that synthetic MGFs-LyP-1 can induce true autophagy, thus providing a certain synergistic effect by enhancing autophagy flux and enhancing DOX cancer treatment at non-toxic concentrations. ${ }^{[28]} \mathrm{Wu}$ et al. used InP nanocomposite functionalized by VEGFR2 $\mathrm{mAb}$ for targeted drug delivery. As the in vivo experiment, only the mice treated with IMAN showed strong nearinfrared fluorescence intensity and concentrated marker area, which completely focused on the tumor site because of the $\mathrm{Ab}$ active targeting. ${ }^{[213]}$ Zhang et al. used GSH-capped red fluorescent AuNCs for rapid tumor bioimaging and photothermal treatment. According to their result, the as-prepared AuNCs possessed strong fluorescence emission and excellent biocompatibility for in vitro cell imaging and in vivo bioimaging of tumors and combined with porphyrin derivatives for photothermal therapy can effectively inhibit tumor growth. ${ }^{[281]}$ Chen et al. have successfully developed a nanoplatform of AuNCs functionalized by cRGD and Apt for dual-targeting tumor image and therapy. The AuNCs were further modified by NIR fluorescence dye (MPA) obtaining a NIR fluorescent dual-targeting probe AuNC-MPA-cRGD-Apt, which displays low cytotoxicity and favorable tumor-targeting capability for tumor imaging. Additionally, they designed a pro-drug AuNC-DOX-cRGDApt by immobilizing DOX onto AuNC-cRGD-Apt to enhance tumor therapy efficacy. ${ }^{[141]}$ Idris et al. used photosensitizers loaded into mesoporous-silica-coated UCNPs as a PDT agent for the first demonstration, conjugated with FA and PEG on the surface for in vivo targeted PDT. Indeed, from their studies, dual encapsulation of MC540 and ZnPc photosensitizers in UCNPs enhanced the therapeutic efficacy of PDT. Additionally, active targeting of the UCNPs complex to tumors by FA modifying has an important role in improving the PDT therapeutic efficacy in tumor-bearing mice. ${ }^{[282]} \mathrm{Ai}$ et al. presented a TMEsensitive strategy based on the enzyme-responsive cross-linking of rare-earth UCNs (CRUN) for tumor localization, upon the tumor-specific cathepsin protease reactions. To obtain the theranostic efficacy, Ce6 was chosen as an effective photosensitizer to couple to the PEI/PAA@UCNs, namely as Ce6-modified UCNs. As result of PDT therapeutic effect of CRUN in living mice, compared with the control of NCRUN (noncrosslinking Ac-FKC ( $\mathrm{StBu}$ ) AC sequence modified particles) and saline, indicated that the CRUN with NIR light irradiation could enhance the tumor therapy outcomes. ${ }^{[283]}$ Yang et al. first successfully used PEGylated nanographene sheets (NGS) for efficient in vivo photothermal therapy by intravenous administration. First, they studied the in vivo behavior of NGS in tumor-bearing mice by in vivo FI and found highly efficient tumor accumulation due to the EPR effect. Additionally, NGS has been proven to be an excellent near-infrared photothermal therapy agent for tumor with no obvious toxicity to mice. ${ }^{[284]} \mathrm{Li}$ et al. investigated a C6-8 Apt conjugated with fluorescent CDs that could inhibit the tumor cell growth in vitro and in vivo by targeting heterogeneous nuclear ribonucleoprotein (hnRNP) A2/B1. C6-8-Apt-CDs significantly inhibited the tumor cell proliferation both in vitro and in vivo, which indicated its potential for the application in cancer diagnosis and therapy. ${ }^{[285]}$ Recently, Zhao et al. prepared a multistage responsive theranostic nanoplatform including a cleavable PEGylated shell and a CD-based core, which exhibited effective accumulation at tumor sites due to elevated the EPR effect and TME trigger. The cascaded responsive property endows multiple advantages of long circulation time, effective tumor accumulation, and gene-controlled release ability, which finally enhanced biocompatibility and cancer therapeutic efficiency. ${ }^{[286]}$

AuNCs were first conjugated with methionine (Met) and MPA, a NIR fluorescent dye, originating a probe of Au-MetMPA by Chen et al. Second, doxorubicin, a widely used clinical anticancer drug, was immobilized on the Met-modified AuNCs to form a prodrug, Au-Met-DOX. The study confirmed the much stronger therapeutic efficacy and tumor suppressing effect of Au-Met-DOX when compared with free DOX and Au-DOX. ${ }^{[287]}$ Yang et al. designed Cy5.5-labeled WS $\mathrm{WS}_{2} \mathrm{IO} @$ MS-PEG by preadsorption with iron oxide (IO) NPs on $\mathrm{WS}_{2}$ nanosheets and then coated with silica shell and PEG as nanodrug delivery of DOX triggered by NIR-induced photothermal heating for enhanced cancer cell killing. As demonstrated in in vivo experiments, the photothermal and chemotherapy synergistic therapeutic effect of $\mathrm{WS}_{2}$-IO@MS-PEG/DOX was obviously superior to monotherapies. Wang et al. developed a novel type of fluorescent core-shell hybrid nanocomposite 
Table 3. Antitumor efficiency of FTNPs based on diverse targeting strategy.

\begin{tabular}{|c|c|c|c|c|c|c|}
\hline Type & Targeting strategy & Core structure & Surface & Size & $\mathrm{AE}[\%]$ & Refs. \\
\hline \multirow[t]{14}{*}{ FL-dye doped NPs } & \multirow[t]{5}{*}{ EPR } & ICG-EPI NPs & Epirubicin & $80-100 \mathrm{~nm}$ & 100 & [319] \\
\hline & & Chitosan-based NPs & Cy5.5/paclitaxel & $250 \mathrm{~nm}$ & 87.5 & [320] \\
\hline & & $\mathrm{WS}_{2}-1 \mathrm{O} @ M S-P E G$ & Cy5.5/DOX & $568.03 \mathrm{~m}^{2} \mathrm{~g}^{-1}$ & 92.3 & [321] \\
\hline & & PEGylated dendrimer & Cy5.5/PTX & $69 \mathrm{~nm}$ & 84.5 & [322] \\
\hline & & PEG-PLA & ICG/DCM-S-CPT & $79 \mathrm{~nm}$ & 96.4 & [279] \\
\hline & \multirow[t]{6}{*}{ EPR\&AT } & DOC & Cy5.5/AS1411 & $90 \mathrm{~nm}$ & 79.6 & [215] \\
\hline & & $\mathrm{MnO}_{2} \mathrm{NPs}$ & $\mathrm{HA} / \mathrm{ICG}$ & $35 \pm 2.5 \mathrm{~nm}$ & 100 & [323] \\
\hline & & $\mathrm{Fe}_{3} \mathrm{O}_{4}-\mathrm{Au}$ & NIR775/LyP-1/DOX & $15-25 \mathrm{~nm}$ & 63.2 & [280] \\
\hline & & Black phosphorus & $\mathrm{FA} / \mathrm{Cy} 7$ & $15-40 \mathrm{~nm}$ & 100 & [324] \\
\hline & & IR825 & $\mathrm{HA} / \mathrm{Cy} 5.5 / \mathrm{PFOB}$ & $100 \pm 10.7 \mathrm{~nm}$ & 98.9 & [325] \\
\hline & & ICy5 & RGD/CPT & $90 \mathrm{~nm}$ & 77.5 & [326] \\
\hline & EPR\&AT\&TME & LHRH-HA & Cy5.5/DOX & $100-150 \mathrm{~nm}$ & 82.9 & [327] \\
\hline & \multirow[t]{2}{*}{ AT } & ICG-PL-PEG & $\mathrm{ICG} / \mathrm{mAb}$ & $21.5 \mathrm{~nm}$ & 70 & [169] \\
\hline & & $\mathrm{HA}-\mathrm{NGs}$ & Cys/cytochrome c & $100 \mathrm{~nm}$ & 80 & [126] \\
\hline \multirow[t]{4}{*}{ QDs } & EPR & Si QDs- $\mathrm{MnO}_{2}$ & BSA Ce6 & $2 \mathrm{~nm}$ & 89.1 & [220] \\
\hline & \multirow[t]{3}{*}{ EPR\&AT } & TMPyP-Zn-QD & R6G/NIR775/FA & $42 \mathrm{~nm}$ & 91.2 & [328] \\
\hline & & $\mathrm{Ag}_{2} \mathrm{Se} \mathrm{QDs}$ & Cetuximab & $2.8 \pm 0.5 \mathrm{~nm}$ & 42.3 & [329] \\
\hline & & InP QDs & mAb/miR-92a & $7 \mathrm{~nm}$ & 66.7 & [213] \\
\hline \multirow[t]{3}{*}{ MNCs } & EPR & AuNCs & Cy5.5/U11 peptide & $53 \mathrm{~nm}$ & 100 & [330] \\
\hline & \multirow[t]{2}{*}{ EPR\&AT } & AuNCs & MPA & $5.6 \mathrm{~nm}$ & 64.1 & [287] \\
\hline & & AuNCs & TSPP & $2 \mathrm{~nm}$ & 72.7 & [281] \\
\hline \multirow[t]{4}{*}{ UCNPs } & EPR & $\mathrm{NaCdF}_{4}$ & Au25 & $40 \mathrm{~nm}$ & 100 & [331] \\
\hline & \multirow[t]{2}{*}{ EPR\&AT } & UCNPs & $\mathrm{FASOC} / \mathrm{ZnPc}$ & $50 \mathrm{~nm}$ & 82.2 & [207] \\
\hline & & Si-UCNPs & $\mathrm{FA} / \mathrm{ZnPc}$ & $100 \mathrm{~nm}$ & 72.4 & [282] \\
\hline & EPR\&TME & UCNPs & Enzyme-responsive peptide/Ce6 & $110 \mathrm{~nm}$ & 70.9 & [283] \\
\hline \multirow[t]{5}{*}{ FCNMs } & \multirow[t]{3}{*}{ EPR } & FCNs & siRNA & $10-20 \mathrm{~nm}$ & 90.9 & [332] \\
\hline & & SWCT & Evans blue/Ce6 & - & 100 & [333] \\
\hline & & Carbon dots & - & $10 \mathrm{~nm}$ & 100 & [334] \\
\hline & EPR\&AT & Carbon dots & Aptamer & $25 \pm 5 \mathrm{~nm}$ & 65.7 & [285] \\
\hline & EPR\&TME & HPAP-CDs & pDNA & $34.3 \mathrm{~nm}$ & 70.8 & [286] \\
\hline
\end{tabular}

incorporating rare-earth $\mathrm{Yb}^{3+}$ and $\mathrm{Er}^{3+}$ ion-doped GdOF as the shell and gold nanorods (GNRs) as the core, creating GNRs@ GdOF: $\mathrm{Yb}^{3+}, \mathrm{Er}^{3+}$. Based on the evidence of in vitro and in vivo studies, compared with the pure GNRs, the GNRs@GdOF:Yb ${ }^{3+}$, $\mathrm{Er}^{3+}$ core-shell structure has better biocompatibility and cancer killing ability. ${ }^{[288]}$

\subsection{Fluorescence-Guided Surgery}

Surgery is an effective way to remove solid tumors, and 50 percent of cancer patients undergo surgery each year worldwide. However, surgical procedures present different challenges, including identifying small lesions, locating metastases, and integrating complete tumor resection. In order to improve the accuracy of surgery, fluorescence guidance is a desirable method. Over the past decade, we have witnessed the rapid development of solid tumor fluorescence molecular imaging in tumor diagnosis and image-guided surgery. With the rapid development of nanotechnology, intraoperative tissue FI technology with fluorescence nanoprobes has become the mainstream of tumor surgery therapy, which could greatly improve the accuracy of tumor resection and surgical success rate.

Preclinical development of FNPs formulations has made great advances, with strategies ranging from passive targeting to active targeting of cell surface receptors and TME responsive targeting, increasing cell uptake through cleavable proteins. ${ }^{[289]}$ These joint efforts may lead to clinical trials using FNPs in the near future. Different from traditional anatomical and molecular imaging technologies, FI technology has the advantages of high safety, high spatial resolution, and strong real-time performance, and has become a highly applicable imaging method for clinical tumor detection and image-guided surgery. In current fluorescence image-guided surgery practice, long tumor retention period with photostable probes is essential for the following precision imaging-guided resection. The effective 


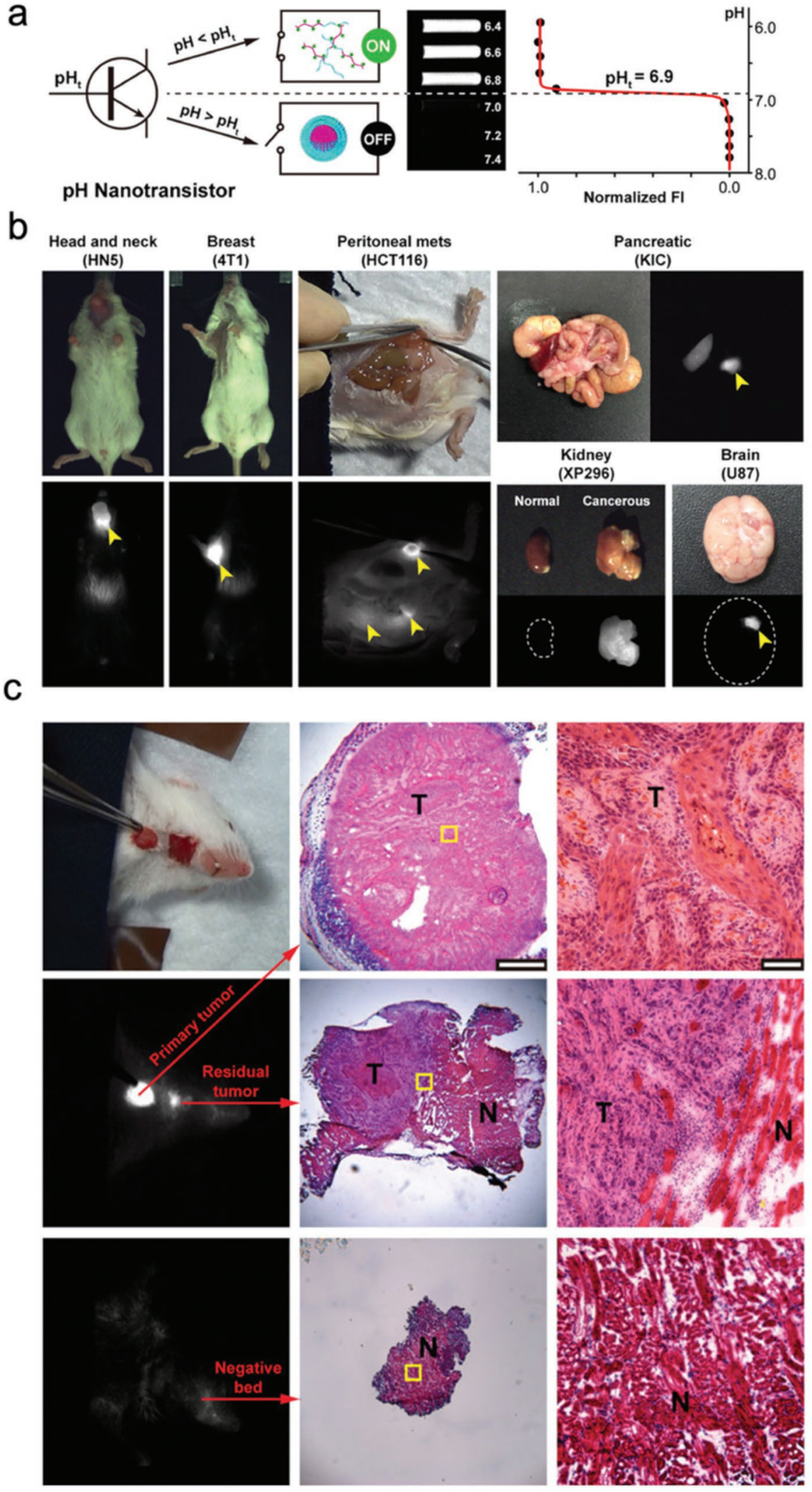

Figure 9. A transistor-like $\mathrm{pH}$ nanoprobe for tumor detection and image guided surgery: a) Schematic of $\mathrm{pH}$ nanotransistor switch at a transition $\mathrm{pH}$ of 6.9; b) SPY Elite clinical camera imaging of a variety of tumor models after $24 \mathrm{~h}$ injection of PINS; c) Surgical resection of primary HN5 tumors. a-c) Reproduced with permission. ${ }^{[217]}$ Copyright 2013, Springer Nature. 


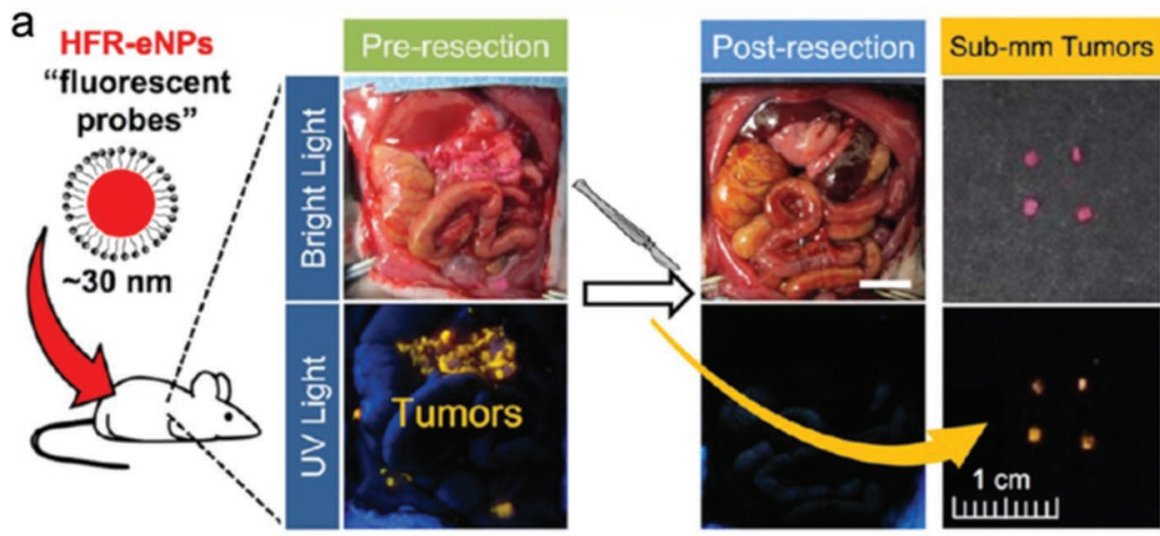

b
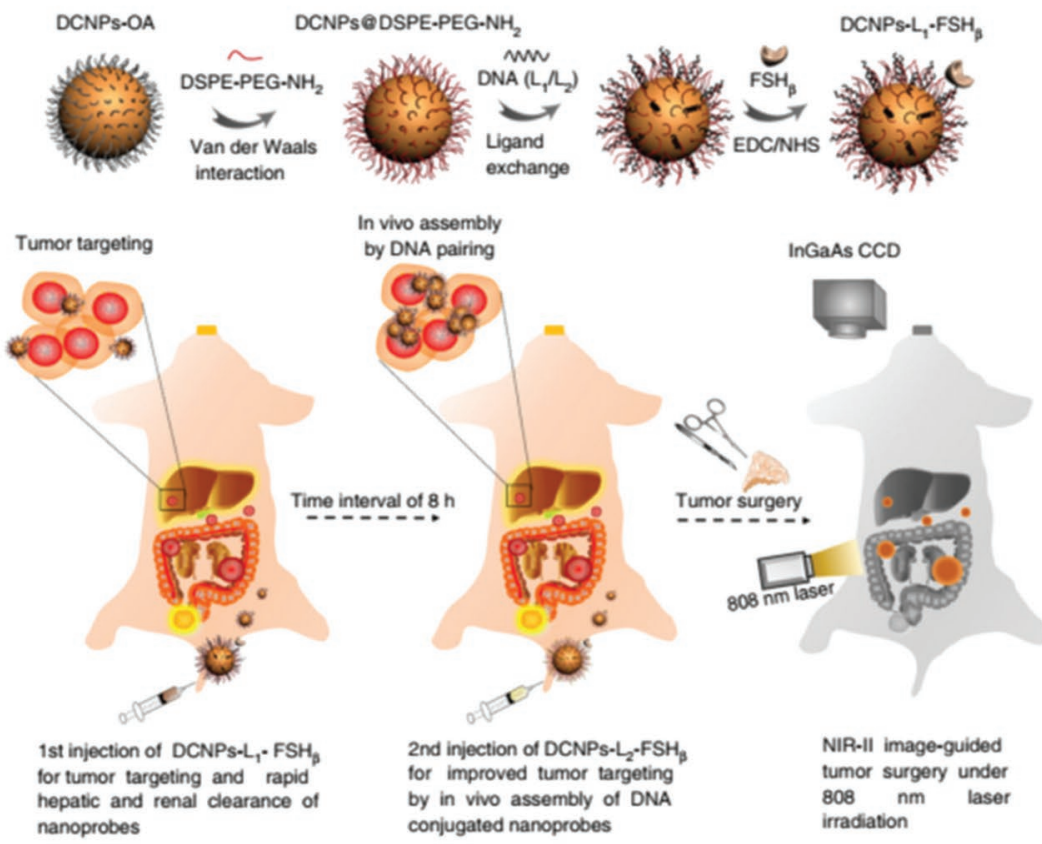

C
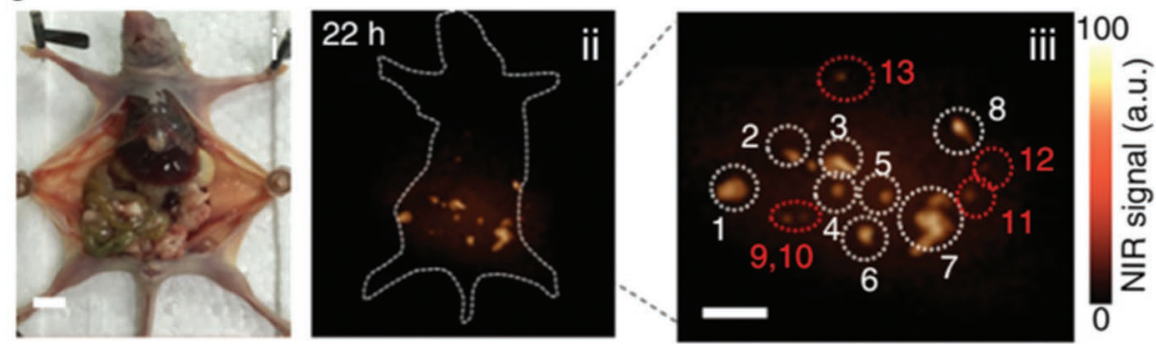

d

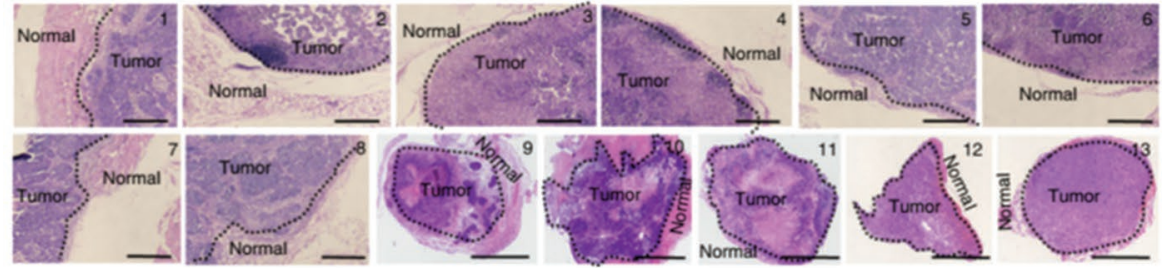

Figure 10. a) Visual assessment of the biological distribution of HFR-eNPs and the feasibility of using HFR-eNPs for cytoreductive surgery. Reproduced with permission. ${ }^{[290]}$ Copyright 2017, American Chemical Society. NIR-II image-guided ovarian metastasis surgery: b) Schematic illustration of NIR-II nanoprobes; c) optical photo of human ovarian adenocarcinoma peritoneal metastases model; d) H\&E staining results of tumor margin marked up above. b-d) Reproduced with permission. ${ }^{[232]}$ Copyright 2016, Springer Nature. 
image-guided surgery strategy with high tumor-to-normal tissue $(\mathrm{T} / \mathrm{N})$ ratio and long tumor retention are the prerequisite to intraoperatively visualize the contrast between tumor nidus and normal tissue in real time.

In recent years, a series of tunable ultra $\mathrm{pH}$-sensitive (UPS) nanoprobes have been developed for a wide range of biomedical imaging applications, including quantitative endolysosomal imaging, tumor detection, and image-guided surgery as $\mathrm{pH}$ imbalance is becoming another recognized common feature of cancer due to tumor metabolic disorders. ${ }^{[217,218,260]}$ To visualize tumors in vivo, a $\mathrm{pH}$-activatable indocyanine green-encoded nanosensor (PINS) was employed as a kind of chemical transistor with a sensitive switch of $\mathrm{pH}$ response. It is similar to electronic transistor gate control to distinguish the small $\mathrm{pH}$ difference with a transition $\mathrm{pH}$ at 6.9 in Figure 9a. ${ }^{[217]}$ A clinical SPY Elite camera can observe the bright tumor illumination observed in a wide variety of tumor models after $24 \mathrm{~h}$ of PINS intravenous injection that may be due to the EPR effect in solid tumors as shown in Figure 9b. By targeting to dysregulated $\mathrm{pH}$ in tumor, PINS has shown broad tumor specificity in a variety of cancer types, which significantly improved accuracy in real-time image-guided tumor resection by accurate tumor margin delineation as demonstrated by higher overall survival rate compared with white light surgery. Surgical removal of the HN5 primary tumor is depicted in Figure 9c, indicating that the SPY Elite camera can successfully detect residual tumors.

So far, the treatment of metastatic peritoneal carcinoma remains a major challenge and is directly correlated with complete resection of primary tumor. As residual microtumors can lead to fatal recurrence and metastasis, in order to improve operative successful rate, Colby et al. designed and synthesized highly fluorescent rhodamine-labeled expansile NPs (HFReNPs) as the visual aid during resection surgery of pancreatic carcinomatosis with high tumor specificity (99\%) and high sensitivity $(92 \%)$ as shown in Figure 10a. ${ }^{290]}$ Recently, to improve the image-guided surgery for metastatic ovarian cancer and overcome the local recurrence, Wang et al. designed the NIR-II emitting DCNPs, which is superior to ICG with good photostability and deep tissue penetration. To investigate the potential application for intraoperative imaging of DCNPs, the optical photo of human ovarian adenocarcinoma peritoneal metastases model with administrated DCNPs was observed, and found that either the large tumor boundary or invisible small metastatic lesion could be identified by NIR-II fluorescence bioimaging when optimal tumor surgery exhibited in the Figure 10b,c. ${ }^{[232]}$

\section{Perspective and Outlook}

With the progress of materials science, spectroscopy and microscopy, the state of the art of FI is impressive. In view of the summary of many literatures, we found that the EPR effect is still the mainstream to design nanocarriers. However, the conclusion has been drawn from the past decades research that the EPR effect works in rodents, but not in humans beings because of the pretty low targeting efficacy. ${ }^{[41]}$ Therefore, scientists began to intensify the active targeting and TME study to make up for the deficiency of the EPR effect. CMPT is a new targeting mechanism proposed by Wang's group. ${ }^{[37]}$ The designed nanoprobe can discern tumor cells from normal cells through the differences of cell membrane permeability between the two cell types. These probes can recognize tumor tissue in a very early stage and track the invasion and metastasis of tumor cells at the single cell level. More importantly, the tumor targeting rate can be improved to as high as 50\%. It can guide the design of new nanocarriers and open new avenues for tumor diagnosis and treatment. At the same time, with the concept of "precision medicine" introduced by Obama in 2015, researchers have developed some new ideas and methods for cancer treatment and have made some progress. ${ }^{[291]}$ Immunotherapy has come to the forefront of cancer treatment. In immunotherapy, drugs enable the body to naturally attack abnormal cancer cells by activating the immune system, which improves the tumor-specific targeting. ${ }^{[292,293]}$ Checkpoint inhibitors are common strategies. The two most common checkpoint inhibition strategies are programmed cell death 1 (PD-1) /PD-1 ligand 1 (PD-L1) blockade and cytotoxic T lymphocyte antigen 4 (CTLA4) inhibition. For example, when T cells are activated, they express PD-1, which can recognize cancer cells. However, tumor cells express PD-L1 to avoid being recognized and cleared by T cells. Binding of PD-1 to PD-L1 could inactivate T cells. Thus, blocking this interaction with $\mathrm{mAb}$ targeting PD-1 or PD-L1 can trigger T-cell-mediated tumor cell death. ${ }^{[292,294]}$ CTLA4 is a molecule that regulates the activation of $\mathrm{T}$ cells. The interaction of CTLA4 with CD80 and CD86 inhibits $\mathrm{T}$ cell activity and promotes tumor progression. By blocking the interaction between CTLA4 and these ligands, T cells maintain the ability of identifying and killing tumor cells. ${ }^{[292,295]} \mathrm{A}$ drug targeting CTLA4 was used to treat advanced melanoma in 2011. ${ }^{[296]}$ Recently, a new immunological method called chimeric antigen receptor $\mathrm{T}$ (CAR-T) cell therapy has attracted people's attention. CAR-T works by collecting $\mathrm{T}$ cells from a patient's blood and then modifying them to express antigen-specific T-cells present on tumor cells. The modified T cells are then reinjected into the same patient. After injection, CAR T cells recognize target antigens on tumor cells and induce tumor cell death. ${ }^{[297]}$ CAR-T has achieved some clinical successes, with many patients achieving prolonged survival. ${ }^{[292]}$ One population of tumor-inducible, erythroblast-like cells (Ter-cells) deriving from megakaryocyte-erythroid progenitor cells are studied providing a new research idea for the development and invasion of tumors, as well as a potential drug research target for the study of complex tumor. ${ }^{[298]}$ Yan et al. and her group first found the mechanism of the role of CD146 in regulating human melanoma cell motility, namely that CD146 physically interacts with ezrin radixin moesin (ERM) proteins and recruits ERM proteins to cell protrusions, promoting the formation and elongation of microvilli. ${ }^{[299]}$ In recent years, nanomaterials combined with immunotherapy have been shown to improve the efficacy of anticancer and immunomodulatory drugs. ${ }^{[300]}$ Yang et al. got the endogenous vaccination by combining DOX with chlorine e6 in hollow $\mathrm{MnO}_{2}$ NPs. $\mathrm{MnO}_{2}$ NPs react with hydrogen peroxide in the TME and alleviating local immunosuppression and improving the efficacy of tumor immunotherapy. After the degradation of $\mathrm{MnO}_{2}$ NPs, chlorine e6 mediated PDT. ${ }^{[301]}$ Liu and co-workers combined PLGA nanoparticles with ICG and TLR7/8 agonist imiquimod, which is a potent immune costimulating agent. This compound system improved the therapeutic 
effect of CTLA4 under the irradiation of NIR. ${ }^{[302]}$ Nam et al. synthesized spiky $\mathrm{Au}$ nanoparticles coated with polydopamine to enable local PDT. It is worth mentioning that PDT treatment can generate adoptive immunity. All the mice treated by PDT survived after second injected of C26 cancer cells, but the unexposed mice died within 35 days. ${ }^{[303]}$ These studies suggest that the combination of nanomaterials and immunotherapy is a promising approach to cancer treatment.

As mentioned above, TME is very complex, with abnormal vascular structure, interstitial fluid pressure and other factors hindering drug delivery. Furthermore, vascular abnormalities facilitate immune evasion. Jain and co-workers have been working on improving drug delivery through the regulation of tumor blood vessels and TME. They have achieved a series of successes. For example, in an ovarian cancer model, chemotherapy was improved by normalizing the tumor stroma and reducing ascites. ${ }^{[304]}$ They improved the drug efficacy by reengineering the tumor vasculature. ${ }^{[305]}$ Normalization of tumor blood vessels can increase tumor infiltration and transformation by immune effector cells. ${ }^{[306]}$ Therefore, combination with antiangiogenesis treatment and immunotherapy may improve outcomes.

Biomolecular recognition, nanobiosensor, nanorobot, computational biology methods, drug action mechanism studies also contributed a lot to improve the cancer therapy and diagnosis. ${ }^{[307]}$ Another novel tumor targeting strategy is the pathway-based targeted therapy. The goal is to regulate an abnormal protein or critical pathway to cancer survival. With the development of genetic engineering and proteomics, it is possible to analyze human proteins and genes, which provides a basis for screening new tumor therapeutic targets. These methods often use gene sequencing and other methods to screen new targets for cancer treatment. Recently, many new tumor therapeutic targets have been discovered through this method with remarkable results. ${ }^{[308,309]}$

Improving the therapeutic effect on cancer, prolonging the life of patients and reducing the toxicity and side effects are the goals that researchers have been pursuing. To this end, scientists have been making continuous efforts. The new design mechanism and strategies give new ideas for cancer treatment whether the immunotherapy, proteomics, or our newly discovered CMPT mechanism. At the same time, some countries have begun to pay attention to the early prevention of cancer. A primary mode of cancer prevention and early detection in the United States is the widespread practice of screening. The fighting against cancer has always existed. We believe that we will eventually find the way to conquer the cancer with the continuous efforts and the discovery of new methods and mechanisms.

\section{Acknowledgements}

J.H., C.L., L.D., and Y.H. contributed equally to this work. This work was been supported by the National Natural Science Foundation of China (Nos. 21371115, 11025526, 21671131, 11875185), the Shanghai University-Universal Medical Imaging Diagnostic Research Foundation (19H00100), the Program for Changjiang Scholars and Innovative Research Team in University (No. IRT13078) and the Portuguese Foundation for Science and Technology (IF/00347/2015).

\section{Conflict of Interest}

The authors declare no conflict of interest.

\section{Keywords}

clearance, diagnosis and therapy, fluorescent nanoparticles, tumor targeting strategies

Received: April 15, 2019

Revised: May 30, 2019

Published online: August 1, 2019

[1] a) D. R. Seeger, J. M. Smith Jr., M. E. Hultquist, J. Am. Chem. Soc. 1947, 69, 2567; b) S. Farber, L. K. Diamond, N. Engl. J. Med. 1948, 238, 787.

[2] a) M. X. Sliwkowski, I. Mellman, Science 2013, 341, 1192; b) S. Farber, D. Pinkel, E. M. Sears, R. Toch, Adv. Cancer Res. 1956, 4, 1.

[3] P. G. Corrie, Medicine 2008, 36, 24.

[4] O. U. Akakuru, H. Louis, O. O. Oyebanji, B. I. Ita, P. I. Amos, M. Philip, J. Nanomed. Nanotechnol. 2018, 9, 481.

[5] a) O. S. Wolfbeis, Chem. Soc. Rev. 2015, 44, 4743; b) J. Shi, P. W. Kantoff, R. Wooster, O. C. Farokhzad, Nat. Rev. Cancer 2017, 17, 20;

[6] a) D. E. Gerber, Am. Fam. Physician 2008, 77, 311; b) T. M. Allen, Nat. Rev. Cancer 2002, 2, 750; c) C. Moorthi, R. Manavalan, K. Kathiresan, J. Pharm. Pharm. Sci. 2011, 14, 67.

[7] G. Hong, A. L. Antaris, H. Dai, Nat. Biomed. Eng. 2017, 1, 10.

[8] F. Ding, Y. Zhan, X. Lu, Y. Sun, Chem. Sci. 2018, 9, 4370.

[9] a) J. T. Hou, W. X. Ren, K. Li, J. Seo, A. Sharma, X. Q. Yu, J. S. Kim, Chem. Soc. Rev. 2017, 46, 2076; b) K. Pu, A. J. Shuhendler, J. V. Jokerst, J. Mei, S. S. Gambhir, Z. Bao, J. Rao, Nat. Nanotechnol. 2014, 9, 233; c) L. Yuan, W. Lin, K. Zheng, L. He, W. Huang, Chem. Soc. Rev. 2013, 42, 622; d) L. He, B. Dong, Y. Liu, W. Lin, Chem. Soc. Rev. 2016, 45, 6449.

[10] T. Terai, T. Nagano, Curr. Opin. Chem. Biol. 2008, 12, 515.

[11] A. B. Chinen, C. M. Guan, J. R. Ferrer, S. N. Barnaby, T. J. Merkel, C. A. Mirkin, Chem. Rev. 2015, 115, 10530.

[12] E. C. Jensen, Anat. Rec. 2012, 295, 2031.

[13] M. Montalti, L. Prodi, E. Rampazzo, N. Zaccheroni, Chem. Soc. Rev. 2014, 43, 4243.

[14] a) S. Santra, D. Dutta, G. A. Walter, B. M. Moudgil, Technol. Cancer Res. Treat. 2005, 4, 593; b) S. Santra, A. Malhotra, Wiley Interdiscip. Rev.: Nanomed. Nanobiotechnol. 2011, 3, 501; c) M. Baker, Nat. Methods 2010, 7, 957; d) L. Shang, G. U. Nienhaus, Mater. Today 2013, 16, 58; e) K. Cherukula, K. Manickavasagam Lekshmi, S. Uthaman, K. Cho, C. S. Cho, I. K. Park, Nanomaterials 2016, 6, 76; f) X. Zhao, C.-X. Yang, L.-G. Chen, X.-P. Yan, Nat. Commun. 2017, 8, 14998; g) L. Zhang, D. Sheng, D. Wang, Y. Yao, K. Yang, Z. Wang, L. Deng, Y. Chen, Theranostics 2018, 8, 1591.

[15] M. J. Ruedas-Rama, J. D. Walters, A. Orte, E. A. Hall, Anal. Chim. Acta 2012, 751, 1.

[16] a) A. Marusyk, K. Polyak, Biochim. Biophys. Acta 2010, 1805, 105; b) M. R. Junttila, F. J. de Sauvage, Nature 2013, 501, 346.

[17] X. Zheng, D. Xing, F. Zhou, B. Wu, W. R. Chen, Mol. Pharmaceutics $2011,8,447$.

[18] B. A. Kairdolf, A. M. Smith, T. H. Stokes, M. D. Wang, A. N. Young, S. Nie, Annu. Rev. Anal. Chem. 2013, 6, 143.

[19] S. J. Rosenthal, J. C. Chang, O. Kovtun, J. R. McBride, I. D. Tomlinson, Chem. Biol. 2011, 18, 10. 
[20] a) Y. Zheng, L. Lai, W. Liu, H. Jiang, X. Wang, Adv. Colloid Interface Sci. 2017, 242, 1; b) K. Bhattacharyya, S. Mukherjee, Bull. Chem. Soc. Jpn. 2018, 91, 447.

[21] L. Cheng, C. Wang, Z. Liu, Nanoscale 2013, 5, 23.

[22] D. K. Chatterjee, M. K. Gnanasammandhan, Y. Zhang, Small 2010, 6, 2781.

[23] a) L. Li, G. Wu, G. Yang, J. Peng, J. Zhao, J. J. Zhu, Nanoscale 2013, 5, 4015; b) J. M. Say, C. van Vreden, D. J. Reilly, L. J. Brown, J. R. Rabeau, N. J. C. King, Biophys. Rev. 2011, 3, 171; c) C. Cha, S. R. Shin, N. Annabi, M. R. Dokmeci, A. Khademhosseini, ACS Nano 2013, 7, 2891

[24] M. Zheng, S. Ruan, S. Liu, T. Sun, D. Qu, H. Zhao, Z. Xie, H. Gao, X. Jing, Z. Sun, ACS Nano 2015, 9, 11455.

[25] a) F. Yin, B. Zhang, S. Zeng, G. Lin, J. Tian, C. Yang, K. Wang, G. Xu, K.-T. Yong, J. Mater. Chem. B 2015, 3, 6081; b) X. Liu, A. L. Miller II, M. J. Yaszemski, L. Lu, RSC Adv. 2015, 5, 33275.

[26] a) G. Yao, L. Wang, Y. Wu, J. Smith, J. Xu, W. Zhao, E. Lee, W. Tan, Anal. Bioanal. Chem. 2006, 385, 518; b) X. Zhao, R. P. Bagwe, W. Tan, Adv. Mater. 2004, 16, 173; c) S. W. Bae, W. Tan, J. I. Hong, Chem. Commun. 2012, 48, 2270; d) X. Wu, M. Wu, J. X. Zhao, Nanomed.: Nanotechnol. Biol. Med. 2014, 10, 297.

[27] a) U. Resch-Genger, M. Grabolle, S. Cavaliere-Jaricot, R. Nitschke, T. Nann, Nat. Methods 2008, 5, 763; b) W. C. W. Chan, S. M. Nie, Sci. Rep. 2019, 9, 10061.

[28] S. Sadeghi, S. Khabbaz Abkenar, C. W. Ow-Yang, S. Nizamoglu, Sci. Rep. 2019, 9, 10061.

[29] a) R. Rossetti, S. Nakahara, L. E. Brus, J. Chem. Phys. 1983, 79, 1086; b) P. Alivisatos, Nat. Biotechnol. 2004, 22, 47; c) X. Michalet, F. F. Pinaud, L. A. Bentolila, J. M. Tsay, S. Doose, J. J. Li, G. Sundaresan, A. M. Wu, S. S. Gambhir, S. Weiss, Science 2005, 307, 538; d) I. L. Medintz, H. T. Uyeda, E. R. Goldman, H. Mattoussi, Nat. Mater. 2005, 4, 435; e) A. M. Smith, H. Duan, A. M. Mohs, S. Nie, Adv. Drug Delivery Rev. 2008, 60, 1226; f) P. Juzenas, W. Chen, Y.-P. Sun, M. A. Neto Coelho, R. Generalov, N. Generalova, I. L. Christensen, Adv. Drug Delivery Rev. 2008, 60, 1600; g) A. M. Smith, S. Nie, Acc. Chem. Res. 2010, 43, 190; h) J. Lia, J.-J. Zhu, Analyst 2013, 138, 2506; i) K. D. Wegner, N. Hildebrandt, Chem. Soc. Rev. 2015, 44, 4792; j) H. R. Chandan, J. D. Schiffman, R. G. Balakrishna, Sens. Actuators, B 2018, 258, 1191.

[30] T. S. Hauck, R. E. Anderson, H. C. Fischer, S. Newbigging, W. C. Chan, Small 2010, 6, 138.

[31] a) R. Jin, Nanoscale 2010, 2, 343; b) L. Shang, S. Dong, G. U. Nienhaus, Nano Today 2011, 6, 401

[32] L. Zhang, E. Wang, Nano Today 2014, 9, 132.

[33] a) J. Ge, Z.-Z. Dong, D.-M. Bai, L. Zhang, Y.-L. Hu, D.-Y. Ji, Z.-H. Li, New J. Chem. 2017, 41, 9718; b) Y. Tao, Y. Lin, Z. Huang, J. Ren, X. Qu, Adv. Mater. 2013, 25, 2594; c) Y. Lei, L. Tang, Y. Xie, Y. Xianyu, L. Zhang, P. Wang, Y. Hamada, K. Jiang, W. Zheng, X. Jiang, Nat. Commun. 2017, 8, 15130; d) R. Liu, W. Xiao, C. Hu, R. Xie, H. Gao, J. Controlled Release 2018, 278, 127.

[34] C. Bouzigues, T. Gacoin, A. Alexandrou, ACS Nano 2011, 5, 8488.

[35] Z. Gu, S. Zhu, L. Yan, F. Zhao, Y. Zhao, Adv. Mater. 2019, 31, 1800662.

[36] a) C. Yue, P. Liu, M. Zheng, P. Zhao, Y. Wang, Y. Ma, L. Cai, Biomaterials 2013, 34, 6853; b) J. M. Rosenholm, C. Sahlgren, M. Linden, Nanoscale 2010, 2, 1870; c) F. Degliangeli, P. Kshirsagar, V. Brunetti, P. P. Pompa, R. Fiammengo, J. Am. Chem. Soc. 2014, 136, 2264

[37] Z. Lei, L. Ding, C. Yao, F. Mo, C. Li, Y. Huang, X. Yin, M. Li, J. Liu, Y. Zhang, C. Ling, Y. Wang, Adv. Mater. 2019, 31, 1807456.

[38] Y. Matsumura, H. Maeda, Cancer Res. 1986, 46, 6387.

[39] H. Maeda, K. Tsukigawa, J. Fang, Microcirculation 2016, 23, 173.

[40] a) J. L. Perry, K. G. Reuter, J. C. Luft, C. V. Pecot, W. C. Zamboni, J. M. Desimone, Nano Lett. 2017, 17, 2879; b) F. Jun, N. Hideaki,
M. Hiroshi, Adv. Drug Delivery Rev. 2011, 63, 136; c) S. Barua, S. Mitragotri, Nano Today 2014, 9, 223.

[41] F. Danhier, J. Controlled Release 2016, 244, 108.

[42] H. Maeda, H. Nakamura, J. Fang, Adv. Drug Delivery Rev. 2013, 65, 71.

[43] S. Taurin, H. Nehoff, K. Greish, J. Controlled Release 2012, 164, 265.

[44] G. Khaled, F. Jun, I. Takao, N. Akinori, M. Hiroshi, Clin. Pharmacokinet. 2003, 42, 1089.

[45] V. Torchilin, Adv. Drug Delivery Rev. 2011, 63, 131.

[46] M. Kanapathipillai, A. Brock, D. E. Ingber, Adv. Drug Delivery Rev. 2014, 79, 107.

[47] a) J. C. Li, L. Sun, S. Jiang, Y. Liu, H. J. Yao, Y. Z. Pu, J. Y. Zhu, Y. G. Zhang, Chin. J. Pharmacol. Toxicol. 2015, 29, 164; b) S. Patel, A. A. Bhirde, J. F. Rusling, X. Chen, J. S. Gutkind, V. Patel, Pharmaceutics 2011, 3, 34 .

[48] T. Stylianopoulos, R. K. Jain, Nanomed. Nanotechnol. Biol. Med. 2015, 11, 1893.

[49] a) L. Michelle, P. L. Choyke, K. Hisataka, Nanomedicine 2008, 3, 703; b) M. R. Longmire, M. Ogawa, P. L. Choyke, H. Kobayashi, Bioconjugate Chem. 2011, 22, 993.

[50] J. Fang, H. Nakamura, H. Maeda, Adv. Drug Delivery Rev. 2011, 63, 136. [51] M. Yu, J. Zheng, ACS Nano 2015, 9, 6655.

[52] I. A. Khawar, J. H. Kim, H. J. Kuh, J. Controlled Release 2015, 201, 78.

[53] A. Makino, S. Kizaka-Kondoh, R. Yamahara, I. Hara, T. Kanzaki, E. Ozeki, M. Hiraoka, S. Kimura, Biomaterials 2009, 30, 5156.

[54] a) I. Brigger, C. Dubernet, P. Couvreur, Adv. Drug Delivery Rev. 2002, 54, 631; b) C. Sun, J. S. H. Lee, M. Q. Zhang, Adv. Drug Delivery Rev. 2008, 60, 1252.

[55] S. Santra, A. Malhotra, Wiley Interdiscip. Rev.: Nanomed. Nanobiotechnol. 2011, 3, 501.

[56] a) H. Ow, D. R. Larson, M. Srivastava, B. A. Baird, W. W. Webb, U. Wiesner, Nano Lett. 2005, 5, 113; b) T. Padmavathy, P. Keith, S. Swadeshmukul, Nanomedicine 2008, 3, 579.

[57] a) C. M. Lee, D. Jang, J. Kim, S. J. Cheong, E. M. Kim, M. H. Jeong, S. H. Kim, D. W. Kim, S. T. Lim, M. H. Sohn, Bioconjugate Chem. 2011, 22, 186; b) J. H. Kim, Y. S. Kim, K. Park, S. Lee, H. Y. Nam, K. H. Min, H. G. Jo, J. H. Park, K. Choi, S. Y. Jeong, J. Controlled Release 2008, 127, 41.

[58] J. Xie, K. Chen, J. Huang, S. Lee, J. Wang, J. Gao, X. Li, X. Chen, Biomaterials 2010, 31, 3106

[59] S. Park, H. Kim, S. C. Lim, K. Lim, E. S. Lee, K. T. Oh, H. G. Choi, Y. S. Youn, J. Controlled Release 2019, 304, 7.

[60] E. I. Altınoğlu, T. J. Russin, J. M. Kaiser, B. M. Barth, P. C. Eklund, K. Mark, J. H. Adair, ACS Nano 2008, 2, 2075.

[61] T. K. Hill, A. M. Mohs, Wiley Interdiscip. Rev. Nanomed. Nanobiotechnol. 2015, 8, 498.

[62] H. Cai, X. Wang, H. Zhang, L. Sun, D. Pan, Q. Gong, Z. Gu, K. Luo, Appl. Mater. Today 2018, 11, 207.

[63] S. Santra, B. Liesenfeld, C. Bertolino, D. Dutta, Z. H. Cao, W. H. Tan, B. M. Moudgil, R. A. Mericle, J. Lumin. 2006, 117, 75.

[64] X. Gao, Y. Cui, R. M. Levenson, L. W. K. Chung, S. Nie, Nat. Biotechnol. 2004, 22, 969.

[65] H. Dong, C. Dong, T. Ren, Y. Li, D. Shi, J. Biomed. Nanotechnol. 2014, 10, 2086.

[66] C. Wong, T. Stylianopoulos, J. Cui, J. Martin, V. P. Chauhan, W. Jiang, Z. Popović, R. K. Jain, M. G. Bawendi, D. Fukumura, Proc. Natl. Acad. Sci., USA 2011, 108, 2426.

[67] E. F. Kirkness, B. J. Haas, W. Sun, H. R. Braig, M. A. Perotti, J. M. Clark, S. H. Lee, H. M. Robertson, R. C. Kennedy, E. Elhaik, D. Gerlach, E. V. Kriventseva, C. G. Elsik, D. Graur, C. A. Hill, J. A. Veenstra, B. Walenz, J. M. C. Tubío, J. M. C. Ribeiro, J. Rozas, J. S. Johnston, J. T. Reese, A. Popadic, M. Tojo, D. Raoult, D. L. Reed, Y. Tomoyasu, E. Kraus, O. Mittapalli, V. M. Margam, H.-M. Li, J. M. Meyer, R. M. Johnson, J. Romero-Severson, J. P. Vanzee, D. Alvarez-Ponce, F. G. Vieira, M. Aguadé, S. Guirao-Rico, J. M. Anzola, K. S. Yoon, J. P. Strycharz, M. F. Unger, 
S. Christley, N. F. Lobo, M. J. Seufferheld, N. Wang, G. A. Dasch, C. J. Struchiner, G. Madey, L. I. Hannick, S. Bidwell, V. Joardar, E. Caler, R. Shao, S. C. Barker, S. Cameron, R. V. Bruggner, A. Regier, J. Johnson, L. Viswanathan, T. R. Utterback, G. G. Sutton D. Lawson, R. M. Waterhouse, J. C. Venter, R. L. Strausberg, M. R. Berenbaum, F. H. Collins, E. M. Zdobnov, B. R. Pittendrigh, Proc. Natl. Acad. Sci. USA 2010, 107, 12168

[68] D. Du, K. Wang, Y. Wen, Y. Li, Y. Li, ACS Appl. Mater. Interfaces 2016, 8, 3287.

[69] K. Yang, J. Wan, S. Zhang, B. Tian, Y. Zhang, Z. Liu, Biomaterials 2012, 33, 2206

[70] T. Yang, Y. Tang, L. Liu, X. Lv, Q. Wang, H. Ke, Y. Deng, H. Yang, X. Yang, G. Liu, Y. Zhao, H. Chen, ACS Nano 2017, 11, 1848.

[71] J. Ge, M. Lan, B. Zhou, W. Liu, L. Guo, H. Wang, Q. Jia, G. Niu, X. Huang, H. Zhou, Nat. Commun. 2014, 5, 4596.

[72] a) S. lijima, Nature 1991, 354, 56; b) H. Dai, Acc. Chem. Res. 2002 $35,1035$.

[73] a) H. Gong, R. Peng, Z. Liu, Adv. Drug Delivery Rev. 2013, 65, 1951; b) K. Welsher, S. P. Sherlock, H. Dai, Proc. Natl. Acad. Sci. USA 2011, 108, 8943

[74] G. Prencipe, S. M. Tabakman, K. Welsher, Z. Liu, A. P. Goodwin, L. Zhang, J. Henry, H. Dai, J. Am. Chem. Soc. 2009, 131, 4783.

[75] Z. Liu, J. T. Robinson, S. M. Tabakman, K. Yang, H. Dai, Mater. Today 2011, 14, 316

[76] K. Welsher, Z. Liu, D. Daranciang, H. Dai, Nano Lett. 2008, 8, 586

[77] Z. Liu, C. Davis, W. B. Cai, L. He, X. Y. Chen, H. J. Dai, Proc. Natl. Acad. Sci. USA 2008, 105, 1410.

[78] C. Wang, X. Ma, S. Ye, C. Liang, K. Yang, L. Guo, C. Li, Y. Li, Z. Liu, Adv. Funct. Mater. 2012, 22, 2363.

[79] J. H. Choi, F. T. Nguyen, P. W. Barone, D. A. Heller, A. E. Moll, D. Patel, S. A. Boppart, M. S. Strano, Nano Lett. 2007, 7, 861.

[80] Z. Liu, W. Cai, L. He, N. Nakayama, K. Chen, X. Sun, X. Chen, H. Dai, Nat. Nanotechnol. 2007, 2, 47.

[81] S. Y. Hong, G. Tobias, K. T. Al-Jamal, B. Ballesteros, H. Ali-Boucetta, S. Lozano-Perez, P. D. Nellist, R. B. Sim, C. Finucane, S. J. Mather, M. L. H. Green, K. Kostarelos, B. G. Davis, Nat. Mater. 2010, 9, 485.

[82] X. Wu, X. He, K. Wang, C. Xie, B. Zhou, Z. Qing, Nanoscale 2010, 2, 2244

[83] Z. T. Luo, K. Y. Zheng, J. P. Xie, Chem. Commun. 2014, 50, 5143.

[84] L. Chen, C. Wang, Z. Yuan, H. Chang, Anal. Chem. 2015, 87, 216.

[85] X.-D. Zhang, J. Chen, Z. Luo, D. Wu, X. Shen, S.-S. Song, Y.-M. Sun, P.-X. Liu, J. Zhao, S. Huo, S. Fan, F. Fan, X.-J. Liang, J. Xie, Adv. Healthcare Mater. 2014, 3, 133.

[86] a) A. N. Gordon, J. T. Fleagle, D. Guthrie, D. E. Parkin, M. E. Gore, A. J. Lacave, J. Clin. Oncol. 2001, 19, 3312; b) D. W. Northfelt, B. J. Dezube, J. A. Thommes, B. J. Miller, M. A. Fischl, A. Friedman-Kien, L. D. Kaplan, C. D. Mond, R. D. Mamelok, D. H. Henry, J. Clin. Oncol. 1998, 16, 2445.

[87] P. S. Gill, J. Wernz, D. T. Scadden, P. Cohen, G. M. Mukwaya, J. H. von Roenn, M. Jacobs, S. Kempin, I. Silverberg, G. Gonzales, M. U. Rarick, A. M. Myers, F. Shepherd, C. Sawka, M. C. Pike, M. E. Ross, J. Clin. Oncol. 1996, 14, 2353

[88] R. K. Jain, T. Stylianopoulos, Nat. Rev. Clin. Oncol. 2010, 7, 653.

[89] C. Heneweer, J. P. Holland, V. Divilov, S. Carlin, J. S. Lewis, J. Nucl. Med. 2011, 52, 625

[90] K. Bourzac, Proc. Natl. Acad. Sci. USA 2016, 113, 12600.

[91] Y. Nakamura, A. Mochida, P. L. Choyke, H. Kobayashi, Bioconjugate Chem. 2016, 27, 2225

[92] a) S. Maki, T. Konno, H. Maeda, Cancer 1985, 56, 751; b) A. Nagamitsu, K. Greish, H. Maeda, Jpn J. Clin. Oncol. 2009, 39, 756.

[93] P. Halloran, T. Mathew, S. Tomlanovich, C. Groth, L. Hooftman, C. Barker, Transplantation 1997, 63, 39.
[94] R. Bazak, M. Houri, S. El Achy, S. Kamel, T. Refaat, J. Cancer Res. Clin. Oncol. 2015, 141, 769.

[95] J. D. Byrne, T. Betancourt, L. Brannon-Peppas, Adv. Drug Delivery Rev. 2008, 60, 1615.

[96] E. Ahmed, S. W. Morton, P. T. Hammond, T. M. Swager, Adv. Mater. 2013, 25, 4504

[97] J. M. Rosenholm, A. Meinander, E. Peuhu, R. Niemi, J. E. Eriksson, C. Sahlgren, M. Linden, ACS Nano 2009, 3, 197.

[98] T. Nakamura, F. Sugihara, H. Matsushita, Y. Yoshioka, S. Mizukami, K. Kikuchi, Chem. Sci. 2015, 6, 1986.

[99] A. M. Santiago, T. Ribeiro, A. S. Rodrigues, B. Ribeiro, R. F. M. Frade, C. Baleizão, J. P. S. Farinha, Eur. J. Inorg. Chem. 2015, 2015, 4579.

[100] M. Liong, J. Lu, M. Kovochich, T. Xia, S. G. Ruehm, A. E. Nel, F. Tamanoi, J. I. Zink, ACS Nano 2008, 2, 889.

[101] J. Liu, P. Du, H. Mao, L. Zhang, H. Ju, J. Lei, Biomaterials 2018 , $172,83$.

[102] a) D. K. Chatterjee, Y. Zhang, Sci. Technol. Adv. Mater. 2007, 8, 131; b) M. Lu, W. Zhang, Y. Gai, T. Yang, P. Ye, G. Yang, X. Ma, G. Xiang, New J. Chem. 2014, 38, 4519; c) Y. Yuan, J. Zhang, L. An, Q. Cao, Y. Deng, G. Liang, Biomaterials 2014, 35, 7881.

[103] M. Nyk, R. Kumar, T. Y. Ohulchanskyy, E. J. Bergey, P. N. Prasad, Nano Lett. 2008, 8, 3834.

[104] D. K. Chatterjee, A. J. Rufaihah, Y. Zhang, Biomaterials 2008, 29, 937.

[105] H. Hu, L. Xiong, J. Zhou, F. Li, T. Cao, C. Huang, Chem. - Eur. J. 2009, 15, 3577.

[106] L. Q. Xiong, Z. G. Chen, M. X. Yu, F. Y. Li, C. Liu, C. H. Huang, Biomaterials 2009, 30, 5592

[107] T. Cao, Y. Yang, Y. Gao, J. Zhou, Z. Li, F. Li, Biomaterials 2011, 32, 2959.

[108] a) C. Wang, L. Cheng, Z. Liu, Biomaterials 2011, 32, 1110; b) Y.-H. Chien, Y.-L. Chou, S.-W. Wang, S.-T. Hung, M.-C. Liau, Y.-J. Chao, C.-H. Su, C.-S. Yeh, ACS Nano 2013, 7, 8516; c) Y. Yang, B. Velmurugan, X. Liu, B. Xing, Small 2013, 9, 2937; d) F. Ai, Q. Ju, X. Zhang, X. Chen, F. Wang, G. Zhu, Sci. Rep. 2015, 5, 10785; e) D. Yang, X. Kang, P. a. Ma, Y. Dai, Z. Hou, Z. Cheng, C. Li, J. Lin, Biomaterials 2013, 34, 1601

[109] Z. Yu, Y. Ge, Q. Sun, W. Pan, X. Wan, N. Li, B. Tang, Chem. Sci. 2018, 9, 3563

[110] a) Y. Choi, S. Kim, M.-H. Choi, S.-R. Ryoo, J. Park, D.-H. Min, B.-S. Kim, Adv. Funct. Mater. 2014, 24, 5781; b) R. Prasad, S. Aiyer, D. S. Chauhan, R. Srivastava, K. Selvaraj, Nanoscale 2016, 8, 4537; c) S. Li, J. Jiang, Y. Yan, P. Wang, G. Huang, N. H. Kim, J. H. Lee, D. He, Mater. Sci. Eng., C 2018, 93, 1054; d) J. Zhang, X. Zhao, M. Xian, C. Dong, S. Shuang, Talanta 2018, $183,39$.

[111] B. Zhang, Y. Li, C. Y. Fang, C. C. Chang, C. S. Chen, Y. Y. Chen, H. C. Chang, Small 2009, 5, 2716.

[112] a) X. Su, C. Chan, J. Shi, M. K. Tsang, Y. Pan, C. Cheng, O. Gerile, M. Yang, Biosens. Bioelectron. 2017, 92, 489; b) H. Ding, Y. Cai, L. Gao, M. Liang, B. Miao, H. Wu, Y. Liu, N. Xie, A. Tang, K. Fan, X. Yan, G. Nie, Nano Lett. 2019, 19, 203.

[113] a) W. Guo, A. Li, Z. Jia, Y. Yuan, H. Dai, H. Li, Eur. J. Pharmacol. 2013, 718, 41; b) C. Zhao, X. Liu, J. Liu, Z. Yang, X. Rong, M. Li, X. Liang, Y. Wu, Colloids Surf., B 2014, 123, 787.

[114] Y. Cui, Q. Xu, P. K.-H. Chow, D. Wang, C.-H. Wang, Biomaterials 2013, 34, 8511

[115] R. Kumar, I. Roy, T. Y. Hulchanskyy, L. N. Goswami, A. C. Bonoiu, E. J. Bergey, K. M. Tramposch, A. Maitra, P. N. Prasad, ACS Nano 2008, 2, 449

[116] D. P. Ferris, J. Lu, C. Gothard, R. Yanes, C. R. Thomas, J. C. Olsen, J. F. Stoddart, F. Tamanoi, J. I. Zink, Small 2011, 7, 1816.

[117] X. Wang, Y. Chang, D. Zhang, B. Tian, Y. Yang, F. Wei, RSC Adv. 2016, 6, 105661.

[118] Y. Jiao, Y. Sun, X. Tang, Q. Ren, W. Yang, Small 2015, 11, 1962. 
[119] B. M. Barth, R. Sharma, E. I. Altinoglu, T. T. Morgan, S. S. Shanmugavelandy, J. M. Kaiser, C. McGovern, G. L. Matters, J. P. Smith, M. Kester, J. H. Adair, ACS Nano 2010, 4, 1279.

[120] C. M. Spillmann, J. Naciri, W. R. Algar, I. L. Medintz, J. B. Delehanty, ACS Nano 2014, 8, 6986.

[121] M. S. Muthu, R. V. Kutty, Z. Luo, J. Xie, S. S. Feng, Biomaterials 2015, 39, 234.

[122] Q. Xu, Y. Liu, S. Su, W. Li, C. Chen, Y. Wu, Biomaterials 2012, 33, 1627.

[123] J. R. E. Fraser, T. C. Laurent, U. B. G. Laurent, J. Intern. Med. 1997, 242, 27.

[124] R. Stern, Semin. Cancer Biol. 2008, 18, 237.

[125] H. Liu, K. Li, L. Xu, D. Wu, J. Nanopart. Res. 2014, 16, 2784.

[126] S. Li, J. Zhang, C. Deng, F. Meng, L. Yu, Z. Zhong, ACS Appl. Mater. Interfaces 2016, 8, 21155.

[127] C. Cheng, Y. Meng, Z. Zhang, Y. Li, Q. Zhang, ACS Appl. Mater. Interfaces 2018, 10, 26882.

[128] R. S. Herbst, Int. J. Radiat. Oncol. Biol. Phys. 2004, 59, S21.

[129] a) J. G. Paez, P. A. Janne, J. C. Lee, S. Tracy, H. Greulich, S. Gabriel, P. Herman, F. J. Kaye, N. Lindeman, T. J. Boggon, K. Naoki, H. Sasaki, Y. Fujii, M. J. Eck, W. R. Sellers, B. E. Johnson, M. Meyerson, Science 2004, 304, 1497; b) R. G. W. Verhaak, K. A. Hoadley, E. Purdom, V. Wang, Y. Qi, M. D. Wilkerson, C. R. Miller, L. Ding, T. Golub, J. P. Mesirov, G. Alexe, M. Lawrence, M. O'Kelly, P. Tamayo, B. A. Weir, S. Gabriel, W. Winckler, S. Gupta, L. Jakkula, H. S. Feiler, J. G. Hodgson, C. D. James, J. N. Sarkaria, C. Brennan, A. Kahn, P. T. Spellman, R. K. Wilson, T. P. Speed, J. W. Gray, M. Meyerson, G. Getz, C. M. Perou, D. N. Hayes, The Cancer Genome Atlas Research Network, Cancer Cell 2010, 17, 98; c) S. V. Sharma, D. W. Bell, J. Settleman, D. A. Haber, Nat. Rev. Cancer 2007, 7, 169; d) W.-W. Bi, W.-H. Zhang, G.-H. Yin, H. Luo, S.-Q. Wang, H. Wang, C. Li, W.-Q. Yan, D.-Z. Nie, Asian Pac. J. Cancer Prev. 2014, 15, 5535; e) I. M. Kjaer, T. Bechmann, I. Brandslund, J. S. Madsen, Clin. Chem. Lab. Med. 2018, 56, 688.

[130] C. L. Tseng, S. Y. Wu, W. H. Wang, C. L. Peng, F. H. Lin, C. C. Lin, T. H. Young, M. J. Shieh, Biomaterials 2008, 29, 3014

[131] Q. Yuan, E. Lee, W. A. Yeudall, H. Yang, Oral Oncol. 2010, 46, 698.

[132] A. Faucon, H. Benhelli-Mokrani, F. Fleury, S. Dutertre, M. Tramier, J. Boucard, L. Lartigue, S. Nedellec, P. Hulin, E. Ishow, Nanoscale 2017, 9, 18094.

[133] G. Chen, L. Wang, T. Cordie, C. Vokoun, K. W. Eliceiri, S. Gong, Biomaterials 2015, 47, 41.

[134] J. H. Lee, K. Lee, S. H. Moon, Y. Lee, T. G. Park, J. Cheon, Angew. Chem., Int. Ed. 2009, 48, 4174.

[135] O. Akhavan, E. Ghaderi, Small 2013, 9, 3593.

[136] A. B. Alvero, D. Kim, E. Lima, N. J. Sumi, J. S. Lee, C. Cardenas, M. Pitruzzello, D. A. Silasi, N. Buza, T. Fahmy, G. Mor, Sci. Rep. 2017, 7, 40989.

[137] Y. Li, Z. Li, X. Wang, F. Liu, Y. Cheng, B. Zhang, D. Shi, Theranostics 2012, 2, 769.

[138] Y. Zhang, G. Hong, Y. Zhang, G. Chen, F. Li, H. Dai, Q. Wang, ACS Nano 2012, 6, 3695.

[139] Y. Lu, Y. Zhong, J. Wang, Y. Su, F. Peng, Y. Zhou, X. Jiang, Y. He, Nanotechnology 2013, 24, 135101.

[140] S. Su, H. Wang, X. Liu, Y. Wu, G. Nie, Biomaterials 2013, 34, 3523.

[141] D. Chen, B. Li, S. Cai, P. Wang, S. Peng, Y. Sheng, Y. He, Y. Gu, H. Chen, Biomaterials 2016, 100, 1.

[142] G. Liang, X. Jin, S. Zhang, D. Xing, Biomaterials 2017, 144, 95.

[143] a) L. Xiong, Z. Chen, Q. Tian, T. Cao, C. Xu, F. Li, Anal. Chem. 2009, 81, 8687; b) J. Jin, Z. Xu, Y. Zhang, Y. J. Gu, M. H. Lam, W. T. Wong, Adv. Healthcare Mater. 2013, 2, 1501.

[144] X. Cao, F. Cao, L. Xiong, Y. Yang, T. Cao, X. Cai, W. Hai, B. Li, Y. Guo, Y. Zhang, F. Li, Nanoscale 2015, 7, 13404.

[145] a) K. Welsher, Z. Liu, S. P. Sherlock, J. T. Robinson, Z. Chen, D. Daranciang, H. Dai, Nat. Nanotechnol. 2009, 4, 773; b) K. Welsher, S. P. Sherlock, H. Dai, Proc. Natl. Acad. Sci. USA 2011, 108, 8943; c) Z. Liu, S. Tabakman, K. Welsher, H. Dai, Nano Res. 2009, 2, 85; d) A. De la Zerda, C. Zavaleta, S. Keren, S. Vaithilingam, S. Bodapati, Z. Liu, J. Levi, B. R. Smith, T. J. Ma, O. Oralkan, Z. Cheng, X. Chen, H. Dai, B. T. Khuri-Yakub, S. S. Gambhir, Nat. Nanotechnol. 2008, 3, 557; e) Z. Chen, S. M. Tabakman, A. P. Goodwin, M. G. Kattah, D. Daranciang, X. Wang, G. Zhang, X. Li, Z. Liu, P. J. Utz, K. Jiang, S. Fan, H. Dai, Nat. Biotechnol. 2008, 26, 1285.

[146] E. Polo, T. T. Nitka, E. Neubert, L. Erpenbeck, L. Vukovic, S. Kruss, ACS Appl. Mater. Interfaces 2018, 10, 17693.

[147] A. Abdukayum, J. T. Chen, Q. Zhao, X. P. Yan, J. Am. Chem. Soc. 2013, 135, 14125.

[148] a) E. Kluza, I. Jacobs, S. J. Hectors, K. H. Mayo, A. W. Griffioen, G. J. Strijkers, K. Nicolay, J. Controlled Release 2012, 158, 207; b) F. Yan, H. Wu, H. Liu, Z. Deng, H. Liu, W. Duan, X. Liu, H. Zheng, J. Controlled Release 2016, 224, 217.

[149] X. Xiong, A. Lavasanifar, ACS Nano 2011, 5, 5202

[150] X. Guan, C. Li, D. Wang, W. Sun, X. Gai, RSC Adv. 2016, 6, 9461.

[151] X. Liu, G. B. Braun, H. Zhong, D. J. Hall, W. Han, M. Qin, C. Zhao, M. Wang, Z. G. She, C. Cao, M. J. Sailor, W. B. Stallcup, E. Ruoslahti, K. N. Sugahara, Adv. Funct. Mater. 2016, 26, 267.

[152] a) L. C. Gomes-da-Silva, A. O. Santos, L. M. Bimbo, V. Moura, J. S. Ramalho, M. C. Pedroso de Lima, S. Simoes, J. N. Moreira, Int. J. Pharm. 2012, 434, 9; b) L. C. Gomes-da-Silva, Y. Fernandez, I. Abasolo, S. Schwartz Jr., J. S. Ramalho, M. C. Pedroso de Lima, S. Simoes, J. N. Moreira, Nanomedicine 2013, 8, 1397; c) D. Chen, D. Yang, C. A. Dougherty, W. Lu, H. Wu, X. He, T. Cai, M. E. Van Dort, B. D. Ross, H. Hong, ACS Nano 2017, 11, 4315.

[153] J. M. Montenegro, V. Grazu, A. Sukhanova, S. Agarwal, J. M. de la Fuente, I. Nabiev, A. Greiner, W. J. Parak, Adv. Drug Delivery Rev. 2013, 65, 677.

[154] M. von Mehren, G. P. Adams, L. M. Weiner, Annu. Rev. Med. 2003, 54, 343.

[155] T. Rajkumar, W. J. Gullick, Breast Cancer Res. Treat. 1994, 29, 3.

[156] X. Hun, Z. Zhang, L. Tiao, Anal. Chim. Acta 2008, 625, 201

[157] T. A. Zdobnova, O. A. Stremovskiy, E. N. Lebedenko, S. M. Deyev, PLoS One 2012, 7, e48248.

[158] I. V. Balalaeva, T. A. Zdobnova, I. V. Krutova, A. A. Brilkina, E. N. Lebedenko, S. M. Deyev, J. Biophotonics 2012, 5, 860.

[159] Y. Wang, J. Chen, J. Irudayaraj, ACS Nano 2011, 5, 9718.

[160] B. W. Ennis, M. E. Lippman, R. B. Dickson, Cancer Invest. 1991, 9, 553.

[161] Y. S. Cho, T. J. Yoon, E. S. Jang, K. S. Hong, S. Y. Lee, O. R. Kim, C. Park, Y. J. Kim, G. C. Yi, K. Chang, Cancer Lett. 2010, $299,63$.

[162] V. G. Deepagan, B. Sarmento, D. Menon, A. Nascimento, A. Jayasree, M. Sreeranganathan, M. Koyakutty, S. V. Nair, J. Rangasamy, Nanomedicine 2012, 7, 507.

[163] L. Yang, H. Mao, Y. A. Wang, Z. Cao, X. Peng, X. Wang, H. Duan, C. Ni, Q. Yuan, G. Adams, M. Q. Smith, W. C. Wood, X. Gao, S. Nie, Small 2009, 5, 235.

[164] N. Gan, L. Jia, L. Zheng, Int. J. Mol. Sci. 2011, 12, 7410.

[165] J. P. Tiernan, I. Nicola, M. Gemma, S. L. Perry, J. V. Rushworth, C. P Louise, P. A. Millner, D. G. Jayne, T. A. Hughes, Nanomedicine $2015,10,1223$.

[166] Z. Li, L. Wu, P. Hu, S. Han, T. Zhang, H. Fan, W. Jin, Q. Jin, Y. Mu, Nanoscale 2012, 4, 7097.

[167] M. Wang, C. C. Mi, W. X. Wang, C. H. Liu, Y. F. Wu, Z. R. Xu, C. B. Mao, S. K. Xu, ACS Nano 2009, 3, 1580.

[168] S. T. Wu, A. J. Fowler, C. B. Garmon, A. B. Fessler, J. D. Ogle, K. R. Grover, B. C. Allen, C. D. Williams, R. Zhou, M. Yazdanifar, C. A. Ogle, P. Mukherjee, BMC Cancer 2018, 18, 457.

[169] X. Zheng, F. Zhou, B. Wu, W. R. Chen, D. Xing, Mol. Pharmaceutics 2012, 9, 514 .

[170] A. D. Ellington, J. W. Szostak, Nature 1990, 346, 818 
[171] P. Tallury, S. Kar, S. Bamrungsap, Y. F. Huang, W. Tan, S. Santra, Chem. Commun. 2009, 2347.

[172] S. Dhar, F. X. Gu, R. Langer, O. C. Farokhzad, S. J. Lippard, Proc. Natl. Acad. Sci. USA 2008, 105, 17356.

[173] Z. Fan, L. Sun, Y. Huang, Y. Wang, M. Zhang, Nat. Nanotechnol. 2016, 11, 388.

[174] Z. Zhao, H. Fan, G. Zhou, H. Bai, H. Liang, R. Wang, X. Zhang, W. Tan, J. Am. Chem. Soc. 2014, 136, 11220.

[175] M. G. Kim, Y. Shon, J. Lee, Y. Byun, B. S. Choi, Y. B. Kim, Y. K. Oh, Biomaterials 2014, 35, 2999.

[176] Z. Sun, Y. Wang, Y. Wei, R. Liu, H. Zhu, Y. Cui, Y. Zhao, X. Gao, Chem. Commun. 2011, 47, 11960.

[177] J. Yin, X. He, K. Wang, Z. Qing, X. Wu, H. Shi, X. Yang, Nanoscale 2012, 4, 110 .

[178] H. Chen, J. Zhao, M. Zhang, H. Yang, Y. Ma, Y. Gu, Mol. Imaging Biol. 2015, 17, 38.

[179] M. E. Davis, C. Zhuo, M. S. Dong, Nat. Rev. Drug Discovery 2008, 7, 771.

[180] W. H. De Jong, P. J. A. Borm, Int. J. Nanomed. 2008, 3, 133.

[181] a) J. A. Joyce, D. T. Fearon, Science 2015, 348, 74; b) F. Spill, D. S. Reynolds, R. D. Kamm, M. H. Zaman, Curr. Opin. Biotechnol. 2016, 40, 41

[182] N. E. Sounni, A. Noel, Clin. Chem. 2013, 59, 85

[183] S. Paget, Cancer. Metastasis. Rev. 1989, 8, 98

[184] S. N. Ekdawi, D. A. Jaffray, C. Allen, Nano Today 2016, 11, 402.

[185] X. Dong, H. J. Liu, H. Y. Feng, S. C. Yang, X. L. Liu, X. Lai, Q. Lu, J. F. Lovell, H. Z. Chen, C. Fang, Nano Lett. 2019, 19, 997.

[186] a) M. V. Blagosklonny, Cancer Cell 2004, 5, 13; b) R. A. Gatenby, R. J. Gillies, Nat. Rev. Cancer 2004, 4, 891; c) C. E. Weber, P. C. Kuo, Surg. Oncol. 2012, 21, 172.

[187] R. H. Thomlinson, L. H. Gray, Br. J. Cancer 1955, 9, 539.

[188] a) G. L. Wang, B. H. Jiang, E. A. Rue, G. L. Semenza, Proc. Natl. Acad. Sci. USA 1995, 92, 5510; b) N. V. lyer, L. E. Kotch, F. Agani, S. W. Leung, E. Laughner, R. H. Wenger, M. Gassmann J. D. Gearhart, A. M. Lawler, A. Y. Yu, G. L. Semenza, Genes Dev. $1998,12,149$

[189] H. W. Liu, X. X. Hu, K. Li, Y. Liu, Q. Rong, L. Zhu, L. Yuan, F. L. Qu, X. B. Zhang, W. Tan, Chem. Sci. 2017, 8, 7689.

[190] K. Kiyose, K. Hanaoka, D. Oushiki, T. Nakamura, M. Kajimura, M. Suematsu, H. Nishimatsu, T. Yamane, T. Terai, Y. Hirata, T. Nagano, J. Am. Chem. Soc. 2010, 132, 15846.

[191] a) W. Piao, S. Tsuda, Y. Tanaka, S. Maeda, F. Liu, S. Takahashi, Y. Kushida, T. Komatsu, T. Ueno, T. Terai, T. Nakazawa, M. Uchiyama, K. Morokuma, T. Nagano, K. Hanaoka, Angew. Chem., Int. Ed. 2013, 52, 13028; b) Q. Cai, T. Yu, W. Zhu, Y. Xu, X. Qian, Chem. Commun. 2015, 51, 14739.

[192] a) T. Thambi, J. H. Park, D. S. Lee, Chem. Commun. 2016, 52 8492; b) I. N. Fleming, R. Manavaki, P. J. Blower, C. West, K. J. Williams, A. L. Harris, J. Domarkas, S. Lord, C. Baldry, F. J. Gilbert, Br. J. Cancer 2015, 112, 238; c) G. Zhang, G. M. Palmer, M. Dewhirst, C. L. Fraser, Nat. Mater. 2009, 8, 747; d) X. Zheng, X. Wang, H. Mao, W. Wu, B. Liu, X. Jiang, Nat. Commun. 2015, 6, 5834 .

[193] G. Bartholomeusz, P. Cherukuri, J. Kingston, L. Cognet, R. Lemos Jr., T. K. Leeuw, L. Gumbiner-Russo, R. B. Weisman, G. Powis, Nano Res. 2009, 2, 279.

[194] F. Perche, S. Biswas, T. Wang, L. Zhu, V. P. Torchilin, Angew. Chem., Int. Ed. 2014, 53, 3362.

[195] S. Chen, Y. Yang, H. Li, X. Zhou, M. Liu, Chem. Commun. 2014, 50, 283.

[196] K. Zhou, Y. Wang, X. Huang, K. Luby-Phelps, B. D. Sumer, ]. Gao, Angew. Chem., Int. Ed. 2011, 50, 6109.

[197] Y. Zhao, T. Ji, H. Wang, S. Li, Y. Zhao, G. Nie, J. Controlled Release 2014, 177, 11.

[198] Y. Dai, C. Xu, X. Sun, X. Chen, Chem. Soc. Rev. 2017, 46, 3830.
[199] L. Miao, Q. Liu, C. M. Lin, C. Luo, Y. Wang, L. Liu, W. Yin, S. Hu, W. Y. Kim, L. Huang, Cancer Res. 2017, 77, 719.

[200] a) R. A. Mathias, S. K. Gopal, R. J. Simpson, J. Proteomics 2013 , 78, 545; b) R. Valenti, V. Huber, M. Iero, P. Filipazzi, G. Parmiani, L. Rivoltini, Cancer Res. 2007, 67, 2912; c) Z. Zhou, D. L. French, G. Ma, S. Eisenstein, Y. Chen, C. M. Divino, G. Keller, S. H. Chen, P. Y. Pan, Stem Cells 2010, 28, 1741 .

[201] F. Balkwill, K. A. Charles, A. Mantovani, Cancer Cell 2005, 7, 211.

[202] J. W. Pollard, Nat. Rev. Cancer 2004, 4, 71.

[203] I. C. Kourtis, S. Hirosue, A. de Titta, S. Kontos, T. Stegmann, J. A. Hubbell, M. A. Swartz, PLOS One 2013, 8, e61646.

[204] M. A. Miller, Y. R. Zheng, S. Gadde, C. Pfirschke, H. Zope, C. Engblom, R. H. Kohler, Y. Iwamoto, K. S. Yang, B. Askevold, N. Kolishetti, M. Pittet, S. J. Lippard, O. C. Farokhzad, R. Weissleder, Nat. Commun. 2015, 6, 8692.

[205] M. F. Cuccarese, J. M. Dubach, C. Pfirschke, C. Engblom, C. Garris, M. A. Miller, M. J. Pittet, R. Weissleder, Nat. Commun. 2017, 8, 14293.

[206] S. Lee, H. Han, H. Koo, J. H. Na, H. Y. Yoon, K. E. Lee, H. Lee, H. Kim, I. C. Kwon, K. Kim, J. Controlled Release 2017, 263, 68.

[207] S. Cui, D. Yin, Y. Chen, Y. Di, H. Chen, Y. Ma, S. Achilefu, Y. Gu, ACS Nano 2013, 7, 676.

[208] Y. Li, J. Tang, L. He, Y. Liu, Y. Liu, C. Chen, Z. Tang, Adv. Mater. 2015, 27, 4075.

[209] K. Fan, X. Jia, M. Zhou, K. Wang, J. Conde, J. He, J. Tian, X. Yan, ACS Nano 2018, 12, 4105.

[210] K. Haedicke, D. Kozlova, S. Grafe, U. Teichgraber, M. Epple, I. Hilger, Acta Biomater. 2015, 14, 197.

[211] Y. Zhang, W. Xiu, Y. Sun, D. Zhu, Q. Zhang, L. Yuwen, L. Weng, Z. Teng, L. Wang, Nanoscale 2017, 9, 15835.

[212] L. Mei, Q. Zhang, Y. Yang, Q. He, H. Gao, Int. J. Pharm. 2014, 474, 95.

[213] Y. Z. Wu, J. Sun, Y. Zhang, M. Pu, G. Zhang, N. He, X. Zeng, ACS Appl. Mater. Interfaces 2017, 9, 13068.

[214] O. S. Kwon, H. S. Song, J. Conde, H. I. Kim, N. Artzi, J. H. Kim, ACS Nano 2016, 10, 1512

[215] D. Wang, B. Liu, Y. Ma, C. Wu, Q. Mou, H. Deng, R. Wang, D. Yan, C. Zhang, X. Zhu, J. Am. Chem. Soc. 2017, 139, 14021.

[216] W. Wang, L. Lin, X. Ma, B. Wang, S. Liu, X. Yan, S. Li, H. Tian, X. Yu, ACS Appl. Mater. Interfaces 2018, 10, 19398.

[217] T. Zhao, G. Huang, Y. Li, S. Yang, S. Ramezani, Z. Lin, Y. Wang, X. Ma, Z. Zeng, M. Luo, E. de Boer, X. J. Xie, J. Thibodeaux, R. A. Brekken, X. Sun, B. D. Sumer, J. Gao, Nat. Biomed. Eng. 2016, 1, 6.

[218] Z. Fan, S. Zhou, C. Garcia, L. Fan, J. Zhou, Nanoscale 2017, 9, 4928.

[219] W. Cheng, H. Cheng, S. Wan, X. Zhang, M. Yin, Chem. Mater. 2017, 29, 4218 .

[220] R. Wang, M. Zhao, D. Deng, X. Ye, F. Zhang, H. Chen, J. Kong, J. Mater. Chem. B 2018, 6, 4592.

[221] X. Jia, M. Pei, X. Zhao, K. Tian, T. Zhou, P. Liu, Engineering 2016, 2, 1641.

[222] N. Puvvada, S. Rajput, B. N. Kumar, S. Sarkar, S. Konar, K. R. Brunt, R. R. Rao, A. Mazumdar, S. K. Das, R. Basu, P. B. Fisher, M. Mandal, A. Pathak, Sci. Rep. 2015, 5, 11760.

[223] C. A. Choi, J. E. Lee, Z. A. I. Mazrad, I. In, H. J. Jeong, S. Y. Park, J. Ind. Eng. Chem. 2018, 63, 208

[224] X. Chen, Z. Liu, Macromol. Rapid Commun. 2016, 37, 1533.

[225] T. Feng, X. Ai, H. Ong, Y. Zhao, ACS Appl. Mater. Interfaces 2016, 8, 18732.

[226] E. S. Lee, Z. Gao, D. Kim, K. Park, I. C. Kwon, Y. H. Bae, J. Controlled Release 2008, 129, 228

[227] Y. Wang, K. Zhou, G. Huang, C. Hensley, X. Huang, X. Ma T. Zhao, B. D. Sumer, R. J. DeBerardinis, J. Gao, Nat. Mater. 2014 13, 204.

[228] T. Wang, D. Wang, J. Liu, B. Feng, F. Zhou, H. Zhang, L. Zhou, Q. Yin, Z. Zhang, Z. Cao, H. Yu, Y. Li, Nano Lett. 2017, 17 5429. 
[229] X. Li, M. R. Szewczuk, C. Malardier-Jugroot, Drug Des., Dev. Ther. 2016, 10, 4101

[230] B. Zhang, T. Jiang, L. Ling, Z. Cao, J. Zhao, Y. Tuo, X. She, S. Shen, X. Jiang, Y. Hu, Z. Pang, ACS Appl. Mater. Interfaces 2016, 8, 8918.

[231] S. Wilhelm, A. J. Tavares, Q. Dai, S. Ohta, J. Audet, H. F. Dvorak, W. C. W. Chan, Nat. Rev. Mater. 2016, 1, 16014.

[232] P. Wang, Y. Fan, L. Lu, L. Liu, L. Fan, M. Zhao, Y. Xie, C. Xu, F. Zhang, Nat. Commun. 2018, 9, 2898.

[233] R. Hardman, Environ. Health. Persp. 2006, 114, 165.

[234] H. Soo Choi, W. Liu, P. Misra, E. Tanaka, J. P. Zimmer, B. Itty Ipe, M. G. Bawendi, J. V. Frangioni, Nat. Biotechnol. 2007, 25, 1165.

[235] R. Kumar, I. Roy, T. Y. Ohulchanskky, L. A. Vathy, E. J. Bergey, M. Sajjad, P. N. Prasad, ACS Nano 2010, 4, 699.

[236] C. Zhou, M. Long, Y. Qin, X. Sun, J. Zheng, Angew. Chem., Int. Ed. 2011, 50, 3168.

[237] J. Lu, M. Liong, Z. Li, J. I. Zink, F. Tamanoi, Small 2010, 6, 1794.

[238] a) L. Campagnolo, M. Massimiani, G. Palmieri, R. Bernardini, C. Sacchetti, A. Bergamaschi, L. Vecchione, A. Magrini, M. Bottini, A. Pietroiusti, Part. Fibre Toxicol. 2013, 10, 21; b) H. F. Wang, J. Wang, X. Y. Deng, H. F. Sun, Z. J. Shi, Z. N. Gu, Y. F. Liu, Y. L. Zhao, J. Nanosci. Nanotechnol. 2004, 4, 1019; c) Z. Liu, W. Cai, L. He, N. Nakayama, K. Chen, X. Sun, X. Chen, H. Dai, Nat. Nanotechnol. 2007, 2, 47; d) X. Liu, H. Tao, K. Yang, S. Zhang, S.-T. Lee, Z. Liu, Biomaterials 2011, 32, 144; e) K. Yang, J. Wan, S. Zhang, Y. Zhang, S.-T. Lee, Z. Liu, ACS Nano 2011, 5, 516.

[239] J. Liu, M. Yu, C. Zhou, S. Yang, X. Ning, J. Zheng, J. Am. Chem. Soc. 2013, 135, 4978.

[240] J. Liu, M. Yu, X. Ning, C. Zhou, S. Yang, J. Zheng, Angew. Chem., Int. Ed. 2013, 52, 12572.

[241] C. Zhang, C. Li, Y. Liu, J. Zhang, C. Bao, S. Liang, Q. Wang, Y. Yang, H. Fu, K. Wang, D. Cui, Adv. Funct. Mater. 2015, 25, 1314.

[242] J. Piao, L. Wang, F. Gao, Y. You, Y. Xiong, L. Yang, ACS Nano 2013, 7, 7227.

[243] C. Liu, Z. Gao, J. Zeng, Y. Hou, F. Fang, Y. Li, R. Qiao, L. Shen, H. Lei, W. Yang, M. Gao, ACS Nano 2013, 7, 7227.

[244] T. Cao, Y. Yang, Y. Sun, Y. Wu, Y. Gao, W. Feng, F. Li, Biomaterials 2013, 34, 7127.

[245] Y. Feng, H. Chen, B. Shao, S. Zhao, Z. Wang, H. You, ACS Appl. Mater. Interfaces 2018, 10, 25511.

[246] X. L. Huang, F. Zhang, L. Zhu, K. Y. Choi, N. Guo, J. X. Guo, K. Tackett, P. Anilkumar, G. Liu, Q. M. Quan, H. S. Choi, G. Niu, Y. P. Sun, S. Lee, X. Y. Chen, ACS Nano 2013, 7, 5684.

[247] H. Chen, Y. Qiu, D. Ding, H. Lin, W. Sun, G. D. Wang, W. Huang, W. Zhang, D. Lee, G. Liu, J. Xie, X. Chen, Adv. Mater. 2018, 30, 1802748.

[248] H. Chen, G. D. Wang, W. Tang, T. Todd, Z. Zhen, C. Tsang, K. Hekmatyar, T. Cowger, R. Hubbard, W. Zhang, J. Stickney, B. Shen, J. Xie, Adv. Mater. 2014, 26, 6761.

[249] Y. Peng, D. Yang, W. Lu, X. Hu, H. Hong, T. Cai, Acta Biomater. 2017, 61, 193.

[250] G. Hong, J. T. Robinson, Y. Zhang, S. Diao, A. L. Antaris, Q. Wang, H. Dai, Angew. Chem., Int. Ed. 2012, 51, 9818.

[251] K. T. Yong, I. Roy, H. Ding, E. J. Bergey, P. N. Prasad, Small 2009, 5, 1997.

[252] X. Ji, H. Wang, B. Song, B. Chu, Y. He, Front. Chem. 2018, 6, 38

[253] a) S. Adams, R. P. Baum, T. Stuckensen, K. Bitter, G. Hor, Eur. J. Nucl. Med. Mol. Imaging 1998, 25, 1255; b) P. L. Kubben, K. J. ter Meulen, O. E. M. G. Schijns, M. P. ter Laak-Poort, J. J. van Overbeeke, H. van Santbrink, Lancet Oncol. 2011, 12, 1062; c) M. F. Kircher, S. S. Gambhir, J. Grimm, Nat. Rev. Clin. Oncol. 2011, 8, 677; d) M. F. Kircher, J. K. Willmann, Radiology 2012, 264, 349.

[254] a) S. Cheung, D. F. O'Shea, Nat. Commun. 2017, 8, 1885; b) Q. Miao, C. Xie, X. Zhen, Y. Lyu, H. Duan, X. Liu, J. V. Jokerst, K. Pu, Nat. Biotechnol. 2017, 35, 1102.
[255] a) S. Johnsen, Biol. Bull. 2001, 201, 301; b) J. V. Frangioni, Curr. Opin. Chem. Biol. 2003, 7, 626.

[256] a) D. Ghosh, A. F. Bagley, Y. J. Na, M. J. Birrer, S. N. Bhatia, A. M. Belcher, Proc. Natl. Acad. Sci. USA 2014, 111, 13948; b) G. M. van Dam, G. Themelis, L. M. A. Crane, N. J. Harlaar, R. G. Pleijhuis, W. Kelder, A. Sarantopoulos, J. S. de Jong, H. J. G. Arts, A. G. J. van der Zee, J. Bart, P. S. Low, V. Ntziachristos, Nat. Med. 2011, 17, 1315; c) H. Kobayashi, P. L. Choyke, Sci. Transl. Med. 2012, 4, 121/r1.

[257] J. T. Robinson, G. Hong, Y. Liang, B. Zhang, O. K. Yaghi, H. Dai, J. Am. Chem. Soc. 2012, 134, 10664.

[258] J. Gao, K. Chen, R. Xie, J. Xie, Y. Yan, Z. Cheng, X. Peng, X. Chen, Bioconjugate Chem. 2010, 21, 604.

[259] J. Qi, C. Chen, X. Zhang, X. Hu, S. Ji, R. T. K. Kwok, J. W. Y. Lam, D. Ding, B. Z. Tang, Nat. Commun. 2018, 9, 1848.

[260] C. Wang, Z. Wang, T. Zhao, Y. Li, G. Huang, B. D. Sumer, J. Gao, Biomaterials 2018, 157, 62.

[261] R. Tivony, L. Larush, O. Sela-Tavor, S. Magdassi, J. Biomed. Nanotechnol. 2014, 10, 1041.

[262] T. Ma, Y. Hou, J. Zeng, C. Liu, P. Zhang, L. Jing, D. Shangguan, M. Gao, J. Am. Chem. Soc. 2018, 140, 211.

[263] N. Huang, S. Cheng, X. Zhang, Q. Tian, J. Pi, J. Tang, Q. Huang, F. Wang, J. Chen, Z. Xie, Z. Xu, W. Chen, H. Zheng, Y. Cheng, Nanomed.: Nanotechnol. Biol. Med. 2017, 13, 83.

[264] J. Wang, G. Zhang, Q. Li, H. Jiang, C. Liu, C. Amatore, X. Wang, Sci. Rep. 2013, 3, 1157.

[265] A. Jain, P. G. J. Fournier, V. Mendoza-Lavaniegos, P. Sengar, F. M. Guerra-Olvera, E. Iniguez, T. G. Kretzschmar, G. A. Hirata, P. Juarez, J. Nanobiotechnol. 2018, 16, 26.

[266] Y. Jin, D. Ni, J. Zhang, F. Han, J. Wang, L. Gao, H. Zhang, Y. Liu, Z. Cui, Z. Yao, X. Feng, W. Bu, Part. Part. Syst. Charact. 2017, 34, 1600393.

[267] L. Zhou, Z. Li, E. Ju, Z. Liu, J. Ren, X. Qu, Small 2013, 9, 4262.

[268] S. Hamd-Ghadareh, A. Salimi, F. Fathi, S. Bahrami, Biosens. Bioelectron. 2017, 96, 308.

[269] H. Zhu, Y. Fang, X. Zhen, N. Wei, Y. Gao, K. Q. Luo, C. Xu, H. Duan, D. Ding, P. Chen, K. Pu, Chem. Sci. 2016, 7, 5118.

[270] C. Yin, X. Zhen, H. Zhao, Y. Tang, Y. Ji, Y. Lyu, Q. Fan, W. Huang, K. Pu, ACS Appl. Mater. Interfaces 2017, 9, 12332.

[271] J. Li, J. Rao, K. Pu, Biomaterials 2018, 155, 217.

[272] H. Zhu, Y. Fang, Q. Miao, X. Qi, D. Ding, P. Chen, K. Pu, ACS Nano 2017, 11, 8998

[273] A. P. Turner, Biosens. Bioelectron. 2015, 65, A1.

[274] W. Zhong, Anal. Bioanal. Chem. 2009, 394, 47.

[275] P. Shi, Z. Liu, K. Dong, E. Ju, J. Ren, Y. Du, Z. Li, X. Qu, Adv. Mater. 2014, 26, 6635.

[276] G. Saranya, M. M. Joseph, V. Karunakaran, J. B. Nair, V. N. Saritha, V. S. Veena, K. Sujathan, A. Ajayaghosh, K. K. Maiti, ACS Appl. Mater. Interfaces 2018, 10, 38807.

[277] C. Ding, Y. Tian, Biosens. Bioelectron. 2015, 65, 183.

[278] J. S. Sidhu, A. Singh, N. Garg, N. Kaur, N. Singh, Analyst 2018, 143, 1853.

[279] X. Wu, X. Sun, Z. Guo, J. Tang, Y. Shen, T. D. James, H. Tian, W. Zhu, J. Am. Chem. Soc. 2014, 136, 3579.

[280] G. Wang, K. Qian, X. Mei, Nanoscale 2018, 10, 10467.

[281] Y. Zhang, J. Li, H. Jiang, C. Zhao, X. Wang, RSC adv. 2016, 6, 63331.

[282] N. M. Idris, M. K. Gnanasammandhan, J. Zhang, P. C. Ho, R. Mahendran, Y. Zhang, Nat. Med. 2012, 18, 1580.

[283] X. Ai, C. J. Ho, J. Aw, A. B. Attia, J. Mu, Y. Wang, X. Wang, Y. Wang, X. Liu, H. Chen, M. Gao, X. Chen, E. K. Yeow, G. Liu, M. Olivo, B. Xing, Nat. Commun. 2016, 7, 10432.

[284] K. Yang, S. Zhang, G. Zhang, X. Sun, S. T. Lee, Z. Liu, Nano Lett. 2010, 10, 3318.

[285] H. Li, L. Guo, A. Huang, H. Xu, X. Liu, H. Ding, J. Dong, J. Li, C. Wang, X. Su, X. Ge, L. Sun, C. Bai, X. Shen, T. Fang, Z. Li, 
Y. Zhou, L. Zhan, S. Li, J. Xie, N. Shao, Biomaterials 2015, 63, 168.

[286] H. Zhao, J. Duan, Y. Xiao, G. Tang, C. Wu, Y. Zhang, Z. Liu, W. Xue, Chem. Mater. 2018, 30, 3438.

[287] H. Chen, B. Li, X. Ren, S. Li, Y. Ma, S. Cui, Y. Gu, Biomaterials 2012, 33, 8461

[288] C. Wang, L. Xu, J. Xu, D. Yang, B. Liu, S. Gai, F. He, P. Yang, Dalton Trans. 2017, 46, 12147.

[289] L. E. Kelderhouse, V. Chelvam, C. Wayua, S. Mahalingam, S. Poh, S. A. Kularatne, P. S. Low, Bioconjugate Chem. 2013, 24, 1075.

[290] A. H. Colby, S. M. Berry, A. M. Moran, K. A. Pasion, R. Liu, Y. L. Colson, N. Ruiz-Opazo, M. W. Grinstaff, V. L. Herrera, ACS Nano 2017, 11, 1466.

[291] S. A. Dugger, A. Platt, D. B. Goldstein, Nat. Rev. Drug Discovery 2018, 17, 183.

[292] R. S. Riley, C. H. June, R. Langer, M. J. Mitchell, Nat. Rev. Drug Discovery 2019, 18, 175.

[293] S. A. Rosenberg, J. Immunol. 2014, 192, 5451

[294] a) C. Granier, E. D. Guillebon, C. Blanc, H. Roussel, C. Badoual, E. Colin, A. Saldmann, A. Gey, S. Oudard, E. Tartour, ESMO Open 2017, 2, e000213; b) D. H. Munn, V. Bronte, Curr. Opin. Immunol. 2016, 39, 1 .

[295] X. Du, F. Tang, M. Liu, J. Su, Y. Zhang, W. Wu, M. Devenport, C. A. Lazarski, P. Zhang, X. Wang, P. Ye, C. Wang, E. Hwang, T. Zhu, T. Xu, P. Zheng, Y. Liu, Cell Res. 2018, 28, 416.

[296] P. Sharma, J. P. Allison, Cell 2015, 161, 205.

[297] a) W. A. Lim, C. H. June, Cell 2017, 168, 724; b) S. Michel, J. Clin. Invest. 2015, 125, 3392.

[298] Y. Han, Q. Liu, J. Hou, Y. Gu, Y. Zhang, Z. Chen, J. Fan, W. Zhou, S. Qiu, Y. Zhang, T. Dong, N. Li, Z. Jiang, H. Zhu, Q. Zhang, Y. Ma, L. Zhang, Q. Wang, Y. Yu, N. Li, X. Cao, Cell 2018, 173 634

[299] Y. Luo, C. Zheng, J. Zhang, D. Lu, J. Zhuang, S. Xing, J. Feng, D. Yang, X. Yan, Oncogene 2012, 31, 306

[300] Q. Sun, M. Barz, B. G. De Geest, M. Diken, W. E. Hennink, F. Kiessling, T. Lammers, Y. Shi, Chem. Soc. Rev. 2019, 48, 351.

[301] G. Yang, L. Xu, Y. Chao, J. Xu, X. Sun, Y. Wu, R. Peng, Z. Liu, Nat. Commun. 2017, 8, 902.

[302] Q. Chen, L. Xu, C. Liang, C. Wang, R. Peng, Z. Liu, Nat. Commun. 2016, 7, 13193.

[303] J. Nam, S. Son, L. J. Ochyl, K. Rui, A. Schwendeman, J. J. Moon, Nat. Commun. 2018, 9, 1074

[304] Y. Zhao, J. Cao, A. Melamed, M. Worley, A. Gockley, D. Jones, H. Nia, Y. Zhang, T. Stylianopoulos, A. S. Kumar, F. Mpekris, M. Datta, Y. Sun, L. Wu, X. Gao, O. Yeku, M. G. del Carmen, D. R. Spriggs, R. K. Jain, L. Xu, Proc. Natl. Acad. Sci. USA 2019, 116, 2210.

[305] T. Stylianopoulos, L. L. Munn, R. K. Jain, Trends Cancer 2018, 4, 258.

[306] F. Dai, J. Kloepper, Z. Amoozgar, G. D. Dan, R. K. Jain, Nat. Rev. Clin. Oncol. 2018, 15, 325.

[307] a) Y. Jiang, X. Pan, J. Chang, W. Niu, W. Hou, H. Kuai, Z. Zhao, J. Liu, M. Wang, W. Tan, J. Am. Chem. Soc. 2018, 140, 6780; b) H. Kuai, Z. Zhao, L. Mo, H. Liu, X. Hu, T. Fu, X. Zhang, W. Tan, J. Am. Chem. Soc. 2017, 139, 9128; c) H. Liang, S. Chen, P. Li, L. Wang, J. Li, J. Li, H. H. Yang, W. Tan, J. Am. Chem. Soc. 2018, 140, 4186; d) I. T. Teng, X. Li, H. A. Yadikar, Z. Yang, L. Li, Y. Lyu, X. Pan, K. K. Wang, W. Tan, J. Am. Chem. Soc. 2018, 140, 14314; e) Y. Wu, L. Zhang, C. Cui, S. Cansiz, H. Liang, C. Wu, I. T. Teng, W. Chen, Y. Liu, W. Hou, X. Zhang, W. Tan, J. Am. Chem. Soc. 2018, 140, 2; f) M. You, Y. Lyu, D. Han, L. Qiu, Q. Liu, T. Chen, C. Sam Wu, L. Peng, L. Zhang, G. Bao, W. Tan, Nat. Nanotechnol. 2017 12, 453; g) G. Zhu, J. Zheng, E. Song, M. Donovan, K. Zhang, C. Liu, W. Tan, Proc. Natl. Acad. Sci. USA 2013, 110, 7998.

[308] Z. Hu, J. Zhou, J. Jiang, J. Yuan, Y. Zhang, X. Wei, N. Loo, Y. Wang, Y. Pan, T. Zhang, X. Zhong, M. Long, K. T. Montone, J. L. Tanyi,
Y. Fan, T. L. Wang, I. M. Shih, X. Hu, L. Zhang, Nat. Commun. 2019, 10, 733

[309] Y. Jiang, A. Sun, Y. Zhao, W. Ying, H. Sun, X. Yang, B. Xing, W. Sun, L. Ren, B. Hu, C. Li, L. Zhang, G. Qin, M. Zhang, N. Chen, M. Zhang, Y. Huang, J. Zhou, Y. Zhao, M. Liu, X. Zhu, Y. Qiu, Y. Sun, C. Huang, M. Yan, M. Wang, W. Liu, F. Tian, H. Xu, J. Zhou, Z. Wu, T. Shi, W. Zhu, J. Qin, L. Xie, J. Fan, X. Qian, F. He, C. Chinese Human Proteome Project, Nature 2019, 567, 257.

[310] S. Tang, M. Chen, N. Zheng, Small 2014, 10, 3139.

[311] a) Y. Xing, J. Rao, Cancer Biomarkers. 2008, 4, 307; b) H. Peng, D. T. Chiu, Chem. Soc. Rev. 2015, 44, 4699; c) T. Kowada, H. Maeda, K. Kikuchi, Chem. Soc. Rev. 2015, 44, 4953; d) A. Gnach, A. Bednarkiewicz, Nano Today 2012, 7, 532.

[312] a) S.-P. Kwon, S. Jeon, S.-H. Lee, H. Y. Yoon, J. H. Ryu, D. Choi, J.-Y. Kim, J. Kim, J. H. Park, D.-E. Kim, I. C. Kwon, K. Kim, C.-H. Ahn, Biomaterials 2018, 150, 125; b) X. Wu, C. Li, S. Liao, L. Li, T. Wang, Z. Su, C. Wang, J. Zhao, C. Sui, J. Lin, Chem. - Eur. J. 2014, 20, 8876

[313] a) Y.-S. Chen, W. Frey, S. Kim, K. Homan, P. Kruizinga, K. Sokolov, S. Emelianov, Opt. Express 2010, 18, 8867; b) P. K. Upputuri, M. Pramanik, J. Biomed. Opt. 2017, 22, 1; c) B. Cox, J. G. Laufer, S. R. Arridge, P. C. Beard, J. Biomed. Opt. 2012, 17, 061202; d) K. Pu, J. Mei, J. V. Jokerst, G. Hong, A. L. Antaris, N. Chattopadhyay, A. I. Shuhendler, T. Kurosawa, Y. Zhou, S. S. Gambhir, Z. Bao, J. Rao, Adv. Mater. 2015, 27, 5184.

[314] H. S. Min, S. Son, D. G. You, T. W. Lee, J. Lee, S. Lee, J. Y. Yhee, J. Lee, M. H. Han, J. H. Park, S. H. Kim, K. Choi, K. Park, K. Kim, I. C. Kwon, Biomaterials 2016, 108, 57.

[315] Q. Fan, K. Cheng, X. Hu, X. Ma, R. Zhang, M. Yang, X. Lu, L. Xing, W. Huang, S. S. Gambhir, Z. Cheng, J. Am. Chem. Soc. 2014, 136, 15185

[316] L.-S. Lin, Z.-X. Cong, J.-B. Cao, K.-M. Ke, Q.-L. Peng, J. Gao, H.-H. Yang, G. Liu, X. Chen, ACS Nano 2014, 8, 3876.

[317] a) Q. Tang, W. Si, C. Huang, K. Ding, W. Huang, P. Chen, Q. Zhang, X. Dong, J. Mater. Chem. B 2017, 5, 1566; b) X. Zhen, J. Zhang, J. Huang, C. Xie, Q. Miao, K. Pu, Angew. Chem., Int. Ed. 2018, 57, 7804; c) L. Cheng, K. Yang, Y. Li, J. Chen, C. Wang, M. Shao, S.-T. Lee, Z. Liu, Angew. Chem., Int. Ed. 2011, 50, 7385; d) T. Yang, Y. Tang, L. Liu, X. Lv, Q. Wang, H. Ke, Y. Deng, H. Yang, X. Yang, G. Liu, Y. Zhao, H. Chen, ACS Nano 2017, 11, 1848.

[318] a) Z. Liu, X. Li, S. M. Tabakman, K. Jiang, S. Fan, H. Dai, J. Am. Chem. Soc. 2008, 130, 13540; b) Y. Ozeki, W. Umemura, Y. Otsuka, S. Satoh, H. Hashimoto, K. Sumimura, N. Nishizawa, K. Fukui, K. Itoh, Nat. Photonics 2012, 6, 845; c) C. H. Camp Jr., Y. J. Lee, J. M. Heddleston, C. M. Hartshorn, A. R. H. Walker, J. N. Rich, J. D. Lathia, M. T. Cicerone, Nat. Photonics 2014, 8, 627; d) X. Wang, C. Wang, L. Cheng, S.-T. Lee, Z. Liu, J. Am. Chem. Soc. 2012, 134, 7414.

[319] Y. Li, G. Liu, J. Ma, J. Lin, H. Lin, G. Su, D. Chen, S. Ye, X. Chen, X. Zhu, Z. Hou, J. Controlled Release 2017, 258, 95.

[320] K. Kim, J. H. Kim, H. Park, Y. S. Kim, K. Park, H. Nam, S. Lee, J. H. Park, R. W. Park, I. S. Kim, K. Choi, S. Y. Kim, K. Park, I. C. Kwon, J. Controlled Release 2010, 146, 219.

[321] G. Yang, H. Gong, T. Liu, X. Sun, L. Cheng, Z. Liu, Biomaterials 2015, 60, 62 .

[322] N. Li, H. Cai, L. Jiang, J. Hu, A. Bains, J. Hu, Q. Gong, K. Luo, Z. Gu, ACS Appl. Mater. Interfaces 2017, 9, 6865.

[323] S. Gao, G. Wang, Z. Qin, X. Wang, G. Zhao, Q. Ma, L. Zhu, Biomaterials 2017, 112, 324.

[324] L. Deng, Y. Xu, C. Sun, B. Yun, Q. Sun, C. Zhao, Z. Li, Sci. Bull. 2018, 63, 917

[325] X. Liang, L. Fang, X. Li, X. Zhang, F. Wang, Biomaterials 2017, 132, 72.

[326] C. Ji, Q. Gao, X. Dong, W. Yin, Z. Gu, Z. Gan, Y. Zhao, M. Yin, Angew. Chem., Int. Ed. 2018, 57, 11384. 
[327] C. J. Lin, C. H. Kuan, L. W. Wang, H. C. Wu, Y. Chen, C. W. Chang, R. Y. Huang, T. W. Wang, Biomaterials 2016, 90, 12.

[328] Y. Shen, Y. Sun, R. Yan, E. Chen, H. Wang, D. Ye, J.-J. Xu, H.-Y. Chen, Biomaterials 2017, 148, 31.

[329] C. N. Zhu, G. Chen, Z. Q. Tian, W. Wang, W. Q. Zhong, Z. Li, Z. L. Zhang, D. W. Pang, Small 2017, 13, 1602309.

[330] H. Li, P. Wang, Y. Deng, M. Zeng, Y. Tang, W. H. Zhu, Y. Cheng, Biomaterials 2017, 139, 30 .
[331] F. He, L. Feng, P. Yang, B. Liu, S. Gai, G. Yang, Y. Dai, J. Lin, Biomaterials 2016, 105, 77.

[332] L. Zhang, W. Zheng, R. Tang, N. Wang, W. Zhang, X. Jiang, Biomaterials 2016, 104, 269.

[333] L. Xie, G. Wang, H. Zhou, F. Zhang, Z. Guo, C. Liu, X. Zhang, L. Zhu, Biomaterials 2016, 103, 219.

[334] J. Ge, Q. Jia, W. Liu, L. Guo, Q. Liu, M. Lan, H. Zhang, X. Meng, P. Wang, Adv. Mater. 2015, 27, 4169. 